NBER WORKING PAPER SERIES

\title{
REFERENCE-DEPENDENT JOB SEARCH: EVIDENCE FROM HUNGARY
}

\author{
Stefano DellaVigna \\ Attila Lindner \\ Balázs Reizer \\ Johannes F. Schmieder \\ Working Paper 22257 \\ http://www.nber.org/papers/w22257
NATIONAL BUREAU OF ECONOMIC RESEARCH
1050 Massachusetts Avenue
Cambridge, MA 02138
May 2016

We thank Patrick Arni, Saurabh Bhargava, Lajos Bódis, Moshe Buchinsky, David Card, Henry Farber, Sebastian Findeisen, Gábor Kézdi, Patrick Kline, Matthew Rabin, Hedvig Horváth, Erzo Luttmer, Edward O'Donoghue, Daniele Paserman, Alex Rees-Jones, Emmanuel Saez, Mihály Szoboszlai, Owen Zidar and audiences at Boston University, Columbia, Cornell, Harvard, IZA, Mannheim (Department and ZEW), Tinbergen, UCLA, University of Regensburg, University of Zurich, the UCSB 2014 Behavioral Conference, the 2014 BEAM conference, the 2014 NBER Labor Studies Summer Institute, the Brookings conference on "Policy lessons from behavioral economics", the 2016 ASSA meetings, and the Hungarian Society of Economists Annual Conference for very helpful comments. We are grateful to János Köllö, Kitti Varadovics, Mónika Bálint, Dániel Biró for giving us access to the administrative data and providing continuous help throughout the project, and to Nagy Csaba and Pelek Zsolt for explaining the practical implementation of the reform. We also thank Tristan Gagnon-Bartsch, Matthew Gudgeon, Avner Shlain, Jessica Shui, and Ferenc Szucs for excellent research assistance and Gautam Rao for sharing his code. Financial support from the Center for Equitable Growth at UC Berkeley, from the Alfred P. Sloan Foundation and from the National Science Foundation is gratefully acknowledged. The views expressed herein are those of the authors and do not necessarily reflect the views of the National Bureau of Economic Research.

NBER working papers are circulated for discussion and comment purposes. They have not been peer-reviewed or been subject to the review by the NBER Board of Directors that accompanies official NBER publications.

(C) 2016 by Stefano DellaVigna, Attila Lindner, Balázs Reizer, and Johannes F. Schmieder. All rights reserved. Short sections of text, not to exceed two paragraphs, may be quoted without explicit permission provided that full credit, including $\odot$ notice, is given to the source. 
Reference-Dependent Job Search: Evidence from Hungary

Stefano DellaVigna, Attila Lindner, Balázs Reizer, and Johannes F. Schmieder

NBER Working Paper No. 22257

May 2016

JEL No. D03,J64,J65

\begin{abstract}
$\underline{\text { ABSTRACT }}$
We propose a model of job search with reference-dependent preferences, where the reference point is given by recent income. Newly unemployed individuals search hard given that they are at a loss, but over time they get used to lower income, and thus reduce their search effort. In anticipation of a benefit cut their search effort rises again, then declines once they get used to the lower benefit level. The model fits the typical pattern of the exit from unemployment, even with no unobserved heterogeneity. The model also makes distinguishing predictions regarding the response to benefit changes, which we evaluate using a unique reform. In 2005, Hungary switched from a single-step UI system to a two-step system, with unchanged overall generosity. The system generated increased hazard rates in anticipation of, and especially following, benefit cuts in ways the standard model has a hard time explaining. We estimate a model with optimal consumption and endogenous search effort, as well as unobserved heterogeneity. The referencedependent model fits the hazard rates substantially better than most versions of the standard model. We estimate a slow-adjusting reference point and substantial impatience, likely reflecting present-bias. Habit formation and a variety of alternative models do not match the fit of the reference-dependent model. We discuss one model which also fits well, but is at odds with calibrated values and other evidence.
\end{abstract}

\author{
Stefano DellaVigna \\ University of California, Berkeley \\ Department of Economics \\ 549 Evans Hall \#3880 \\ Berkeley, CA 94720-3880 \\ and NBER \\ sdellavi@econ.berkeley.edu \\ Attila Lindner \\ Department of Economics \\ University College London \\ 30 Gordon Street \\ London \\ WC1H 0AX \\ United Kingdom \\ and CERS-HAS, IZA and IFS \\ a.lindner@ucl.ac.uk
}

\author{
Balázs Reizer \\ Department of Economics \\ Central European University \\ Nádor u 9. \\ 1051 Budapest \\ Hungary \\ and CERS-HAS \\ reizer.balazs@krtk.mta.hu \\ Johannes F. Schmieder \\ Department of Economics \\ Boston University \\ 270 Bay State Road \\ Boston, MA 02215 \\ and IZA \\ and also NBER \\ johannes@bu.edu
}

A online appendix is available at http://www.nber.org/data-appendix/w22257 


\section{Introduction}

Unemployment insurance programs in most Western countries follow a common design. The benefits are set at a constant replacement rate for a fixed period, typically followed by lower benefits under unemployment assistance. In such systems, the hazard rate from unemployment typically declines from an initial peak the longer workers are unemployed, surges at unemployment exhaustion, and declines thereafter. This has been shown in a variety of settings, such as in the United States (Katz and Meyer, 1990), Hungary (Micklewright and Nagy, 1999), Austria (Card et al., 2007a), Slovenia (van Ours and Vodopivec, 2008), Germany (Schmieder et al., 2012a), and France (Le Barbanchon, 2012).

It is well-known that a basic job search model a la Mortensen (1986) and van den Berg (1990) is unable to match this pattern. This model predicts an increasing exit hazard up until benefit expiration, with a constant exit rate thereafter. To match the time path, job search models add unobserved heterogeneity among workers. More productive workers are more likely to find a job initially, leading to a decrease in the hazard over time as the workers still unemployed are predominantly of the less productive type.

In this paper, we propose, and test, a behavioral model of job search which can account for this time path of unemployment even in the absence of unobserved heterogeneity. Namely, we incorporate one of the best established facts in psychology, that people's perceptions and decisions are influenced by relative comparisons. We assume that workers have referencedependent preferences over their utility from consumption. As in prospect theory (Kahneman and Tversky, 1979), workers are loss-averse with respect to consumption below a reference point. Further, we assume that this reference point is given by recent earnings.

To fix ideas, consider a reference-dependent worker who was just laid off and assume, for now, hand-to-mouth consumption. At the time of job loss, the reference point of the unemployed is the previous wage, which is significantly higher than the unemployment benefit, the new consumption level. The unemployed, therefore, finds the new state of unemployment particularly painful given the loss relative to the reference point, and so she searches hard at the beginning of a UI spell. Over the weeks of unemployment, however, the reference point shifts as the individual adapts to the lower benefit level, and the loss is thus mitigated. Hence, the worker's search effort decreases. As the end of the UI benefits draws near, the worker, if still unemployed, anticipates the loss in consumption due to the exhaustion of the benefits, and searches harder. This force is at work also in the standard model, but it is heightened by the anticipation of the future loss aversion. If the worker does not find a job by the UI expiration, the worker once again slowly adjusts to the new, lower benefit level.

The hazard from unemployment for this reference-dependent worker decreases from the ini-

tial peak, increases at exhaustion, then decreases again. Hence, the predicted hazard matches 
the patterns documented above, even in absence of unobserved heterogeneity.

How would one distinguish the standard job search model from a reference-dependent model? Consider two UI systems, the first offering a constant benefit path until period $T$, with the second offering higher initial benefits up to period $T_{1}<T$ but lower benefits between $T_{1}$ and $T$ (Figure 1a). The two systems have the same welfare benefit level after period $T$. The standard model with no heterogeneity predicts that, starting from period $T$, the hazard rate in the two systems would be the same, as the future payoffs are identical (Figure 1b). Furthermore, the hazard rate in the periods right before period $T$ will be higher in the system with two-step benefits given the lower benefits at that point.

The reference-dependent model makes three different predictions (Figure 1c). First, right after period $T$ the hazard in the one-step system would be higher because of the higher loss in consumption compared to the recent benefits. Second, this difference would attenuate over time and ultimately disappear as the reference point adjusts to the lower benefit level. Third, the hazard rate in the first UI system increases already in advance of period $T$, in anticipation of the future loss aversion. Notice that, while these predictions are developed in the absence of heterogeneity to highlight the intuition, we fully integrate heterogeneity in our estimates.

We evaluate a change in the Hungarian unemployment insurance system which is ideally suited for a test of the above predictions. Before November 2005, the Hungarian system featured a constant replacement rate for 270 days, followed by lower unemployment assistance benefits. After November 2005, the system changed to a two-step unemployment system: benefits are higher in the first 90 days, but lower between days 90 and 270, compared to the pre-period (Figure A-1). There was no major change in the unemployment assistance system taking place after 270 days. As such, this UI set-up corresponds to the hypothetical case outlined above with period $T$ corresponding to 270 days.

An important feature of the Hungarian reform is that the total benefits paid out until day 270 remain about the same after the reform. Hence, differences in savings and in selection in the pre- and post- period are likely to be small, allowing for a more straightforward comparison.

We evaluate the reform by comparing the hazard rates into employment in the year before and after the reform. The evidence is well in line with the predictions of the referencedependent model. In the weeks immediately preceding the 270-day exhaustion of benefits, the pre-reform hazard rates rise above the post-reform hazard rates. In the months following the exhaustion, the pre-reform hazard rates remain higher, and they ultimately converge to the post-reform level only after a couple months. The observed pattern around the exhaustion is consistent with the anticipation of, and then the direct effect of the higher loss in consumption for individuals in the pre-reform. The ultimate convergence between the two hazards indicates, in this interpretation, the timing of the reference point adjustment. 
We present several robustness checks. Controlling for a broad set of controls and alternative definitions of our sample barely affects the estimated hazards. Also, an interrupted time series analysis shows that the break in the hazards occurs immediately in the quarter of introduction of the reform, and does not appear to reflect previous trends.

While the evidence is qualitatively consistent with predictions of the reference-dependent model, it is important to compare the quantitative fit of the behavioral model with the fit of the standard model allowing for unobserved heterogeneity. To do so, we structurally estimate a model with optimal search effort, log utility, and unobserved heterogeneity in the form of types of individuals with different search costs. ${ }^{1}$ Given that the reference-dependent model has two extra parameters (loss-aversion and updating horizon for the reference point), we allow for one less cost type, two versus three in the standard model, thus equating the number of estimated parameters. We estimate the model with a minimum-distance estimator, matching the empirical hazard rates in the pre- and post-reform to the predictions of the model.

The preferred estimate for the standard model does a relatively good job of fitting the hazards in the first 200 days. More specifically, the presence of heterogeneous types allows to qualitatively match the spike in the hazard at 90 days post-reform. The standard model, however, is unable to capture the observed behavior leading up to, and following, the exhaustion of benefits. In particular, the hazard rates from day 270 on in the pre- and post-period are predicted to be almost identical, contrary to the empirical findings.

The reference-dependent model captures the spike at 90 days and the subsequent decrease, similar to the standard model (and with a closer fit). Importantly, this behavioral model also captures key features of the data which the standard model does not fit: the increase in hazard in the month prior to the expiration of benefits in the pre-period, the spike at 270 days, the decrease thereafter, and the ultimate convergence of the hazard between the preand post-period after a few months. The fit of the model is by no means perfect: the model underpredicts the spike at 270 days and the difference in hazards in the following two months. Still, it captures most of the qualitative features which the standard model does not fit at all.

An important caveat is that these estimates assume hand-to-mouth consumers. However, reference-dependent workers should build precautionary savings to smooth the upcoming loss utility due to a benefit decrease, eliminating the elevated hazards at benefit exhaustion. Thus, the good fit of the reference-dependent model may depend crucially on an ad hoc assumption. To address this concern, in our benchmark estimates we incorporate a consumption-savings decision and estimate time preferences in addition to job search parameters.

The results point to an important interaction between reference dependence and impatience. As the intuition above suggested, the reference-dependent model with optimal con-

\footnotetext{
${ }^{1}$ For tractability, the model does not allow for a reservation wage choice, a restriction we revisit later.
} 
sumption does not provide a good fit for the data if we impose high degrees of patience. Once we allow for estimated discount rates, however, the reference-dependent model fits the data well, as in the hand-to-mouth estimates. The point estimates indicate a significant weight on gain-loss utility, slow updating of the reference point, and high impatience. The standard model, with similarly high estimated impatience, fits the data significantly worse than the reference-dependent model and in fact somewhat worse than the hand-to-mouth standard model. ${ }^{2}$ Thus, the estimates with optimal consumption confirm the better fit of the reference-dependent model, and additionally point to the role of impatience.

But are these estimates plausible? The estimate for loss aversion is in the range of the previous literature, but the estimated discount factor is arguably implausibly small at 0.9 for a 15-day period, leading to an annual discount factor of 0.08 (The estimated discount factor for the standard model is similarly small). What appears to be extreme impatience may, however, reflect mis-specified time preferences. Building on evidence in a large number of settings, including job search (DellaVigna and Paserman, 2005), we allow for present-biased time preferences (Laibson, 1997; O’Donoghue and Rabin, 1999), with an additional discount factor $\beta$ between the current period and the future.

The estimates allowing for present bias do as well (in fact, attain a better fit) as the estimates with exponential discounting, but imply much more reasonable discounting. We estimate a present-bias parameter $\beta=0.58$, well within the range of estimates in the literature, for an implied annual discount factor of 0.52 for the first year and 0.88 for later years. The fit of standard model instead does not improve if we allow for present-bias preferences. Thus, the evidence appears to point, not just to reference dependence, but also to impatience and likely present-bias among unemployed workers.

We then examine further the components of the reference-dependent model. The results do not depend on unobserved heterogeneity: a reference-dependent model with no heterogeneity provides nearly as good a fit. The results also do not depend on the exact reference-point updating rule, as the fit is similar with an alternative $\operatorname{AR}(1)$ updating assumption. Further, the fit does not depend on allowing for gain utility (achieved at reemployment). What is critical for the results, as expected, is that loss aversion experienced as income decreases.

How does reference dependence compare to habit formation? Models a la Constantinides (1990) and Campbell and Cochrane (1999), like the reference-dependent model, induce a temporarily higher marginal utility of income following a benefit cut as consumption gets closer to the habit. Thus, they could plausibly fit the patterns in the data. We highlight

\footnotetext{
${ }^{2}$ In the hand-to-mouth case, the best fit for the standard model is for a relatively high degree of patience. Yet, for such level of patience, the workers should not go hand-to-mouth. Once we endogenize consumption, such estimates with high patience are not optimal any more, given that they would lead the workers to save and thus smooth the benefit jumps more than observed in the data. Thus, endogenizing the consumption decision is an important check for the ability of the standard model to fit the observed patterns.
} 
a key difference. In the reference-dependent model, the impact of the loss on search effort is approximately proportional to the size of the loss. Instead, in the habit-formation model larger decreases in consumption have disproportionate effects. Given this, the habit-formation model underpredicts the spike in hazard at 270 days, since the benefit step-down at 90 days is proportionally larger. We also estimate habit-formation models with multiplicative habits (e.g. Abel, 1990) that are equivalent to reference-dependent models with no loss aversion. These models provide a better fit than the standard model, though not quite as good as the reference-dependent model, confirming the role of loss aversion in our estimates.

Could alternative versions of the standard model fit the data as well as the referencedependent model? We allow for, among other assumptions, different starting assets, background consumption, time-varying search costs, and a delay between search effort and the jobs start. We also estimate the model using different weights, using probability of exit instead of hazard, and excluding the spikes from the moments. None of these changes sizeably affect the fit of the standard model, or of the reference-dependent model.

We then examine alternative forms of unobserved heterogeneity. While in the benchmark estimates we assume heterogeneity in search cost in the spirit of Paserman (2008), we allow for more cost types, for heterogeneity in re-employment wage, or in the search elasticity with respect to the returns to search. The first two forms of heterogeneity do not close the gap with the reference-dependent model, but the model with heterogeneous search elasticity fits much better, even outperforming the reference-dependent model. This model explains the observed spikes by allowing for a type with such high search elasticity (over 50) that only searches once benefits fall below a threshold.

But is the model with heterogeneous search elasticity plausible? We provide two implications and two additional pieces of evidence which, in our view, cast doubt on it. First, this model fits the data well only for very high elasticities; if we restrict the elasticities to be no higher than 5 (already quite high), the fit does not come close to matching the referencedependent model. Second, given the high elasticities, the model makes the unlikely prediction that, if welfare benefits were lowered, or increased, by just 10 percent, search effort would skyrocket, or conversely go to zero.

Further, we examine an earlier UI reform which lengthens the duration of unemployment assistance. The impact of the reform on the hazard path is very limited, mostly shifting the spike, consistent with out-of-sample predictions for the reference-dependent model. Instead, the model with heterogeneous cost elasticity predicts a substantial dip in the hazards.

We also compare the dynamic selection implied by the estimated models to the selection on observables in the data. We show that the selection implied by the standard model differs both qualitatively and quantitatively from the observed selection; instead, the implied selection is 
close to the observed selection for the reference-dependent model.

Finally, we briefly discuss other job search models which we do not estimate but which could potentially explain some of the findings. A model of storable offers (as in Boone and van Ours 2012) could explain the spike in hazard at benefit exhaustion, but not the pattern of the hazards in the following months. A model of skill depreciation or screening (e.g. Schmieder et al., 2016) can explain decreasing hazards over the spell, but such decrease would plausibly be the same pre- and post-reform. Two classes of models which could potentially explain the findings are worker learning and consumption commitments (Chetty, 2003 and Chetty and Szeidl, 2016). A worker may learn over time that finding jobs is harder than expected, and this learning may take place later in the pre-reform period, given the different benefit structure. A worker with committed consumption would increase search effort to avoid paying a fixed cost of adjustment; if despite this, she does not find a job soon enough, she will pay the cost and then decrease search. These dynamics could generate some of the hazard patterns after day 270. While both models have intuitive features, unfortunately neither is tractable enough to estimate on our sample. ${ }^{3}$ For tractability reasons, we also do not estimate models with reservation wage choice and optimal consumption-savings. ${ }^{4}$

To sum up, reference dependence, in combination with impatience, can help explain patterns in job search that are hard to rationalize with most alternative models, even allowing for unobserved heterogeneity. These results have implications for potential redesigns of unemployment insurance policies, a point to which we return briefly in the conclusions.

The paper relates to the literature on unemployment insurance design (e.g. Chetty, 2008; Kroft and Notowidigdo, forthcoming; Schmieder et al., 2012a). Within this literature, we evaluate a unique reform: changing the time path of the benefit schedule, keeping the overall payments approximately constant. The paper is consistent with recent evidence of sharp consumption drops at unemployment entry and UI exhaustion for unemployed workers (Ganong and Noel, 2015; Kolsrud et al., 2015), suggesting approximate hand-to-mouth behavior.

The paper also contributes to a literature on behavioral labor economics, including work on employer-employee gift exchange (Akerlof, 1982; Fehr et al., 1993; Gneezy and List, 2006), horizontal pay equity (Card et al., 2012; Breza et al., 2015), and target earnings in labor supply (Camerer et al., 1997; Farber, 2015). Within job search, DellaVigna and Paserman (2005) consider the impact of present-bias while Spinnewijn (2013) examines the role of overconfidence. We show that a reference-dependent model of job search makes unique predictions,

\footnotetext{
${ }^{3}$ The consumption commitment model requires to keep track of a fixed cost decision, making the model cumbersome to estimate. To address this issue, Chetty (2003) makes the timing of fixed cost payment exogenous. A consumption commitment model with exogenous consumption readjustment, as in Chetty (2003), would not explain our findings.

${ }^{4}$ We present in the appendix estimates with reservation wage choice for the hand-to-mouth case. The results should be considered only suggestive, as endogenizing consumption is very important.
} 
and that the data points to a combination of reference dependence and present bias. ${ }^{5}$

The paper also adds to the evidence on reference dependence from settings including insurance choice (Sydnor, 2010; Barseghyan et al., 2013), labor supply (Fehr and Goette, 2007; Farber, 2015), domestic violence (Card and Dahl, 2011), goal setting (Allen et al., forthcoming), and tax elusion (Engström et al., 2015; Rees-Jones, 2013). Across these settings, the reference point is the status-quo, or the forward-looking expectation (Kôszegi and Rabin, 2006). We estimate the speed of updating of a backward-looking reference point as in Bowman et al. (1999), similar to Post et al. (2008). This paper is also part of a literature on structural behavioral economics (Laibson et al., 2007; Conlin et al., 2007; DellaVigna et al., 2012).

The papers proceeds as follows. In Section 2, we present a model of job search and reference dependence. In Section 3 we present the institutional details and the data for the Hungary unemployment insurance reform, which we evaluate in Section 4. In Section 5 we present the structural estimates, and we conclude in Section 6.

\section{Model}

In this section we present a discrete-time model of job search with reference-dependent preferences and present-biased preferences. We build on the job search intensity model presented in Card et al. (2007a) and in Lentz and Tranaes (2005) by adding a reference dependent utility function in consumption with a backward looking reference point.

Model Setup. As in Card et al. (2007a) we make two simplifying assumptions. First, jobs last indefinitely once found. Second, wages are exogenously fixed, eliminating reservation-wage choices. Each period a job seeker decides search effort $s_{t} \in[0,1]$, representing the probability of receiving a job offer at the end of period $t$ and thus of being employed in period $t+1$. Search costs are given by the function $c\left(s_{t}\right)$, which we assume to be time-separable, twice continuously differentiable, increasing, and convex, with $c(0)=0$ and $c^{\prime}(0)=0$.

In each period individuals receive income $y_{t}$, either UI benefits $b_{t}$ or wage $w_{t}$, and consume $c_{t}$. In the general model consumers smooth consumption over time by accumulating (or running down) assets $A_{t}$. Assets earn a return $R$ per period so that consumers face a perperiod budget constraint $\frac{A_{t+1}}{1+R}=A_{t}+y_{t}-c_{t}$ and a borrowing constraint $A_{t} \geq-L$. We also consider a simplified model with hand-to-mouth consumption, $c_{t}=y_{t}$.

The direct utility from consumption in period $t$ for an unemployed person is $v\left(c_{t}\right)$, where $v($.$) is an increasing and concave function. The novel aspect is the fact that the reference-$ dependent individual has, in addition to consumption utility $v\left(c_{t}\right)$, also gain-loss utility. Fol-

\footnotetext{
${ }^{5}$ Koenig et al. (2016) model a reference-dependent reservation wage choice in that the wage offers with some probability equal a previous wage (the reference). Their paper focuses on job matches and reservation wages, as opposed to on the dynamics of exit from unemployment.
} 
lowing the functional form of Köszegi and Rabin (2006), flow utility in each period is

$$
u\left(c_{t} \mid r_{t}\right)=\begin{array}{lll}
v\left(c_{t}\right)+\eta\left[v\left(c_{t}\right)-v\left(r_{t}\right)\right] & \text { if } & c_{t} \geq r_{t} \\
v\left(c_{t}\right)+\eta \lambda\left[v\left(c_{t}\right)-v\left(r_{t}\right)\right] & \text { if } & c_{t}<r_{t}
\end{array}
$$

where $r_{t}$ denotes the reference point in period $t$. The utility consists of consumption utility $v\left(c_{t}\right)$ and gain-loss utility $v\left(c_{t}\right)-v\left(r_{t}\right)$. When consumption is above the reference point $\left(c_{t} \geq r_{t}\right)$, the individual derives gain utility $v\left(c_{t}\right)-v\left(r_{t}\right)>0$, which receives weight $\eta$. When consumption is below the reference point $\left(c_{t}<r_{t}\right)$, the individual derives loss utility $v\left(c_{t}\right)-v\left(r_{t}\right)<0$, with weight $\lambda \eta$. The parameter $\lambda \geq 1$ captures loss aversion: the marginal utility is higher for losses than for gains. This reference-dependent utility function builds on prospect theory Kahneman and Tversky (1979) without, for simplicity, modelling diminishing sensitivity or probability weighting. The standard model is a special case for $\eta=0$.

The second key assumption is the determination of the reference point $r_{t}$. Unlike in the literature on forward-looking reference points (Köszegi and Rabin, 2006), but in the spirit of the tradition on backward-looking reference points (Bowman et al., 1999), the reference point is the average of income over the $N$ previous periods: ${ }^{6}$

$$
r_{t}=\frac{1}{N+1} \sum_{k=t-N}^{t} y_{k}
$$

To gain perspective on the impact of reference dependence, consider an individual in steady state with consumption, income, and reference point equal to $y$. Then in period $T$, consider a small, permanent decrease in income from $y$ to $y-\Delta y<y$, and an identical decrease in consumption from $c=y$ to $y-\Delta y \cdot{ }^{7}$ In period $T$, utility changes to $v(y-\Delta y)+$ $\eta \lambda[v(y-\Delta y)-v(y)]$. The short-term change in utility equals, up to a linear approximation, $-(1+\eta \lambda) \Delta y * v^{\prime}(y)$. Over time, however, the reference point adjusts to $y-\Delta y$ so that the utility after $N$ periods is $v(y-\Delta y)$. Hence, the long-term change in utility equals $-\Delta y v^{\prime}(y)$. Thus, $\eta \lambda$ captures the weight on additional short-term utility in response to an income loss.

Value Functions. The unemployed choose search effort $s_{t}$ and consumption $c_{t}$ in each period and face the following value function, where $\delta$ is the discount factor:

$$
V_{t}^{U}\left(A_{t}\right)=\max _{s_{t} \in[0,1] ; A_{t+1}} u\left(c_{t} \mid r_{t}\right)-c\left(s_{t}\right)+\delta\left[s_{t} V_{t+1 \mid t+1}^{E}\left(A_{t+1}\right)+\left(1-s_{t}\right) V_{t+1}^{U}\left(A_{t+1}\right)\right]
$$

\footnotetext{
${ }^{6}$ Notice that if $N=0$, then $r_{t}=b_{t}$. In the hand-to-mouth case, where $c_{t}=y_{t}$, the reference-dependent utility then simplifies to the direct-consumption utility, $u\left(c_{t} \mid r_{t}\right)=v\left(c_{t}\right)$ and therefore the standard model is embedded. For the model with optimal consumption, even setting $N=0$ the standard model is not embedded. In the estimation below we also consider an alternative $\mathrm{AR}(1)$ reference point formation process.

${ }^{7} \mathrm{~A}$ sudden permanent drop in consumption could occur, for example, if the individual is a hand-to-mouth consumer and benefits suddenly drop.
} 


$$
\text { subject to: } c_{t}=A_{t}+y_{t}-\frac{A_{t+1}}{1+R}
$$

The assumption that the reference point is function of past income and not of past consumption simplifies the value functions substantially, since the value function of unemployment depends only on assets $A_{t}: V_{t}^{U}\left(A_{t}\right)$. For the employed, the reference point depends also on for how long the person has been employed; hence, the value function can be written as $V_{t \mid j}^{E}\left(A_{t}\right)$ for an individual who is employed in period $t$ and who found a job in period $j$. Note also the assumptions on timing: the job-seeker chooses search effort $s_{t}$ in period $t$; with probability $s_{t}$ a job offer materializes, in which case the individual earns wage $w$ starting in period $t+1$.

Once an individual finds a job at time $\mathrm{j}$, the value of employment in period $t$ is given by:

$$
V_{t \mid j}^{E}\left(A_{t}\right)=\max _{c_{t}>0} u\left(c_{t} \mid r_{t}\right)+\delta V_{t+1 \mid j}^{E}\left(A_{t+1}\right)
$$

Given Equation (2) the first order condition for the optimal level of search effort $s_{t}^{*}$ in the case of an interior solution can be written as:

$$
c^{\prime}\left(s_{t}^{*}\left(A_{t+1}\right)\right)=\delta\left[V_{t+1 \mid t+1}^{E}\left(A_{t+1}\right)-V_{t+1}^{U}\left(A_{t+1}\right)\right] .
$$

Thus we can rewrite the unemployed problem as:

$$
\begin{aligned}
V_{t}^{U}\left(A_{t}\right)= & \max _{A_{t+1}} u\left(A_{t}+y_{t}-\frac{A_{t+1}}{1+R} \mid r_{t}\right)-c\left(s_{t}^{*}\left(A_{t+1}\right)\right) \\
& +\delta\left[s_{t}^{*}\left(A_{t+1}\right) V_{t+1 \mid t+1}^{E}\left(A_{t+1}\right)+\left(1-s_{t}^{*}\left(A_{t+1}\right)\right) V_{t+1}^{U}\left(A_{t+1}\right)\right]
\end{aligned}
$$

We solve the model by backwards induction, deriving first the steady-state optimal consumption in the employed state. This allows us to solve for the optimal consumption path for each asset level and to obtain the value functions $V_{t \mid t}^{E}\left(A_{t}\right)$ for each $t$ and each asset level $A_{t}$. Then we solve the dynamic programming problem for the unemployed, moving backwards from the steady state, solving for the optimal consumption path and search effort path for each possible starting value of the asset vector.

Front-Loading The Benefit Path. To highlight the implications of reference dependence, we consider a hypothetical unemployment insurance reform that closely corresponds to our empirical setting. To build intuition and for tractability, we consider in detail the case of hand-to-mouth consumers with no heterogeneity and then briefly discuss the extension to the general case. In the case of hand-to-mouth consumers, assets are not a control variable and thus we can solve for $s_{t}^{*}: s_{t}^{*}=\mathcal{C}\left(\delta\left[V_{t+1 \mid t+1}^{E}-V_{t+1}^{U}\right]\right)$, where $\mathcal{C}()=.c^{-1}($.$) .$

Consider a UI system with benefits $b_{1}$ for the first $T_{1}$ periods benefits and benefits $b_{2}$ from period $T_{1}$ until $T$. After period $T$, there is a lower second tier (such as social assistance) with 
benefits $\underline{b}$. A single-step UI system, like the one in the US, is captured by $b_{1}=b_{2}=b_{\text {constant }}$ and is illustrated by the blue solid line in Figure 1a).

Consider a reform that front-loads the benefit path by raising benefits $b_{1}$ in the first $T_{1}$ periods and reducing benefits $b_{2}$ in periods $T_{1}$ to $T$, while leaving second-tier benefits $\underline{b}$ unchanged, as illustrated by the red dashed line in Figure 1a). Furthermore, the reform leaves untouched the total amount of benefits paid to an individual unemployed for $T$ periods:

$$
b_{1} T_{1}+b_{2}\left(T-T_{1}\right)=b_{\text {constant }} T
$$

Equation (5) implies $\frac{\partial b_{2}}{\partial b_{1}}=-\frac{T_{1}}{T-T_{1}}$. We now partially characterize how search $s_{t}^{*}$ is affected by an increase in $b_{1}$ subject to constraint (5). We express the results in terms of $\frac{d s_{t}^{*}}{d b_{1}}=$ $\frac{\partial s_{t}^{*}}{\partial b_{1}}-\frac{T_{1}}{T-T_{1}} \frac{\partial s_{t}^{*}}{\partial b_{2}}$, where the total derivative takes the implied adjustment of $b_{2}$ into account. ${ }^{8}$

Proposition 1. Assume a hand-to-mouth unemployed job-seeker and consider a shift in the benefit path that front-loads the benefits $b_{1}$ keeping the overall benefits paid constant.

a) In the standard model $(\eta=0)$, the search effort in all periods after benefit expiration at $T$ is unaffected: $\frac{d s_{T+i}^{*}}{d b_{1}}=0$, for $i=0,1, \ldots$

b) In the reference-dependent model ( $\eta>0$ and $\lambda \geq 1$ ) search effort (weakly) decreases in the first $N$ periods after $T$, and remains constant in later periods: $\frac{d s_{T+i}^{*}}{d b_{1}} \leq 0$, for $i=0,1, \ldots N-1$ and $\frac{d s_{T+i}^{*}}{d b_{1}}=0$, for $i=N, N+1, \ldots$ Furthermore, if the adjustment speed $N$ of the reference point is shorter than $T$, then the inequality is strict: $\frac{d s_{T+i}^{*}}{d b_{1}}<0$, for $i=0,1, \ldots N-1$

Part a) is straightforward. In the standard model, the search decision depends exclusively on future benefits and wages, and the reform leaves unaffected the benefits past period $\mathrm{T}$.

The intuition for part b), which we prove in the appendix, is as follows. An increase in $b_{1}$ affects search effort in period $T$ through changes in $V_{T+1}^{E}$ and $V_{T+1}^{U}$. These value functions are affected because frontloading the benefit path (increasing $b_{1}$ and reducing $b_{2}$ ) will reduce the reference point at time $T, r_{T}$, as long as $N<T$. This will increase both the value of employment (due to an increase in gain utility) and the value of unemployment (due to a decrease in loss utility). If $\lambda \geq 1$ the decrease in loss utility will be larger than the increase in gain utility, leading to a reduction in search effort.

These predictions are illustrated in Figures 1b) and c). In the standard model (Figure 1b), optimal search effort increases under both regimes up until period $T$, and then plateaus after period $T$ at a level that is unaffected by the front-loading of benefits (Proposition 1a). Generally, the hazard rate for the front-loaded regime (the dotted red line) will be higher than the one for constant benefits in the periods right before period $T$, given the moral hazard.

\footnotetext{
${ }^{8}$ Note that search effort in period $t$ is not affected by UI benefits in period $t$, since the individual will only start a job found in period $t$ in period $t+1$. Thus search effort $s_{t}$ corresponds to the exit hazard from unemployment in period $t+1: s_{t}=h_{t+1}$.
} 
In contrast, under reference dependence (Figure 1c), search effort in period $T$ is substantially higher under the constant-benefit regime (continuous blue line). Individuals in this regime experience a sharper drop in consumption and thus (for $N<T$ ) significant loss utility due to the higher reference point. Second, the difference in hazards persists but shrinks for $N$ periods, at which point the reference point has fully adapted to the lower benefits under either regime, and thus search effort converges. A third implication (not captured in the Proposition) is that in the last few periods before period $T$, for sufficiently large loss aversion $\lambda$, the hazard is higher under the constant-benefit regime compared to the front-loaded regime. The anticipation of larger future losses under the constant-benefits regime generates this anticipatory effect, counteracting the moral hazard effect of more generous benefits.

Notice that Proposition 1 does not hold with either heterogeneity or optimal consumption. With heterogeneous types, differences in the path of benefits up to period $T$ may lead to a different composition of types surviving at period $T$, and thus differences in the hazard even in the standard model, violating Proposition 1a). However, given the assumption of constant total benefit payout, differences in type composition are likely to be small.

Introducing savings in the model also invalidates Proposition 1 since individuals may have different savings at period $T$, thus creating differences in hazards, even under the standard model. However, given that the total benefit payments are constant, such differences in savings are likely to be small. We address both heterogeneity and savings in the estimation section.

Present Bias. We extend the model by allowing for present-bias (Laibson, 1997; O'Donoghue and Rabin, 1999), with an additional discount factor $\beta \leq 1$ between the current period and the future. The present bias factor $\beta$ induces time inconsistency and fits behavior in a range of settings (see Frederick et al., 2002; DellaVigna, 2009). In the context of job search, DellaVigna and Paserman (2005) solve for a job search model with present-biased preferences. We assume that individuals are naive about their future present-bias: they (wrongly) assume that in the future they will make decisions based on regular discounting $\delta$. We make this assumption mostly for computational reasons, since the naive agent problem can be solved using the value functions of the exponential agent (given that the naive worker believes she will be exponential from next period). In addition, the evidence on present bias is largely consistent with the naivete' assumption (DellaVigna, 2009).

The naive hyperbolic discounting individual solves the following value functions:

$$
\begin{aligned}
V_{t}^{U, n}\left(A_{t}\right)= & \max _{s_{t} \in[0,1] ; A_{t+1}} u\left(c_{t} \mid r_{t}\right)-c\left(s_{t}\right)+\beta \delta\left[s_{t} V_{t+1 \mid t+1}^{E}\left(A_{t+1}\right)+\left(1-s_{t}\right) V_{t+1}^{U}\left(A_{t+1}\right)\right] \\
& \text { subject to: } c_{t}=A_{t}+y_{t}-\frac{A_{t+1}}{1+R}
\end{aligned}
$$


and

$$
V_{t+1 \mid t+1}^{E, n}\left(A_{t+1}\right)=\max _{c_{t}>0} u\left(c_{t} \mid r_{t}\right)+\beta \delta V_{t+2 \mid t+1}^{E}\left(A_{t+1}\right)
$$

where the functions $V_{t+1}^{U}$ and $V_{t+1 \mid t+1}^{E}$ are given by equations (2) and (3) above for the exponential discounters. Note that this adds one more step to the solution algorithms, since we first solve for all possible values of $V_{t+1}^{U}$ and $V_{t+1 \mid t+1}^{E, n}$ and then we solve for the optimal consumption and search paths given by $V_{t+1}^{U, n}$ and $V_{t+1 \mid t+1}^{E, n}$.

\section{Data and Institutions}

\subsection{Unemployment Insurance in Hungary}

Hungary had a generous two-tier unemployment insurance system up to 2005. In the first tier, potential duration and benefit amount depended on past UI contribution. ${ }^{9}$ The maximum potential duration, obtained after around 4 years of contribution, was 270 days, ${ }^{10}$ while the benefit level was based on the earnings in the previous year. After the exhaustion of first-tier benefits, unemployment assistance (UA) benefits could be claimed in the second tier. The UA benefit amount was the same for everybody, with the potential duration depending on age.

On May 30th, 2005 the Hungarian government announced a comprehensive reform of the UI system ${ }^{11}$, with the goal of speeding up transition from unemployment to employment. The government changed the benefit calculations formula in the first tier, but did not alter the way potential duration and the earnings base were calculated. Before the reform, the benefit in the first tier was constant with a replacement rate of $65 \%$ and with minimum and maximum benefit caps. The reform introduced a two-step benefit system. For the first step, the length was half of the potential duration in the first tier, and at most 91 days, and the replacement was lowered to $60 \%$ with increased minimum and maximum benefit caps. For most claimants these changes meant lower benefits than under the old schedule. In the second tier everybody received the new minimum benefit amount, reducing benefits for most claimants compared to before. The benefit formula changes are summarized in Appendix Figure A-1.

The most prominent change occurred for those with 270 days of eligibility (four years of UI contributions before lay-off) and base year earnings above the new benefit cap (that is, they earned more than 114,000HUF (\$570) per month in 2005). As Figure 2 shows, for this group the duration of benefits in the first tier remains 270 days. While in the old system the

\footnotetext{
${ }^{9}$ Every worker in the formal sector must pay a UI contribution. In 2005 , employers contributed $3 \%$ to the UI fund, while employees $1 \%$. There is no experience rating of UI benefits in Hungary.

${ }^{10}$ More specifically, potential benefit in the first tier was calculated as UI contribution days in the last 4 years divided by 5 , but at most 270 days.

${ }^{11}$ The reform was part of a wider government program called "100 steps". Policies related to the labor market and unemployment insurance (such as reemployment bonus and training policies) are discussed later. In addition to that, VAT and corporate income tax were decreased from January 1st 2006.
} 
benefits were constant in the first tier, under the new rules benefits increased substantially in the first 90 days, but decreased afterwards. An important feature of the reform for this group is that the increase in weekly benefits in the first 90 days is about twice as large as the decrease in weekly benefit between 90 and 270 days, keeping the total benefit pay-out for individuals unemployed for 270 days the same.

Even though the main element of the reform was the new benefit formula, there were other changes occurring at the same time. Most notably, a reemployment bonus scheme was introduced with a bonus amount equal to $50 \%$ of the remaining total first-tier benefits. However, claiming the bonus was not without costs. If the bonus was claimed, then the entitlement for the unused benefit days was nulled. This could be very costly for risk-averse agents or for those who could only find an insecure job. Also, the bonus could only be claimed after the date of first-tier benefit exhaustion. This meant hassle costs, since UI claimants had to show up and fill out the paper work in the local UI office. Given these costs, it is not surprising that the take-up rate of reemployment bonus was only $6 \%$, making it unlikely that it had substantial effects. As a robustness check, we show that the results are not sensitive to dropping the reemployment bonus users from the sample. ${ }^{12}$

In addition to the introduction of the reemployment bonus, there were two other minor relevant changes. First, those who claimed UI benefit before February 5th, 2005 faced a longer ${ }^{13}$, but somewhat lower, benefit in the second tier. ${ }^{14}$ To avoid this complication, we only focus on those who claimed their benefits after February 5th, 2005. Second, there were minor changes in financing training programs. ${ }^{15}$ However, participation in training programs was very low (less than 5\%) in our sample and our results are robust to dropping these claimants.

Those who exhausted benefits in both tiers (UI and UA) and were still unemployed could claim means-tested social assistance. The duration of social assistance is indefinite, while the amount depends on family size, family income, and wealth. In most cases social assistance

\footnotetext{
${ }^{12}$ Lindner and Reizer (2015) investigate the reemployment bonus in detail and further show that it does not affect the unemployment duration.

${ }^{13}$ Before the reform, the potential duration in the second tier was 270 days above age 45 and 180 days below 45. Those who claimed UI after February 5th, 2005 were eligible for 180 days above age 50 and 90 days below 50 in the second tier.

${ }^{14}$ The change in the duration and benefit level in the second tier was introduced at November 1st, 2005 at the same time as other changes. However, it affected everybody who claimed second tier (UA) benefits after November 1st, 2005. A UI claimant who claimed her benefits after February 5th, 2005 and had 270 days potential eligibility could only claim second tier benefits (UA) after November 1st, 2005. Therefore, claimants between February 5th, 2005 and November 1st, 2005 are under the old benefit system for the first tier, but face the same second tier (UA) insurance scheme, see Figure 3.

${ }^{15}$ Unemployed participating in training programs received the so-called income substituting benefit. Before November 1st, 2005 this amount was 22,200HUF (\$111) or 44,400HUF (\$222), depending on household characteristics and type of training. This benefit was payed in excess of the UI. After November 1st, the benefit was $34,200 \mathrm{HUF}$ (\$171) for everybody, but the UI benefit was suspended during training. Although we only observe training participation after November 1st, 2005, aggregate data show that the probability of participation in training programs remained constant throughout this period Frey (2009).
} 
benefits are lower than the second tier UI benefit level. ${ }^{16}$

\subsection{Data}

We use administrative data ${ }^{17}$ on social security contributions for roughly 4 million individuals between January 2002 and December 2008. The sample consists of a 50\% de facto random sample of all Hungarian citizens who were older than 14 and younger than 75 in $2002 .{ }^{18}$ The data contains information on UI claims from February 2004 to December 2008 as well as basic information used by the National Employment Service, like the starting and ending date of the UI benefit spells and the earnings base used for benefit calculation.

In this paper we only focus on UI claimants who are eligible for the maximum potential duration (270 days) in the first tier. In addition, we restrict our sample to those who are older than 25 years and younger than 49 years, since specific rules apply close to retirement. Moreover, we identify as our main sample UI claimants with high earnings base, since our goal is to explore the variation in Figure 2. To construct a consistent sample over time, we focus on the unemployed with earnings base above the 70th percentile among the UI claimants in a given year. In 2005, a UI claimant at the 70th percentile earned 100,800 HUF (\$504). ${ }^{19}$

To evaluate the reform, we construct two comparison groups of workers who entered UI just before or just after the reform, since the claiming date determined the relevant regime. Due to the change in unemployment assistance in February 2005, we use all UI claimants between February 5th, 2005 and October 15, 2005 (to avoid getting too close to the reform) as our pre-reform group. For the post-reform group, we take UI entrants in the same date range (February 5 to October 15) in 2006 so as to match possible seasonal patterns. Figure 3 shows the timing of the two comparison groups and the range for which our data is available. For robustness checks, we later show results using data in the earlier and later ranges as well.

Table 1 shows basic descriptives for the two groups. The basic demographic characteristics, such as age at time of claiming, education and log earnings in the years 2002 - 2004, are similar before and after the reform. The waiting period (the number of days between job loss and the time of claiming UI benefits) is almost identical across the two groups, indicating that people towards the end of our before sample were not trying to delay UI claiming dates in order to become eligible to the new regime. ${ }^{20}$ The take-up rates of the reemployment bonus scheme,

\footnotetext{
${ }^{16}$ For large families, social assistance can be more generous than UI. However, social assistance cannot be claimed before all other benefits have been exhausted in the UI system.

${ }^{17}$ The dataset is provided by the Institute of Economics - Hungarian Academy of Sciences.

${ }^{18}$ More precisely the sample is composed of everybody born on the 1st of January, 1927, and every second day thereafter (3rd of January, 5th of January etc.).

${ }^{19}$ Our results are robust to alternative earnings thresholds over time. For example, we estimated our main specifications for those whose (real) earnings base was above 114,000 HUF (\$570) and obtained virtually the same results.

${ }^{20}$ Appendix Figure A-2 shows the unemployment rate and GDP growth rate around the two periods in
} 
which was introduced in 2005, are quite low. Below we present robustness checks to address the possibility that this bonus may have affected our results.

\section{Reduced Form Results}

\subsection{Estimating Hazard Plots}

In this section, we evaluate the impact of the reform on the exit rates from unemployment. We estimate the hazard rates with a linear probability model separately for each 15-day period ${ }^{21}$, indexed by $t$, after entering unemployment insurance:

$$
I\left(t_{i}^{*}=t \mid t_{i}^{*} \geq t\right)=\beta_{0, t}+\beta_{1, t} P O S T_{i}+X_{i} \gamma+\epsilon_{i t},
$$

where $i$ indexes individuals and $t_{i}^{*}$ represents the duration of unemployment of individual $i$. The left hand side is an indicator for individual $i$ finding a job in period $t$, conditional on still being unemployed at the beginning of the period. The variable $P O S T_{i}$ is an indicator for individual $i$ claiming benefits in the post-reform period, while $X_{i}$ is a matrix of control variables. The equation is estimated separately for each period $t$ on the sample of individuals who are still unemployed at time $t$ (that is conditional on $t_{i}^{*} \geq t$ ). The estimates for $\beta_{0, t}$ are estimates for the hazard function in the pre-period, while the estimates for $\beta_{1, t}$ represent the shift of the hazard function between the before and after period. In our baseline estimates we do not control for any observables $X_{i}$, and show results controlling for $X_{i}$ as robustness. ${ }^{22}$

\subsection{Main Result}

Figure 4a) shows the estimates of equation (8) for each $t$ with no controls. The blue line represents the coefficient estimates of $\beta_{0, t}$, the estimated hazard function in the before period, while the red line represents the estimated $\beta_{0, t}+\beta_{1, t}$, the after period hazard. Vertical lines indicate that the difference between the two series is statistically significant at the $5 \%$ level.

Hungary. The unemployment rate was quite stable at around 7.5 percent during and after the two sample periods. GDP growth was also stable during the sample periods, only slowing down at the beginning of 2007. Below we show extensive robustness checks, showing that our results are not driven by changes in the economic environment that occurred later and that the shape of the hazard rates are in fact very stable over time except for the exact point when the UI policy changes.

${ }^{21}$ We choose a 15 -day period so that the benefit path steps after 90 days and 270 days occur at integer values of these periods. The results are very similar with hazards computed at 7 days or 30 days.

${ }^{22}$ Note that these hazard functions should not be viewed as consistent estimates at the individual level, but rather as estimates of the average hazard function in the population. While the natural experiment, assuming the conditional independence assumption holds, identifies the causal effect of the reform on the average population hazard function, the shape of this average hazard function is potentially affected by duration dependence or by changes in selection due to the reform. While we address differential selection in our reduced form results section by comparing the estimated hazards controlling and not controlling for observables, an important aspect of our structural estimation below will be to explicitly model unobserved heterogeneity. 
The exit rate from unemployment in the pre-reform period shows a familiar pattern for a one-step unemployment system. The exit hazard falls in the first months after entering UI, then it increases as it approaches the exhaustion point of UI benefits (at 270 days). After this exhaustion point, it falls and spikes again as people exhaust the second tier benefits, unemployment assistance, at 360 days. The hazard rate then decreases monotonically, as unemployed people are only eligible for welfare programs.

The exit hazard changes substantially after the introduction of a two-step system. The hazard rate increases at 90 days, at the end of the higher unemployment insurance benefit, and remains elevated compared to the pre-reform period for the following 2.5 months. By 180 days, the pre- and post-reform hazards have converged, and both hazards increase at the exhaustion of UI benefits at 270 days. Importantly though, the post-reform hazard increases significantly less, and the pre-reform hazard remains significantly higher for three months following UI exhaustion. Finally, by 360 days, the end of unemployment assistance, the two hazards have once again converged.

The most striking difference occurs around day 270, when in the pre-reform period the exit hazard remains significantly higher after the UI exhaustion point (270 days) relative to the post-reform period. As we discussed above, this difference in hazards is hard to reconcile with the standard model: from day 270 onwards, the benefit levels are identical in the preand post-period, and in addition the total amount of benefits received up to day 270 is also almost identical. Hence, in the standard model we would expect similar hazards (even with heterogeneity, as we show below). A modified standard model with storable offers could potentially match the spike at 270 days, but it still does not explain the persistent difference in the hazards after the exhaustion of benefits.

The difference in hazards instead fits nicely with the reference-dependent model: the workers in the pre-reform period experience a larger drop-off in benefits around day 270, inducing a spike in loss utility and thus an increase in the value of search. The persistence for three months of the higher hazard indicates slow adjustment of the reference point. Furthermore, the increase in hazard in the pre-period happens already in anticipation of benefit expiration at day 270, consistent with the reference-dependent model.

While we focus mainly on the hazard rate around day 270 because it leads to the most distinct predictions, the observed patterns around day 90 are also consistent with reference dependence. The spike in the hazard at 90 days in the post-period, corresponding to the first step down in benefits, disappears after 3-4 months, consistent once again with loss utility and a slowly-adjusting reference point. However, the spike itself in this period could also be explained by the standard model with unobserved heterogeneity, as we show below.

Figure 4b) shows the estimated survival function for the two groups. We obtain these 
estimates using a variant of equation (8), where we estimate the equation again pointwise for all $t$ but including the whole sample and taking $P\left(t_{i}^{*} \geq t\right)$ as the outcome variable. The survival functions diverge after 90 days, with lower survival probabilities in the after group than in the before group. This difference persists until around 300 days, after which the two lines converge. Since the expected duration in unemployment is simply the integral over the survival function from 0 onwards, the expected unemployment duration is significantly reduced in the after period. It is striking that even though the reform made the UI system more generous on average (since short term unemployed received more benefits, while the long-term unemployed received about the same), the expected duration decreased.

\subsection{Robustness Checks}

The results presented so far do not control for demographic characteristics. Even though the differences in demographics between the pre- and the post-period are quite small (Table 1), they could potentially explain differences in the hazard patterns over time if the demographic impacts on the hazard rates are large. Thus, we re-estimate equation (8) controlling for a rich set of observable characteristics, where we allow these characteristics to have arbitrary effects on the hazard function at each point, the only restriction being that the effect is the same in the before and after period. As Figure 5a) shows, controlling for observables has virtually no effect on the hazard rates, implying that they cannot explain our findings. ${ }^{23}$

A separate concern regards the introduction of the reemployment bonus in November 1st, 2005. While the take-up rate of the bonus was just $6 \%$ in our sample, it may still affect the hazard rate in the post-reform period, especially in the first 90 days. As a check, we drop all individuals that received a reemployment bonus and estimate our baseline specification on this restricted sample; the results are virtually unchanged (Figure 5b)).

In order to assure that the differences in the hazard rates are in fact due to the reform in the UI system and not simply the result of some general trend, we exploit the fact that we have additional data from 2004 and after 2006. First, we estimate two placebo tests for whether there are differences in the two years before the reform and the one year before the reform, using the same estimation strategy as before. We report these results in Appendix Figure A3a), revealing that the hazard rates are virtually unchanged between 2004 and 2005. There is a small difference right after the 270 line, which is expected due to the reduction in unemployment assistance in February 2005, leading to a slight increase in the hazard at this point in 2005. Similarly Appendix Figure A-3b) shows that there are virtually no differences between the hazards 1 and 2 years after the reform, again indicating that the differences between our

\footnotetext{
${ }^{23}$ Alternatively we also used propensity score reweighting to estimate the hazards in the pre- and post-period, holding the observables constant over time and obtained almost identical results (not shown).
} 
before- and after-period line up nicely with the reform.

We explore the timing further by plotting time-series graphs of the exit hazards over specific intervals. Figure 6a) shows the evolution over time of the exit hazard between 30 and 90 days (red line) and between 90 and 150 days (black line). Each dot indicates the average hazard for each 3-month period between 2004 and 2007, with quarter 1 indicating the first 3-month period after the reform. Prior to the reform, the hazard at 90-150 days is smaller than the hazard at 30-90 days, consistent with the patterns in Figure 5. Subsequent to the reform introducing a step down of benefits after 90 days, the pattern abruptly changes. Already in the first quarter after the reform, the hazard at 90-150 days increases sizeably, becoming similar to the hazard at 30-90 days, a pattern that remains largely similar over the next 6 quarters. The figure provides little evidence of previous trends, suggesting that the changes in hazards are indeed a causal effect of the reform.

Figure 6b) provides parallel evidence for the hazard at 210-270 days versus at 270-330 days. In the quarters pre-reform, the hazard at 270-330 days is significantly higher than the hazard at 210-270 days, a pattern that changes abruptly with the first quarter following the reform. The time-series plots again indicate a change that is coincidental with the reform and not due underlying trends or changes in the macroeconomic environment.

\section{Structural Estimation}

\subsection{Set-up and Estimation}

We use the model of Section 2, imposing six additional assumptions, some of which we relax later. The first three assumptions concern the utility function. First, we assume that the search cost function has a power form as in Paserman (2008) and Chetty (2003): $c(s)=$ $k s^{1+\gamma} /(1+\gamma)$. This form implies that the parameter $\gamma$ is the inverse of the elasticity of search effort with respect to the net value of employment. ${ }^{24}$ Second, we assume log utility, $v(b)=\ln (b)$. Third, similar to Bloemen (2005) and Paserman (2008), we model heterogeneity as three types of unemployed workers that differ in their cost of search $k$.

Fourth, to avoid modelling on-the-job search, we start the worker problem in the first period of unemployment, and thus fit the hazard from the second period on. ${ }^{25}$ Fifth, we set past wages equal to the median earnings in our sample, which is 135,000 HUF (\$675), and assume that reemployment wages are constant over the UI spell and equal to past wages. ${ }^{26}$

\footnotetext{
${ }^{24}$ To see this, recall that the first-order condition of search effort (equation 4) is $c^{\prime}\left(s^{*}\right)=v$, where we denote with $v$ the net value of employment (that is, the right-hand-side of equation 4). Given the parametric assumption, this yields $s^{*}=(v / k)^{1 / \gamma}$, and the elasticity of $s^{*}$ with respect to $v$ is $\eta_{s, v}=(d s / d v) v / s=1 / \gamma$.

${ }^{25}$ Recall that a successful job search in period $t$ yields a job in period $t+1$.

${ }^{26}$ In a robustness check, we present estimates assuming a lower reemployment wage.
} 
Sixth, we assume that individuals start with zero assets, that they cannot borrow against their future income, and that they earn no interest on saved assets.

The vector of parameters $\xi$ that we estimate for the standard model are: (i) the three levels of search cost $k_{\text {high }}, k_{\text {med }}$, and $k_{\text {low }}$, with the assumption $k_{\text {high }} \geq k_{\text {med }} \geq k_{\text {low }}$, and the two probability weights $p_{\text {low }}$ and $p_{\text {med; }}$ (ii) the search cost curvature $\gamma$; (iii) the time preference parameters $\delta$ and $\beta$. For the reference-dependent model, we estimate in addition: (iv) the loss aversion parameter $\lambda$; and (v) the number of (15-day) periods $N$ over which the backward-looking reference point is formed. ${ }^{27}$ To keep the number of parameters the same as for the standard model, in the reference-dependent model we assume only two cost types, thus removing parameters $k_{m e d}$ and $p_{m e d}$. Notice that the weight $\eta$ on gain-loss utility is set to 1 in the benchmark estimates rather than being estimated; thus, the loss-aversion parameter $\lambda$ can be interpreted also as the overall weight on the losses. The reason for this assumption is that over the course of the unemployment spell the individual is always on the loss side since the benefits are always (weakly) lower than the reference point. Hence, it is difficult to estimate a separate weight on gain utility and loss utility. ${ }^{28}$

Estimation. We use a minimum-distance estimator. Denote by $m(\xi)$ the vector of moments predicted by the theory as a function of the parameters $\xi$, and by $\hat{m}$ the vector of observed moments. The minimum-distance estimator chooses the parameters $\hat{\xi}$ that minimize the distance $(m(\xi)-\hat{m})^{\prime} W(m(\xi)-\hat{m})$, where $W$ is a weighting matrix. As a weighting matrix, we use a diagonal matrix that has as diagonal elements the inverse of the variance of each moment. ${ }^{29}$ To calculate the theoretical moments, we use backward induction. First we numerically compute the steady-state search and steady-state value of unemployment using a hybrid bisection-quadratic interpolation method, pre-implemented in Matlab as the fzero routine. Then we solve backwards for the optimal search intensity and consumption path in each period as a function of the asset level. Finally, we use the initial asset level as a starting value to determine the actual consumption path and search intensity in each period.

Under standard conditions, the minimum-distance estimator using weighting matrix $W$ achieves asymptotic normality, with estimated variance $\left(\hat{G}^{\prime} W \hat{G}\right)^{-1}\left(\hat{G}^{\prime} W \hat{\Lambda} W \hat{G}\right)\left(\hat{G}^{\prime} W \hat{G}\right)^{-1} / N$, where $\hat{G} \equiv N^{-1} \sum_{i=1}^{N} \nabla_{\xi} m_{i}(\hat{\xi})$ and $\hat{\Lambda} \equiv \operatorname{Var}[m(\hat{\xi})]$ (Wooldridge, 2010). We calculate $\nabla_{\xi} m(\hat{\xi})$ numerically in Matlab using an adaptive finite difference algorithm.

Moments. As moments $m(\xi)$ we use the 15-day hazard rates from day 15 to day 540 for both the pre-reform and post-reform period, for a total of $35^{*} 2=70$ moments. We do not use the hazard from the first 15 day period, since it would require modelling search on the job.

\footnotetext{
${ }^{27}$ In the estimations tables we report the speed of adjustment in days, which is just $\mathrm{N}^{*} 15$.

${ }^{28}$ In principle, the weight on gain utility $\eta$ can be separately identified as we show in a robustness section, since gain utility affects the utility of reemployment, but the reemployment utility does not allow for very precise identification of $\eta$.

${ }^{29}$ As robustness check below, we alternatively use the identity matrix as a weighting matrix.
} 
Identification. While the parameters are identified jointly, it is possible to address the main sources of identification of individual parameters. The cost of effort parameters $k_{j}$ are identified from both the level of search intensity and the path of the hazards over time. This is clearest in the standard model, where the heterogeneity in the parameters is needed, for example, to explain the decay in the hazard after day 360, when benefits remain constant and thus, in absence of heterogeneity, the hazard would be constant in the standard model (but not in the reference-dependent model). The search cost curvature parameter, $\gamma$, is identified by the responsiveness of the hazard rate to changes in benefits since $1 / \gamma$ is the elasticity of search effort with respect to the (net) value of finding a job.

The time preference parameters are identified by the presence of spikes around benefit cuts, among other moments. If the unemployed workers are patient, they save in advance of benefit decreases so as to smooth consumption. Impatient workers, instead, save little if at all and thus experience a sharp decrease in consumption around the benefit change. This consumption drop then induces a sharp increase in search effort as the benefits decrease.

Turning to the reference-dependence parameters, for a given value of $\eta$ (fixed to 1 in the benchmark specification), $\lambda$ denotes the magnitude of the loss utility. A major component to identification is the extent to which the hazard for the pre-period is higher both before and after day 270, in response to a larger loss. Instead, the standard model has essentially identical hazards from day 270 onwards. The loss parameter is also identified by the response to other changes in the benefits, such as at 90 days in the post-period. The parameter $N$, which indicates the speed at which the losses are reabsorbed into the reference point, is identified by the fact that the pre- and post-reform hazards converge a few months after day 270. The speed of convergence of the hazard after day 90 also suggests several months of adjustment.

\subsection{Hand-to-Mouth Estimates}

To build intuition, we first present estimates assuming that workers in each period consume the per-period income. Figure 7a) presents the fit for the standard model with 3-type heterogeneity. The model fits quite well the surge in hazard around day 90 in the post-period, and the decreasing path of the hazard in the first 200 days. The fit is also reasonably good for the period from day 400 on. However, the fit between days 250 and 400 is poor. As discussed above, the standard model predicts that the hazard rates for the pre- and post-period should be almost exactly the same after day 270. As such, the model misses both the sharp difference in hazard between day 260 and day 360, as well as the spikes at both 260 and 360 days.

In comparison, Figure 7b) displays the fit of the reference-dependent model with two types (and thus the same number of parameters as in the standard model). The fit in the first 250 days is very good, though it was quite good also for the standard model. But, as anticipated, 
the model does much better for longer durations, where the standard model fits poorly. In particular, the model fits better the surge in the hazard rate in the pre-period in anticipation of the benefit cut after 270 days (which is larger in the pre period than in the post-period), as well as the elevated level for the following three months, compared to the pre-period. Then the model tracks quite well the period following the exhaustion of unemployment assistance (after 360 days). The fit of the reference-dependent model, while superior to the standard model, is certainly not perfect. The most striking aspect of the data which the model does not capture is the large spike on day 270 for the pre-period; storable offers may play a role in this case. In addition, the reference-dependent model under-fits the difference in hazards between the pre- and post-period after day 270.

In Table 2 we present the parameter estimates. The estimates for the standard model (Column (1)) indicate substantial heterogeneity in cost $\mathrm{k}$ and low cost curvature $\hat{\gamma}=.13$. This implies a high elasticity of search effort to incentives, needed to fit the substantial hazard increases in response to benefits changes. The estimates for the reference-dependent model (Column (2)) indicate a substantial weight on loss utility, $\hat{\lambda}=3.5$ (s.e. 1.3), and slow adjustment of the reference point, $\hat{N}=216$ (s.e. 9) days. At the bottom of the Table, we report the goodness of fit $(\mathrm{GOF})$ measure $(m(\xi)-\hat{m})^{\prime} W(m(\xi)-\hat{m})$. The reference-dependent model has a substantially better fit (GOF of 170 versus 215), for equal number of parameters.

\subsection{Benchmark Estimates with Consumption-Savings}

While the previous estimates indicate that a reference-dependent model can fit the patterns in the data quite well, there is a key concern with the hand-to-mouth estimates. Individuals who anticipate experiencing loss utility from a benefit cut should save in anticipation, allowing them to smooth consumption around the benefit cut. In turn, this would imply smoother hazards around the benefit cuts than in the data. This consumption smoothing, however, is ruled out in the hand-to-mouth model.

A parallel issue arises for the hand-to-mouth estimates of the standard model. The estimated patience parameter in the standard model $(\hat{\delta}=.98)$ implies forward-looking individuals who are quite responsive in their search effort to future benefit cuts. And yet, by assumption these individuals do not save in anticipation of the cuts. For these reasons, we now turn to the estimates modelling a consumption-savings choice, in addition to the search effort choice.

Figure 8a) shows the fit for the standard model with three types, compared with the fit in Figure 8b) for a reference-dependent model with two types (with once again the same number of parameters). The qualitative fit is similar to the fit obtained for hand-to-mouth consumers (Figures 7a) and b)): the reference-dependent model better fits the path in the hazard.

How is that possible in light of the above intuition about counteracting savings? For an 
answer, we turn to Table 3 which displays the corresponding parameter estimates in Columns (1) and (2). The most striking element is the high estimated degree of impatience: 15-day discount factors of $\delta=0.89$ for the reference-dependent model and $\delta=0.93$ for the standard model. Either estimate implies an annual discount factor of 0.17 or lower. Appendix Figure A-4a) provides further evidence on the identification of the discount factor. Each point in the figure indicates the goodness of fit of the best-fitting estimate for a particular (15-day) discount factor. For patient individuals $(\delta=0.995$ or higher $)$, the reference-dependent model does poorly: loss-averse workers with a high degree of patience would build a buffer stock, thus smoothing the loss utility. As individuals become more impatient, already for $\delta=0.95$ the reference dependent model has a good fit (and better than the standard model), with the best fit, as we saw in the table, for an even lower discount factor. The fit of the standard model also improves as the discount factor decreases, though less steeply.

These results stress the importance of modelling optimal consumption: both the standard model and the reference-dependent model have a somewhat worse fit compared to the hand-tomouth estimates. The hand-to-mouth results embed an inconsistent combination of relatively high patience (and thus forward-looking search effort) and yet no consumption smoothing. In the consumption-savings model, the discount factor drives at the same time both the search decision and the consumption-savings decision, putting additional restrictions on the model.

Returning to the point estimates, the downside of this set of results is that the model which best accommodates the data - the reference-dependent one - requires a degree of impatience which is hard to reconcile with other estimates in the literature. Yet, this high estimated degree of impatience may be due to a mis-specification of the discounting function. A growing body of evidence, summarized among others in Frederick et al. (2002) and DellaVigna (2009), suggests that the beta-delta model of time preferences due to Laibson (1997) and O'Donoghue and Rabin (1999) provides a better fit of observed behavior in a number of settings. The betadelta model includes an additional discount factor $\beta$ between the present and the next period to capture the present bias, inducing a time inconsistency.

Thus, in a second set of estimates we allow for beta-delta discounting ${ }^{30}$ in both the standard model and the reference-dependent model. To keep the number of parameters constant, we set the long-term discount factor $\delta$ to .995. The results in Columns (3) and (4) of Table 3 and in Figure 8c) show that the fit is better than in the models with delta discounting for the reference-dependent model with much more plausible discounting: the estimated present-bias parameter is $\beta=0.58$, implying a discount factor of 0.46 for the first year and of 0.88 for subsequent years. This indicates a substantial degree of impatience, but in line with esti-

\footnotetext{
${ }^{30} \mathrm{We}$ assume that consumers are naive about the future self-control problem mostly for computational simplicity, especially given the complexity of estimating the consumption decision. In addition, the naiveté assumption is arguably better supported by the evidence (DellaVigna, 2009).
} 
mates in the literature. For example, Paserman (2008), building on the model in DellaVigna and Paserman (2005), estimates a job search model with beta-delta preferences and obtains estimates for beta ranging between 0.40 and 0.89 , depending on the sample. Laibson et al. (2007), based on life-cycle consumption choices, estimates a $\beta$ between 0.51 and 0.82 .

In light of both the higher plausibility and the better fit, we adopt the reference-dependent model with beta-delta discounting as the benchmark behavioral model in the rest of the paper. For the standard model, especially given the small difference in fit between the two discounting functions, we use the more standard delta discounting. ${ }^{31}$

How do the two models achieve their fit? In Appendix Figures A-5 and A-6 we report plots for key model components, focusing on the high-cost type. In the standard model, the flow utility follows the step down in the benefits, with the size of the later steps accentuated by the curvature of the utility function. In the reference-dependent model, the flow utility captures also the intensity of the loss relative to the reference point. The value of unemployment decreases over time in the standard model as expected, while in the reference-dependent model it actually increases over most of the range, reflecting the importance of reference point adaptation. This fits the observed decrease in search effort over time, even for a given type. Furthermore, the value of unemployment declines sharply in correspondence to the benefit drop. (This sharp drop reflects the estimated impatience). The next panel shows the reference point path, which is decreasing over time. Notice that from around day 250 the reference point is higher in the pre-reform group, which contributes to generate higher loss utility and thus a larger increase in search effort near benefit expiration.

In Appendix Figure A-6, the value of employment, which is almost constant in the standard model, increases monotonically over time for the reference-dependent model, as getting a job is associated with a larger gain utility as the reference point declines. This latter force does not account for much of the results, as we illustrate later when we turn off gain utility. Turning to consumption and assets, consumption tracks quite closely the per-period earnings, especially in the reference-dependent model. As such, assets get depleted quickly and remain at zero or close for the rest of the spell. While we do not observe consumption in our data, other work (e.g. Ganong and Noel, 2015) has documented that consumption for UI recipients tracks income rather closely with sharp drops at UI entry and benefit exhaustion.

In the final set of columns in Table 3 we return to a key motivation of the paper. We argued that the reference-dependent model can, at least in principle, capture the qualitative features of the hazard from unemployment without any heterogeneity. Yet, the estimates of reference-dependent model allow for two heterogeneous types. In Columns (5) and (6), we remove any heterogeneity and estimate the reference-dependent model with only one cost type.

\footnotetext{
${ }^{31}$ The results for the reference-dependent models with either delta or beta-delta discounting are qualitatively similar in all the subsequent specifications.
} 
This bare-bones model fits the data better than the standard model (goodness of fit of 183 compared to 227), despite having two fewer parameters. As Figure 8d) shows, the qualitative fit is almost as good as in the reference-dependent models with heterogeneity.

\subsection{Reference-Dependence Variants}

In Table 4 we consider variants of the benchmark reference-dependent model, reproduced in Column (1). First, instead of defining the reference point as the average of income over the $N$ previous periods, we assume an $\mathrm{AR}(1)$ process for the reference point:

$$
r_{t}=\rho r_{t-1}+(1-\rho) y_{t}=(1-\rho) \sum_{i=1}^{\infty} \rho^{i} y_{t-i}
$$

This updating rule has longer "memory" and adjusts more smoothly than the benchmark reference point, with the speed of adjustment captured by $\rho .{ }^{32}$ Column (2) of Table 4 shows the estimated speed of adjustment $\rho=0.77$, which implies faster adjustment (half-life is 40 days) than in the benchmark case. The goodness of fit with $\operatorname{AR}(1)$ updating is very similar to the one in the benchmark estimates. Figure 9a) shows the fit of this AR(1) model. ${ }^{33}$

Next, we disentangle the role played by gain and loss utility. So far, we have arbitrarily set the gain utility parameter, $\eta$, to 1 and estimated the weight on loss utility, $\eta \lambda$. In Columns (3) and (4) we examine the role of gain and loss utility by including only one at a time in the model. In Column (3) we assume no gain utility when workers get a job, but still estimate the loss utility weight $\eta \lambda$. The fit of the model, visible in Figure 9b), is almost as good as the benchmark reference-dependent one, and the estimated speed of updating of the reference point is nearly the same (though not, as expected, the estimated loss aversion). In Column (4), we instead assume no loss utility and model gain utility. This model does worse than even the standard model (Figure 9c). This indicates the key role played by loss utility.

Next, we present a parallel take on this result. Columns (5) and (6) report the estimates setting, respectively, a value of $\eta$ of 0.2 and of 5 . As the (assumed) weight on gain utility $\eta$ increases, the estimated $\lambda$ decreases, holding the term $\eta \lambda$, which is the weight on loss utility, at comparable (though not constant) levels. The goodness of fit under these alternative assumptions for $\eta$ is almost the same as in the standard model. In Column (7), we estimate

\footnotetext{
${ }^{32}$ When we implement this estimate we assume that the memory of the AR(1) update goes back to 1050 days (or 70 15-day periods).

${ }^{33}$ We adopt as benchmark the N-period reference point for computational reasons, since the long memory of the AR(1) model makes the estimates more time-consuming. In addition, we do not estimate models with a forward-looking reference point as in Kôszegi and Rabin (2006). These models typically give rise to multiple equilibria which would complicate the model solution significantly. However, notice that it is unclear that forward-looking reference points would explain the difference in hazards after period 270. By that point, the forward-looking reference points would presumably be the same in the pre- and post-period, leading to similar predictions for the two periods (up to equilibrium selection), counterfactually.
} 
separately $\eta$ and $\lambda$, with the fit shown in Figure 9d). The two parameters are in principle separately identified, but the estimate for $\eta(4.5)$ is imprecise, and the goodness of fit is again close to the benchmark model. As such, in the rest of the paper we hold $\eta$ fixed to 1 .

\subsection{Habit Formation}

How does reference dependence compare to habit formation? Models a la Constantinides (1990) and Campbell and Cochrane (1999) assume utility $u(c-z r)$, where $r$ is the habit formed from past consumption and $u$ is a concave function. Habit formation, like reference dependence, induces a temporarily high marginal utility following a benefit cut, as consumption $c$ gets closer to the habit $z r$. Thus, it could also plausibly fit the patterns in the data.

We estimate a version of a habit formation model replacing the reference dependent utility function (defined in Equation (1)) with the utility:

$$
v\left(c_{t}, r_{t}\right)=\log \left(c_{t}-z r_{t}\right)
$$

where $z$ captures the responsiveness to changes in the habit and $r_{t}$ is calculated the same way as before, but reinterpreted as a measure of habit stock. ${ }^{34}$ The estimates are in Columns (1) and (2) of Table 5, allowing for a fixed $\mathrm{N}$ for updating of the reference point and for an $\operatorname{AR}(1)$ process. In either case, the fit is not close to the fit of the reference-dependent model, and is in fact slightly worse than the standard model (see also Figures 10a-b).

This may appear surprising given the similar intuition behind the two models. The models however differ in a key aspect. In the reference-dependent model, the impact of the loss, $\lambda(u(c)-u(r))$, on search effort is approximately proportional to the size of the loss. Instead, in the habit-formation model larger decreases in consumption have disproportionate effect, as $c$ gets closer to $z r$. Given this, the habit-formation model fits the data less well, since it predicts a larger spike at the 90-day (post reform) benefit decrease, and a much smaller spike for the later (proportionally smaller) benefit decreases. ${ }^{35}$ Allowing for three unobserved types (Column (3)) only partially improves the fit.

Next, we consider a second type of habit-formation models with so-called multiplicative habits (Abel, 1990), with utility $\log (c)-z \log (r)$. This utility function is equivalent (up to a linear transformation) to our reference-dependent model with loss aversion $\lambda$ set to 1 and $\eta$ set to $z /(1-z)$. In Column (4) (and in Figure 10d) we present estimates from this multiplicativehabit model: the fit is superior to the one of the first habit-formation model, though still not

\footnotetext{
${ }^{34}$ Observe that this function is not defined whenever $c_{t}<z r_{t}$, complicating the estimation. To avoid this problem, Campbell and Cochrane (1999) made $z$ a non-linear function of $y_{t}-r_{t}$. We treat $z$ as a parameter instead and check in the optimum that our utility function is defined for the relevant $y_{t}$ and $r_{t}$.

${ }^{35}$ In addition, the habit-formation model is also computationally trickier to estimate, as the estimated habit parameter $\gamma$ has to always satisfy the condition $c>\gamma r$.
} 
close to the benchmark model. This result stresses again the importance of loss aversion.

\subsection{Robustness}

In Table 6 we consider the robustness of the standard and reference-dependent model to alternative specifications. We present additional checks in Appendix Table A-1.

In Column (1) we estimate both time preference parameters, $\beta$ and $\delta$. While the fit is somewhat better than in the benchmark models, the two time preference parameters appear to be quite collinear; thus, in the benchmark specifications we fix one of the two parameters. In Column (2) we allow for background consumption: workers receive non-market income $n$ during unemployment, in addition to the benefits earned, to capture home production. The estimates are very similar to the standard ones. In Column (3), while still allowing for background consumption, we make the alternative assumption that workers are not eligible for welfare; thus, benefits fall to 0 after 360 days. ${ }^{36}$ This alternative assumption improves somewhat the fit of both the reference-dependent model and the standard model. In Column (4) we allow for a linear time trend in the baseline cost factor allowing for skill depreciation or conversely learning by searching. This additional parameter improves the fit of the referencedependent model while leaving the fit of the standard model essentially unaffected.

In Column (5) we explore the role played by the spikes at days 270 and 360, since one may worry that such spikes play a disproportional role in the identification given the quadratic distance measure. The model estimated dropping these moments from the objective function (see also Appendix Figure A-7c and d) yields similar patterns indicating that the results are not driven by the spikes. We also consider the importance of timing in the model. We assume that jobs start one period after the offer is received, but what if the hiring process takes longer? In Column (6) we assume a 2-period (that is, approximately one-month) delay between the job search and the start of the wage payments. As Appendix Figures A-8a) and b) show, the change in timing does not shift the spike. Rather, job-seekers start their search effort earlier, taking into account the longer delay. In Column (7) we allow for a lower reemployment wage set at two thirds of the average previous wage. The alternative assumption worsens somewhat the fit of both models, with little substantive impact on the estimates. In Column (8) we test the importance of the assumption of zero initial assets: endowing workers with $\$ 600$ in their last period of employment does not affect much the estimates (see also Appendix Figure A-7a) and b)), though the fit is somewhat worse than under the assumption of zero assets (which itself is most consistent with the estimated high impatience).

In Appendix Table A-1 we present additional robustness results. In Column (1) we use

\footnotetext{
${ }^{36}$ While unemployed workers are generally eligible for welfare after benefit exhaustion, the rules are complex and we do not observe a good measure of welfare take up. Thus, we explore this alternative.
} 
the identity matrix to weight the moments and in Column (2) we use the moments estimated after controlling for observables (shown in Figure 5b)). Though the goodness of fit cannot be compared to the previous estimates, the qualitative conclusions remain the same. In Columns (3) and (4), instead of using the hazard rates as moments, we use the estimated (unconditional) probability of exiting unemployment in each 15-day period. The advantage of this alternative procedure is that we can use the full variance-covariance matrix for weights, which we do in Column (3). Once again, while the goodness of fit measures are not comparable to the benchmark models, the pattern of the results is very similar. Finally, the estimates are similar if we use the 30-day hazards or 7-day hazards, instead of 15-day hazards.

\subsection{Unobserved Heterogeneity}

So far, we have modeled one form of heterogeneity, in search costs, ${ }^{37}$ and allowed for a fixed number of types: three in the standard model and two in the behavioral model. In Table 7, we relax both assumptions.

First, we increase the number of heterogeneous cost types from 2 types (Column (1)) all the way to 5 types (Column (4)). Allowing for additional types in the standard model improves the fit all the way to 4 types; estimates with 5 or more types have trouble converging. Still, even the model with 4 or 5 types does significantly worse in terms of fit than the reference-dependent model (Figure 11a). For the reference-dependent model, there is essentially no improvement in fit going from 2 types to more types. Indeed, estimates of the reference-dependent model with more than 3 types have trouble converging.

Next, we consider alternative forms of unobserved heterogeneity, such as in the reemployment wage. We take the 10th, 50th, and 90th percentile of the reemployment wage, as well as the fractions of each type (taken to be 20 percent, 60 percent, and 20 percent respectively) from the data. We then estimate three cost parameters $k_{j}$, one for each type. This alternative specification (Column (5)) improves somewhat the fit of the standard model, as Figure 11b) also shows, but the fit of the reference-dependent model is still significantly better.

In Column (6) we allow for heterogeneity in the curvature parameter $\gamma$. While this form of heterogeneity does not affect the estimates of the reference-dependent model, it improves dramatically the fit of the standard model. The estimates fit both the spike at 270 and at 360 days, as well as the difference between the pre- and post-reform period (Figure 11(c)). Indeed, this is the only specification with a better fit than the reference-dependent model. How does this model attain such good fit? The fit relies heavily on types with a very different elasticity of search (which equals $1 / \gamma$ ). Initially, most exits are of the low-elasticity types $\left(\gamma_{\text {high }}=1.01\right.$ ), but the spike at day 270 is driven by the medium-elasticity types $\left(\gamma_{m e d}=0.20\right)$. These types

\footnotetext{
${ }^{37}$ The heterogeneity on search costs is based on papers such as Bloemen (2005) and Paserman (2008).
} 
were barely searching up until day 270, but their search intensity spikes in presence of lower benefits. The spike at 360 days is due to the high-elasticity types, with an elasticity over 50 $\left(\gamma_{\text {low }}=0.016\right)$, that start searching once benefits hit the welfare level.

How critical are the high-elasticity types for the fit of the model? We re-estimate the model restricting the elasticity to be no higher than $10(\gamma \geq 0.1$, Column $(7))$ and no higher than $5(\gamma \geq 0.2$, Column (8)). With such restrictions in place, the model does not match any more the fit of the reference-dependent model (see also Figure 11d)).

\subsection{Tests of Gamma Heterogeneity}

The previous sections show that only one version of the standard model matches (in fact, surpasses) the fit of the reference-dependent model: the gamma-heterogeneity model. How should we compare then the two models? In this section we present a calibration and additional evidence, with more evidence in the next section.

As we just showed, the gamma-heterogeneity model requires two types with a very large elasticity of search effort. To consider the implications of such elasticities, consider a hypothetical comparative statics: a 10 percent increase, or decrease, in the level of welfare benefits paid out after 360 days. Figures 12a) and b) show that, in response to such a small benefit change, the search effort of reference-dependent workers would barely change compared to the benchmark estimates. In the gamma-heterogeneity model, instead, the hazard rates would go to nearly 1 (for a $10 \%$ benefit decrease, Figure 12a)) or to nearly 0 (for a $10 \%$ increase, Figure 12b)). The workers still unemployed by day 360 are mostly the high-elasticity types, and even small changes in the setting lead to massive changes in search effort. We find this implied response unrealistic. Importantly, this high elasticity, and thus the ensuing extreme response, is critical for the fit of the gamma-elasticity model, as we documented above.

While there are no reforms in the welfare system in our period, we do observe a reform in the unemployment assistance system occurring one year before our 'pre' period (see Figure 3). The benefit duration in this second tier goes from 180 days before the change to 90 days after the change for the individuals in our sample. ${ }^{38}$ We use this reform, which we have not employed so far, as an out-of-sample test, since the macroeconomic setting was similar and the group of workers affected is the same.

Figure 12c) shows the hazard for the 2-year-prior period, as well as the predictions for the benchmark reference-dependent estimates (Column (4) in Table 3) and for the gammaheterogeneity estimates (Column (6) in Table 7). The reference-dependent model fits the pre-period well, with an out-of-sample SSE of 73.4. The gamma heterogeneity model, instead,

\footnotetext{
${ }^{38}$ This change applied to individuals aged 45 and lower. Since our sample includes only individuals up to 50 years old, the reform applies to the large majority of the sample. Excluding the $46-50$ year olds barely affects the estimates.
} 
fits quite poorly the period of the lengthened unemployment assistance (between 300 and 450 days), with an out-of-sample SSE of 130.5. In this period, the medium-elasticity types are disappearing from the sample, and the high-elasticity types are not searching yet. The gamma heterogeneity type appears to overfit the data in sample. The out-of-sample fit of the standard model with heterogeneity in cost levels is better (SSE of 91.6), but does not reach the reference-dependent model. We present a final piece of evidence in the next section.

\subsection{Dynamic Selection throughout the UI spell}

The standard model captures reasonably well the dynamics in the hazards in the first 270 days as well as some of the trend after that, especially in the gamma-heterogeneity version. To achieve this fit, changes in the unobserved types over time play a key role; without types, the hazards would be monotonically (weakly) increasing over time. How plausible then is the amount of heterogeneity that the standard model requires? And how does it compare to the heterogeneity needed in the reference-dependent model?

While we cannot measure the time-changing unobserved heterogeneity, we propose that a useful metric is the time-varying selection on observables of the unemployed. Assuming that unobservable factors that influence job search correlate with these observable characteristics, these estimates convey useful information.

To document the dynamic selection along observables, we regress at the individual level the realized unemployment duration (censored at 540 days) on a rich set of observables: education, age groups, gender, waiting period (the number of days between job lost and UI claimed), log past earnings, indicators for county of residence, day of the month UI claimed, and occupation (1 digit) of the last job. As Web Appendix Table WA-1 shows, for both individuals in the pre- and post-sample (Columns (1) and (2)), these variables are reliable predictors of non-employment duration, with an $R^{2}$ of 0.05-0.06. Panel B shows that the predicted unemployment duration based on these estimates for the pre-period varies between 230 days (5th percentile) and 370 days (95th percentile), a good amount of variation.

The dotted lines with crosses in Figure 13a-b) show the predicted unemployment duration averaging across all individuals who exit unemployment in a given 15-day period. While predicted unemployment increases (unsurprisingly) throughout the spell, the overall relationship is quite flat: predicted unemployment only increases from 280 days to 295 days after around 2 years. Furthermore, the pattern of selection is not much affected by the UI benefit path. The lines for the pre- and post-reform period are fairly parallel for most of the spell. ${ }^{39}$ Selection on observables thus plays only a limited role in the data.

\footnotetext{
${ }^{39}$ The fact that dynamic selection seems to be small and not much affected by the UI regime has been shown before, for example Schmieder et al. (2016).
} 
The selection over time in predicted duration has a counterpart in the structural models. For each cost type, we compute the expected unemployment duration in the pre-reform period. We then calculate the average expected duration for unemployed individuals who leave in a given period according to the estimated models. The reference-dependent model (solid lines in Figure 13) predicts that the type composition changes only in the first 90 days and not by much; thus the expected unemployment duration line is quite flat and not so dissimilar from what we observe empirically. The standard model with cost heterogeneity (Figure 13a)) instead displays a large amount of dynamic selection, with a large swing until 200 days, with no corresponding evidence in the data. The predicted heterogeneity for the gamma-heterogeneity model (Figure 13b)) is even more at odds with the data, with an initial swing, and then an abrupt swing between 300 and 360 days, corresponding to the transition from the mediumto the high-elasticity type. There is no evidence of a corresponding shift in the data.

Thus, the pattern of dynamic selection implied by two versions of the standard model appear at odds with the much more muted and monotonic selection in the data. We should be clear that it is not surprising that the selection on observables be more muted than the selection implied by the model, given that we only observe part of the selection. However, the extent of the difference is quite striking, given the rich set of variables used in calculating dynamic selection. Moreover, it is puzzling for the standard model that the observed selection does not display any of the trends in the model predictions, even on a more muted scale. ${ }^{40}$

\subsection{Reservation Wages}

So far we take the reemployment wage as fixed so the unemployed accept every job offer. ${ }^{41}$ While this is consistent with a literature documenting a small role of reservation wages for job search dynamics (e.g. Card et al., 2007a; Krueger and Mueller, 2013; Schmieder et al., 2016), a natural question is whether introducing a reservation wage would change our conclusions. For tractability, we estimate a reference-dependent model with choice of search effort and reservation wage, but with hand-to-mouth consumers. These results should be considered only suggestive, as endogenizing consumption is important, as we documented above.

We reestimate the model incorporating job acceptance decisions, using additional moments based on reemployment wages and solving by backward induction. In this expanded model,

\footnotetext{
${ }^{40}$ While the Altonji et al. (2005) procedure motivates this test, the parallel is imperfect. Altonji et al. (2005) infers the impact of unobservable variables on the the magnitude of an estimate, based on the impact of the observables. In our case, we would like to infer the extent and the role of unobserved heterogeneity in the structural model, based on the heterogeneity captured by observables. The underlying assumption of our procedure is that the set of observable variables used in predicting dynamic selections are rich enough to capture (part of) the dynamic selection if its there, and also that the time path of dynamic selection caused by observables is similar to the one caused by unobserved factors. .

${ }^{41}$ In the baseline model there is a single reemployment wage for everyone, while in the models in Table 7, Column (5) we allow for 3 different groups of workers, each facing a different fixed reemployment wage.
} 
individuals draw job offers from a (stationary) log-normal wage offer distribution and decide whether or not to accept it. For simplicity, we also abstract away from gain (or loss) utility at reemployment. We set the standard deviation of the wage offer distribution at 0.5 , close to the standard deviation of the actual reemployment wages, and we estimate the mean of the wage offer distribution. As additional moments, we use the average reemployment wage of individuals exiting unemployment in period $t$ after entering the UI system, adding 70 additional moments in the minimum distance estimator. ${ }^{42}$

Web Appendix Table WA-2 shows the results in Columns (1) and (2). The referencedependent model has a better fit than the standard model (GOF of 272 versus 308), largely due to the reference-dependent model providing a better fit for the hazard moments (see also Web Appendix Figures WA-1). Notice however that the estimates in Columns (1) and (2), not unlike the hand-to-mouth estimates in Table 2, have relatively patient unemployed workers, at odds with the maintained assumption of hand-to-mouth consumption. For the sake of comparison, Columns (3) and (4) provide estimates of the hand-to-mouth models with no reservation wage choice assuming no gain utility at reemployment.

\section{Discussion and Conclusion}

We provided evidence that a model with reference-dependent preferences can explain qualitative features of the hazards which plausible versions of the standard model have a hard time fitting. The model itself builds on one of the most robust behavioral models, reference dependence, and uses a natural candidate for a backward-looking reference point. We also find that job seekers are substantially impatient, likely in the form of present-bias preferences.

This evidence has policy implications. A key prediction of reference-dependent job search is that step-wise benefit schedule can induce considerably more search than predicted by the standard job search models. Moreover, if the social planner wants the job seekers to search more than they do (e.g. because she uses a lower discount rate for welfare assessment than that of the unemployed), then having benefit drops over the UI spell is likely to be an inexpensive way to achieve that goal. In support of that, Lindner and Reizer (2015) show that the Hungarian UI reform examined here did not just speed up exits to employment, but it was revenue-neutral from the perspective of the government. Therefore, the evidence presented here opens the door to potential redesigns in unemployment insurance policies.

\footnotetext{
${ }^{42}$ The reemployment wage moments are estimated as in Lindner and Reizer (2015), allowing for a linear time trend.
} 


\section{References}

Abel, Andrew B, "Asset prices under habit formation and catching up with the Joneses," The American Economic Review, 80 (2), (1990), 38-42.

Akerlof, George A, "Labor contracts as partial gift exchange," The Quarterly Journal of Economics, 97 (4), (1982), 543-569.

Allen, Eric, Patricia Dechow, Devin Pope, and George Wu, "Reference-Dependent Preferences: Evidence from Marathon Runners," Management Science, (forthcoming).

Altonji, Joseph G, Todd E Elder, and Christopher R Taber, "Selection on Observed and Unobserved Variables: Assessing the Effectiveness of Catholic Schools," Journal of Political Economy, 113 (1), (2005).

Barseghyan, Levon, Francesca Molinari, Ted O'Donoghue, and Joshua C. Teitelbaum, "The Nature of Risk Preferences: Evidence from Insurance Choices," The American Economic Review, 103 (2013), 2499-2529.

Bloemen, Hans G, "Job Search, Search Intensity, and Labor Market Transitions an Empirical Analysis," Journal of Human Resources, 40 (1), (2005), 232-269.

Bowman, David, Deborah Minehart, and Matthew Rabin, "Loss aversion in a consumptionsavings model," Journal of Economic Behavior \&f Organization, 38 (2), (1999), 155-178.

Breza, Emily, Supreet Kaur, and Yogita Shamdasani, "The Morale Effects of Pay Inequality," Technical Report, Working paper (2015).

Camerer, Colin, Linda Babcock, George Loewenstein, and Richard Thaler, "Labor supply of New York City cabdrivers: One day at a time," The Quarterly Journal of Economics, 112 (2), (1997), 407-441.

Campbell, John Y and John H Cochrane, "By Force of Habit: A Consumption-Based Explanation of Aggregate Stock Market Behavior," The Journal of Political Economy, $10^{\text {r7 }}$ (2), (1999), 205-251.

Card, David, Alexandre Mas, Enrico Moretti, and Emmanuel Saez, "Inequality at Work: The Effect of Peer Salaries on Job Satisfaction," American Economic Review, 102 (6), (2012), 2981-3003.

— and Gordon B. Dahl, "Family Violence and Football: The Effect of Unexpected Emotional Cues on Violent Behavior," The Quarterly Journal of Economics, 126 (2011), 103-143.

_ , Raj Chetty, and Andrea Weber, "Cash-On-Hand and Competing Models of Intertemporal Behavior: New Evidence from the Labor Market," Quarterly Journal of Economics, 122 (4), (2007a), 1511-1560.

Chetty, Raj, "Consumption commitments, unemployment durations, and local risk aversion," Working Paper 10211, National Bureau of Economic Research (2003). 
_ , "Moral hazard versus liquidity and optimal unemployment insurance," Journal of political Economy, 116 (2), (2008), 173-234.

- and Adam Szeidl, "Consumption Commitments and Habit Formation," Econometrica, 84 (2), (2016), 855-890.

Conlin, Michael, Ted O'Donoghue, and Timothy J. Vogelsang, "Projection Bias in Catalog Orders," American Economic Review, 97 (2007), 1217-1249.

Constantinides, George M., "Habit Formation: A Resolution of the Equity Premium Puzzle," Journal of Political Economy, 98 (3), (1990), pp. 519-543.

DellaVigna, Stefano, "Psychology and Economics: Evidence from the Field," Journal of Economic Literature, 47 (2), (2009), 315-372.

- and M. Daniele Paserman, "Job search and impatience," Journal of Labor Economics, 23 (3), (2005), 527.

_ , John. A. List, and Ulrike Malmendier, "Testing for Altruism and Social Pressure in Charitable Giving," Quarterly Journal of Economics, 127 (2012), 1-56.

Engström, Per, Katarina Nordblom, Henry Ohlsson, and Annika Persson, "Tax Compliance and Loss Aversion," American Economic Journal: Economic Policy, 7 (4), November (2015), $132-64$.

Farber, Henry S., "Why You Can'T Find a Taxi in the Rain and other Labor Supply Lessons from Cab Drivers*," The Quarterly Journal of Economics, (2015).

Fehr, Ernst and Lorenz Goette, "Do Workers Work More if Wages Are High? Evidence from a Randomized Field Experiment," The American Economic Review, 97 (2007), 298-317.

_, Georg Kirchsteiger, and Arno Riedl, "Does fairness prevent market clearing? An experimental investigation," The Quarterly Journal of Economics, 108 (2), (1993), 437-459.

Frederick, Shane, George Loewenstein, and Ted O'donoghue, "Time discounting and time preference: A critical review," Journal of Economic Literature, 40 (2), (2002), 351-401.

Frey, Maria, "The legal and institutional environment of the labour market," in Fazekas Kroly and KllJnos, eds., The Hungarian labor market-Review and Analysis, Institute of Economics IE-HAS, National Employment Service - Hungary, (2009).

Ganong, Peter and Pascal Noel, "How Does Unemployment Affect Consumer Spending?," mimeo, (2015).

Gneezy, Uri and John A List, "Putting behavioral economics to work: Testing for gift exchange in labor markets using field experiments," Econometrica, 74 (5), (2006), 1365-1384.

Kahneman, Daniel and Amos Tversky, "Prospect theory: An analysis of decision under risk," Econometrica: Journal of the Econometric Society, (1979), 263-291. 
Katz, Lawrence F and Bruce D Meyer, "Unemployment insurance, recall expectations, and unemployment outcomes," The Quarterly Journal of Economics, 105 (4), (1990), 973-1002.

Koenig, Felix, Alan Manning, and Barbara Petrongolo, "Reservation wages and the wage flexibility puzzle," mimeo, (2016).

Kolsrud, J., Camille Landais, Peter Nilsson, and Johannes Spinnewijn, "The Optimal Timing of Unemployment Benefits: Theory and Evidence from Sweden," Technical Report (2015).

Köszegi, Botond and Matthew Rabin, "A model of reference-dependent preferences," The Quarterly Journal of Economics, 121 (4), (2006), 1133-1165.

Kroft, Kory and Matthew J. Notowidigdo, "Should Unemployment Insurance Vary with the Unemployment Rate? Theory and Evidence," Review of Economic Studies, (forthcoming).

Krueger, Alan B. and Andreas Mueller, "A Contribution to the Empirics of Reservation Wages," Mimeo, (2013).

Laibson, David, "Golden eggs and hyperbolic discounting," The Quarterly Journal of Economics, (1997), 443-477.

_ , Andrea Repetto, and Jeremy Tobacman, "Estimating Discount Functions with Consumption Choices over the Lifecycle," Working paper, (2007).

Le Barbanchon, Thomas, "The Effect of the Potential Duration of Unemployment Benefits on Unemployment Exits to Work and Match Quality in France," Insee, CREST, Working Paper, (2012-21), (2012).

Lentz, Rasmus and Torben Tranaes, "Job Search and Savings: Wealth Effects and Duration Dependence," Journal of Labor Economics, 23 (July), (2005), 467-489.

Lindner, Attila and Balázs Reizer, "Frontloading the Unemployment Benefits: An Empirical Assessment," mimeo, (2015).

Micklewright, John and Gyula Nagy, "Living standards and incentives in transition: the implications of UI exhaustion in Hungary," Journal of Public Economics, 73 (1999), 297319 .

Mortensen, Dale T, "Job search and labor market analysis," Handbook of labor economics, 2 (1986), 849-919.

O'Donoghue, Ted and Matthew Rabin, "Doing it now or later," American Economic Review, (1999), 103-124.

Paserman, M Daniele, "Job search and hyperbolic discounting: Structural estimation and policy evaluation," The Economic Journal, 118 (531), (2008), 1418-1452.

Post, Thierry, Martijn J Van den Assem, Guido Baltussen, and Richard H Thaler, "Deal or no deal? Decision making under risk in a large-payoff game show," The American economic review, (2008), 38-71. 
Rees-Jones, Alex, "Loss Aversion Motivates Tax Sheltering: Evidence from U.S. Tax Returns," Working paper, (2013).

Schmieder, Johannes F, Till Von Wachter, and Stefan Bender, "The Effects of Extended Unemployment Insurance over the Business Cycle: Evidence from Regression Discontinuity Estimates over 20 years," The Quarterly Journal of Economics, 127 (2), (2012a), 701-752.

_ , Till von Wachter, and Stefan Bender, "The Effect of Unemployment Benefits and Nonemployment Durations on Wages," The American Economic Review, (2016).

Spinnewijn, Johannes, "Training and Search during Unemployment," Journal of Public Economics, 99 (2013), 49-65.

Sydnor, Justin, "(Over)Insuring Modest Risks," American Economic Journal: Applied Economics, 2:4 (2010), 177-199.

van den Berg, Gerard J, "Nonstationarity in job search theory," The Review of Economic Studies, 57 (2), (1990), 255-277.

van Ours, Jan and Milan Vodopivec, "Does reducing unemployment insurance generosity reduce job match quality?," Journal of Public Economics, 92 (3-4), (2008), 684-695.

Wooldridge, Jeffrey M., Econometric analysis of cross section and panel data, MIT Press, (2010). 
Table 1: Descriptive Statistics: Comparing Means of Main Variables Pre- and Post UI Reform

\begin{tabular}{lcccc}
\hline & before & after & diff & t-stat \\
& $(1)$ & $(2)$ & $(3)$ & $(4)$ \\
\hline Percent Women & $41 \%$ & $46 \%$ & $5.2 \%$ & 5.75 \\
& $(0.006)$ & $(0.006)$ & & \\
Age in Years & 36.8 & 36.9 & 0.06 & 0.47 \\
& $(0.1)$ & $(0.1)$ & & \\
Imputed Education (years) & 12.83 & 13.00 & 0.17 & 4.20 \\
based on occupation & $(0.028)$ & $(0.031)$ & & \\
Log Earnings in 2002 & 11.55 & 11.52 & -0.03 & -3.56 \\
& $(0.006)$ & $(0.006)$ & & \\
Log Earnings in 2003 & 11.70 & 11.68 & -0.03 & -2.72 \\
& $(0.005)$ & $(0.007)$ & & \\
Log Earnings in 2004 & 11.79 & 11.78 & -0.01 & -1.37 \\
& $(0.007)$ & $(0.007)$ & & \\
Waiting period* & 31.1 & 32.0 & 0.84 & 1.18 \\
Reemployment bonus claimed & $(0.47)$ & $(0.51)$ & & \\
& 0.000 & 0.059 & 0.059 & 19.81 \\
Participate in training & $(0)$ & $(0.003)$ & & \\
Number of observations ${ }^{\dagger}$ & N.A. & 0.042 & & \\
\hline
\end{tabular}

Notes:

Participation in training programs was not recorded prior to 2006 .

* Number of days between job loss and UI claim.

$\dagger$ There are some missing values for earnings in 2002-2004 . 
Table 2: Structural Estimation of Standard and Reference Dependent Model with Hand-to-Mouth Consumers

\begin{tabular}{|c|c|c|}
\hline & $\begin{array}{c}\text { Standard } \\
\text { 3-type } \\
(1)\end{array}$ & $\begin{array}{c}\text { Ref. Dep. } \\
\text { 2-type } \\
(2)\end{array}$ \\
\hline \multicolumn{3}{|l|}{ Parameters of Utility Function } \\
\hline Loss aversion $\lambda$ & & $\begin{array}{c}3.55 \\
(1.27)\end{array}$ \\
\hline $\begin{array}{l}\text { Adjustment speed of reference point } \mathrm{N} \\
\text { in days }\end{array}$ & & $\begin{array}{c}216.49 \\
(9.06)\end{array}$ \\
\hline Discount factor (15 days) $\delta$ & $\begin{array}{c}0.98 \\
(0.06)\end{array}$ & $\begin{array}{c}0.91 \\
(0.02)\end{array}$ \\
\hline \multicolumn{3}{|c|}{ Parameters of Search Cost Function } \\
\hline Curvature of search cost $\gamma$ & $\begin{array}{c}0.13 \\
(0.26)\end{array}$ & $\begin{array}{c}0.60 \\
(0.15)\end{array}$ \\
\hline Search cost for high cost type $k_{\text {high }}$ & $\begin{array}{l}126.59 \\
(151.97)\end{array}$ & $\begin{array}{l}203.17 \\
(70.10)\end{array}$ \\
\hline Search cost for medium cost type $k_{m e d}$ & $\begin{array}{c}75.65 \\
(117.65)\end{array}$ & \\
\hline Search cost for low cost type $k_{\text {low }}$ & $\begin{array}{c}26.38 \\
(45.36)\end{array}$ & $\begin{array}{l}16.03 \\
(6.52)\end{array}$ \\
\hline Share of high cost UI claimant & $\begin{array}{c}0.34 \\
(0.17)\end{array}$ & $\begin{array}{c}0.98 \\
(0.01)\end{array}$ \\
\hline Share of medium cost UI claimant & $\begin{array}{c}0.49 \\
(0.16)\end{array}$ & \\
\hline \multicolumn{3}{|l|}{ Model Fit } \\
\hline $\begin{array}{l}\text { Number of moments used } \\
\text { Number of estimated parameters } \\
\text { Goodness of Fit }\end{array}$ & $\begin{array}{c}70 \\
7 \\
215.2\end{array}$ & $\begin{array}{c}70 \\
7 \\
170.2\end{array}$ \\
\hline
\end{tabular}

Notes:

The table shows parameter estimates for the standard and the reference dependent search model. Estimation is based on minimum distance estimation, using the hazard rates in the pre- and post-reform periods as the moments.

Standard errors for estimated parameters in parentheses. 
Table 3: Benchmarks Estimates with Endogeneous Savings

\begin{tabular}{|c|c|c|c|c|c|c|}
\hline & $\begin{array}{c}\text { Standard } \\
3 \text { type } \\
\text { delta est } \\
(1)\end{array}$ & $\begin{array}{c}\text { Ref. Dep. } \\
2 \text { type } \\
\text { delta est } \\
(2)\end{array}$ & $\begin{array}{c}\text { Standard } \\
3 \text { type } \\
\text { beta est } \\
(3)\end{array}$ & $\begin{array}{c}\text { Ref. Dep. } \\
2 \text { type } \\
\text { beta est } \\
(4)\end{array}$ & $\begin{array}{c}\text { Ref. Dep. } \\
1 \text { type } \\
\text { delta est } \\
(5)\end{array}$ & $\begin{array}{c}\text { Ref. Dep. } \\
1 \text { type } \\
\text { beta est } \\
(6)\end{array}$ \\
\hline \multicolumn{7}{|l|}{ Parameters of Utility Function } \\
\hline Loss aversion $\lambda$ & & $\begin{array}{c}4.17 \\
(0.69)\end{array}$ & & $\begin{array}{c}4.31 \\
(0.32)\end{array}$ & $\begin{array}{c}4.95 \\
(0.59)\end{array}$ & $\begin{array}{c}4.69 \\
(0.62)\end{array}$ \\
\hline $\begin{array}{l}\text { Adjustment speed of reference point } \mathrm{N} \\
\text { in days }\end{array}$ & & $\begin{array}{l}204.17 \\
(17.94)\end{array}$ & & $\begin{array}{l}172.80 \\
(11.64)\end{array}$ & $\begin{array}{l}184.22 \\
(10.98)\end{array}$ & $\begin{array}{l}167.52 \\
(11.15)\end{array}$ \\
\hline Discount factor ( 15 days) $\delta$ & $\begin{array}{c}0.93 \\
(0.01)\end{array}$ & $\begin{array}{c}0.89 \\
(0.02)\end{array}$ & 0.995 & 0.995 & $\begin{array}{l}0.891 \\
(0.02)\end{array}$ & 0.995 \\
\hline Discount factor $\beta$ & 1 & 1 & $\begin{array}{c}0.92 \\
(0.01)\end{array}$ & $\begin{array}{c}0.58 \\
(0.03)\end{array}$ & 1 & $\begin{array}{c}0.58 \\
(0.19)\end{array}$ \\
\hline \multicolumn{7}{|l|}{ Parameters of Search Cost Function } \\
\hline Curvature of search cost $\gamma$ & $\begin{array}{c}0.4 \\
(0.046)\end{array}$ & $\begin{array}{c}0.7 \\
(0.2)\end{array}$ & $\begin{array}{c}0.07 \\
(0.01)\end{array}$ & $\begin{array}{c}0.4 \\
(0.0)\end{array}$ & $\begin{array}{c}0.8 \\
(0.2)\end{array}$ & $\begin{array}{c}0.4 \\
(0.2)\end{array}$ \\
\hline Search cost for high cost type $k_{\text {high }}$ & $\begin{array}{c}168.1 \\
(98.595)\end{array}$ & $\begin{array}{c}281.4 \\
(122.2)\end{array}$ & $\begin{array}{c}441.8 \\
(.)\end{array}$ & $\begin{array}{l}104.7 \\
(14.2)\end{array}$ & $\begin{array}{c}355.7 \\
(154.9)\end{array}$ & $\begin{array}{l}108.5 \\
(18.3)\end{array}$ \\
\hline Search cost for medium cost type $k_{m e d}$ & $\begin{array}{c}49.7 \\
(1.894)\end{array}$ & & $\begin{array}{l}98.0 \\
(9.7)\end{array}$ & & & \\
\hline Search cost for low cost type $k_{\text {low }}$ & $\begin{array}{l}12.9 \\
(1.239)\end{array}$ & $\begin{array}{l}13.9 \\
(7.2)\end{array}$ & $\begin{array}{l}13.3 \\
(1.9)\end{array}$ & $\begin{array}{c}3.1 \\
(1.0)\end{array}$ & & \\
\hline Share of high cost UI claimant & $\begin{array}{c}0.2 \\
(0.074)\end{array}$ & $\begin{array}{c}0.99 \\
(0.01)\end{array}$ & $\begin{array}{c}0.2 \\
(0.02)\end{array}$ & $\begin{array}{c}0.99 \\
(0.01)\end{array}$ & & \\
\hline $\begin{array}{l}\text { Share of medium cost UI claimant } \\
\text { Model Fit }\end{array}$ & $\begin{array}{c}0.6 \\
(0.059)\end{array}$ & & $\begin{array}{c}0.7 \\
(0.01)\end{array}$ & & & \\
\hline $\begin{array}{l}\text { Number of moments used } \\
\text { Number of estimated parameters } \\
\text { Goodness of Fit }\end{array}$ & $\begin{array}{c}70 \\
7 \\
227.5\end{array}$ & $\begin{array}{c}70 \\
7 \\
182.4\end{array}$ & $\begin{array}{c}70 \\
7 \\
229.0\end{array}$ & $\begin{array}{c}70 \\
7 \\
175.9\end{array}$ & $\begin{array}{c}70 \\
5 \\
194.0\end{array}$ & $\begin{array}{c}70 \\
5 \\
183.5\end{array}$ \\
\hline
\end{tabular}

Notes:

The table shows parameter estimates for the standard and the reference-dependent search model. Estimation is based on minimum distance estimation, using the hazard rates in the pre- and post-reform periods as the moments. Standard errors for estimated parameters in parentheses.

(.) indicates that the parameter is not well identified, i.e. the Hessian cannot be inverted close to the reported values and therefore we do not provide standard errors. The other standard errors are calculated by inverting the Hessian matrix after dropping the parameter from the matrix. 


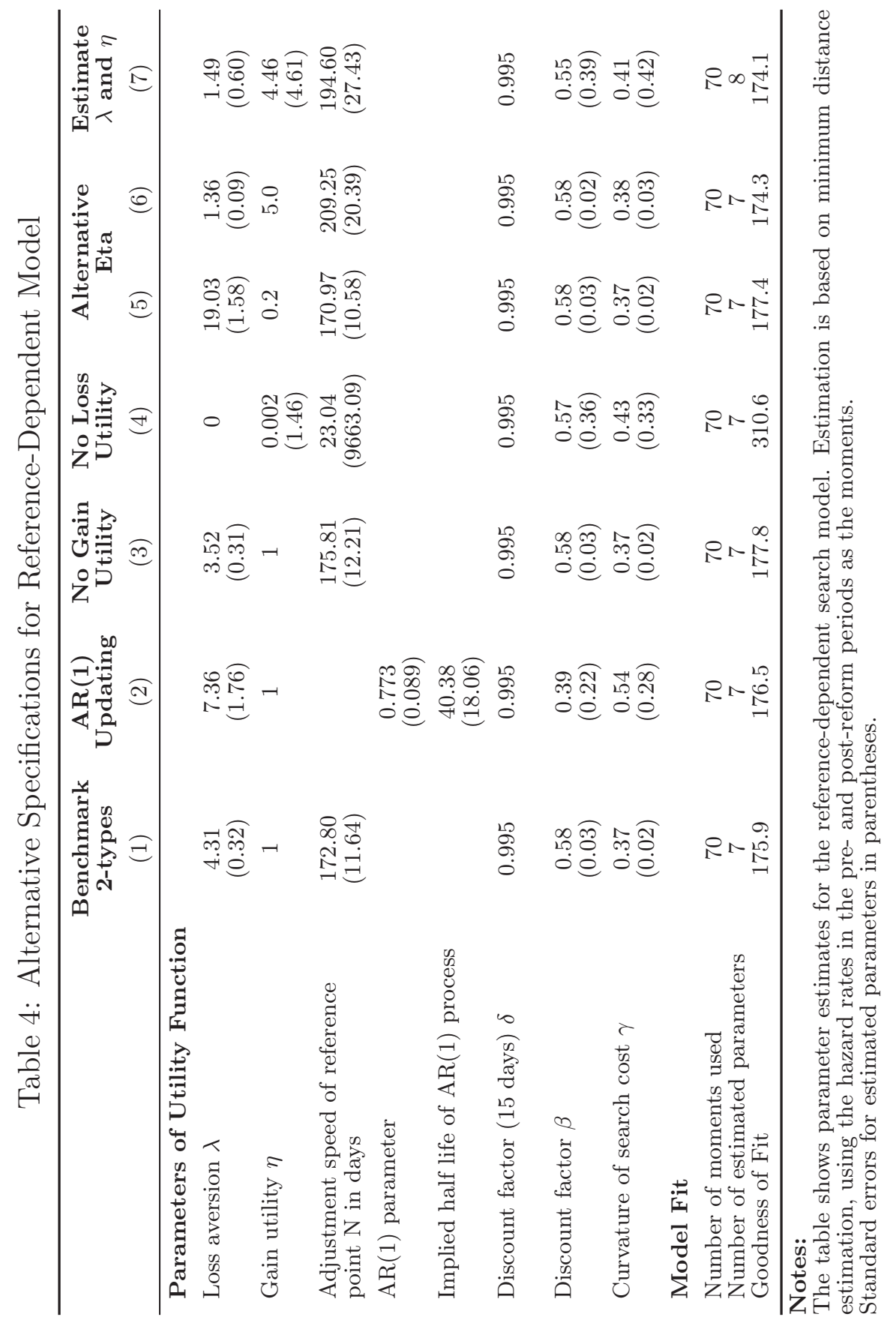


Table 5: Structural Estimation of the Habit Formation Model

\begin{tabular}{|c|c|c|c|c|}
\hline & \multicolumn{3}{|c|}{$\begin{array}{c}\text { Habit Model a la } \\
\text { Constantinides }(1990) \\
\log \left(c_{t}-z r_{t}\right)\end{array}$} & \multirow{3}{*}{$\begin{array}{c}\text { Habit Model a la } \\
\text { Abel }(1990) \\
\log \left(c_{t}\right)-z \log \left(r_{t}\right) \\
\text { 2-type } \\
(4)\end{array}$} \\
\hline & 2-type & $\begin{array}{l}\text { 2-type } \\
\operatorname{AR}(1)\end{array}$ & 3 -type & \\
\hline & (1) & $(2)$ & $(3)$ & \\
\hline \multicolumn{5}{|l|}{ Parameters of Utility Function } \\
\hline Habit formation parameter $z$ & $\begin{array}{c}0.45 \\
(.)\end{array}$ & $\begin{array}{c}0.26 \\
(.)\end{array}$ & $\begin{array}{c}0.26 \\
(0.056)\end{array}$ & $\begin{array}{c}0.92 \\
(0.01)\end{array}$ \\
\hline $\begin{array}{l}\text { Adjustment speed of reference point } \mathrm{N} \\
\text { in days }\end{array}$ & $\begin{array}{l}224.1 \\
(14.5)\end{array}$ & & $\begin{array}{l}240.4 \\
(48.1)\end{array}$ & $\begin{array}{l}225.6 \\
(18.4)\end{array}$ \\
\hline $\mathrm{AR}(1)$ parameter & & $\begin{array}{c}0.87 \\
(0.07)\end{array}$ & & \\
\hline Implied half life of $\mathrm{AR}(1)$ process & & $\begin{array}{l}74.03 \\
(42.81)\end{array}$ & & \\
\hline Discount factor (15 days) $\delta$ & $\begin{array}{c}0.925 \\
(0.002)\end{array}$ & $\begin{array}{l}0.903 \\
(0.007)\end{array}$ & $\begin{array}{c}0.916 \\
(0.005)\end{array}$ & $\begin{array}{l}0.941 \\
(0.002)\end{array}$ \\
\hline \multicolumn{5}{|c|}{ Parameters of Search Cost Function } \\
\hline Curvature of search cost $\gamma$ & $\begin{array}{c}0.46 \\
(0.03)\end{array}$ & $\begin{array}{c}0.60 \\
(0.01)\end{array}$ & $\begin{array}{c}0.49 \\
(0.04)\end{array}$ & $\begin{array}{c}0.35 \\
(0.01)\end{array}$ \\
\hline Search cost for high cost type $k_{h i g h}$ & $\begin{array}{l}144.7 \\
(7.2)\end{array}$ & $\begin{array}{l}163.7 \\
(10.2)\end{array}$ & $\begin{array}{c}260.4 \\
(154.0)\end{array}$ & $\begin{array}{l}391.0 \\
(5.6)\end{array}$ \\
\hline Search cost for medium cost type $k_{m e d}$ & & & $\begin{array}{l}74.5 \\
(2.4)\end{array}$ & \\
\hline Search cost for low cost type $k_{\text {low }}$ & $\begin{array}{l}64.9 \\
(2.7)\end{array}$ & $\begin{array}{l}30.9 \\
(2.1)\end{array}$ & $\begin{array}{l}13.2 \\
(3.0)\end{array}$ & $\begin{array}{l}106.7 \\
(9.5)\end{array}$ \\
\hline Share of high cost UI claimant & $\begin{array}{c}0.48 \\
(0.080)\end{array}$ & $\begin{array}{c}0.78 \\
(0.02)\end{array}$ & $\begin{array}{c}0.21 \\
(0.118)\end{array}$ & $\begin{array}{c}0.87 \\
(0.01)\end{array}$ \\
\hline Share of low cost UI claimant & & & $\begin{array}{c}0.73 \\
(0.10)\end{array}$ & \\
\hline \multicolumn{5}{|l|}{ Model Fit } \\
\hline $\begin{array}{l}\text { Number of moments used } \\
\text { Number of estimated parameters } \\
\text { Goodness of Fit }\end{array}$ & $\begin{array}{c}70 \\
7 \\
235.7\end{array}$ & $\begin{array}{c}70 \\
7 \\
251.6\end{array}$ & $\begin{array}{c}70 \\
9 \\
220.3\end{array}$ & $\begin{array}{c}70 \\
7 \\
202.8\end{array}$ \\
\hline
\end{tabular}

\section{Notes:}

The table shows parameter estimates for the habit-formation model. Estimation is based on minimum distance estimation, using the hazard rates in the pre- and post-reform periods as the moments.

Standard errors for estimated parameters in parentheses. The parameter estimates for $z$ in columns (1) and (2) are not well identified (i.e. the Hessian cannot be inverted for $z$ close to the reported values) and therefore we do not provide standard errors for them. The other standard errors are calculated by inverting the Hessian matrix after dropping $z$ from the matrix. 


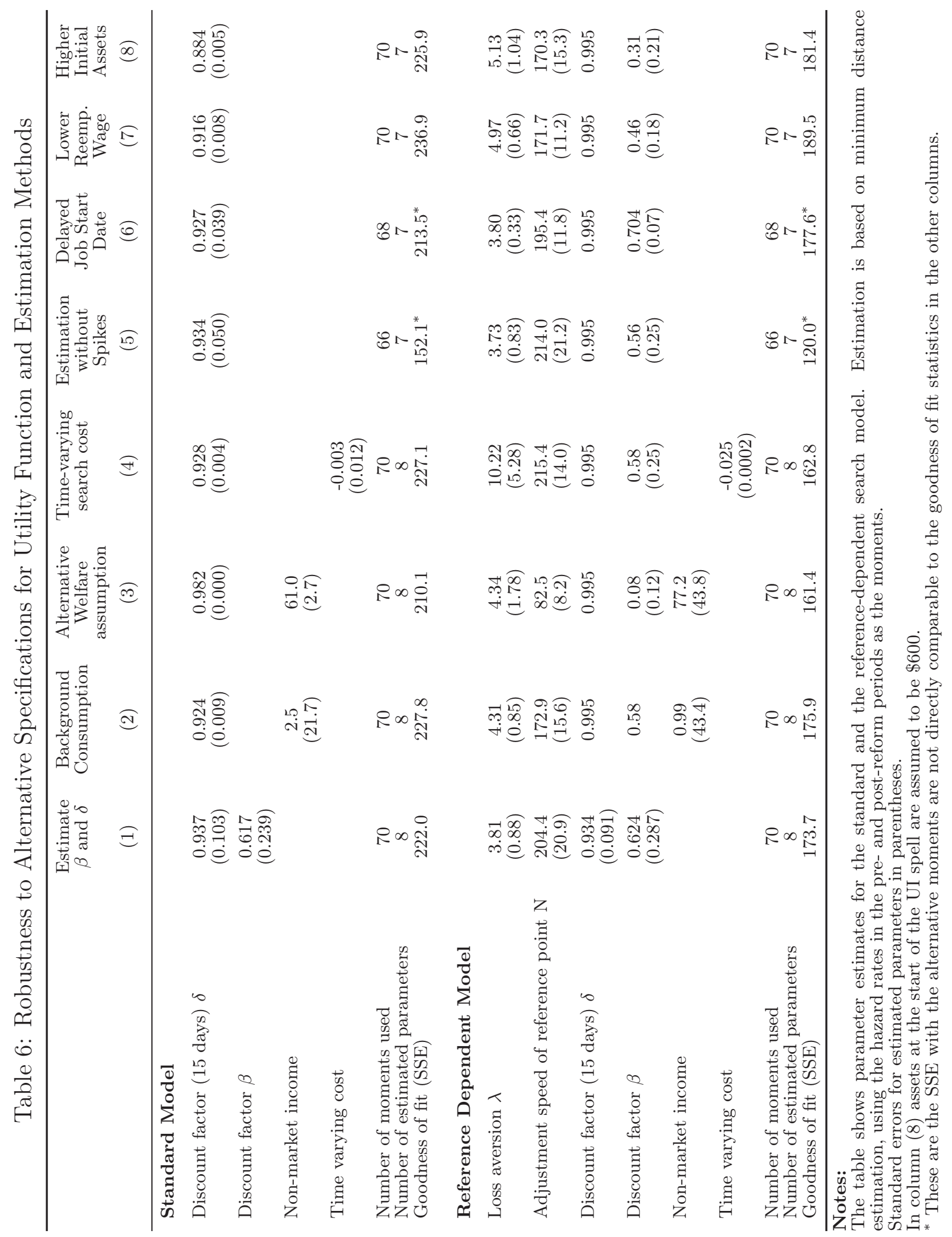




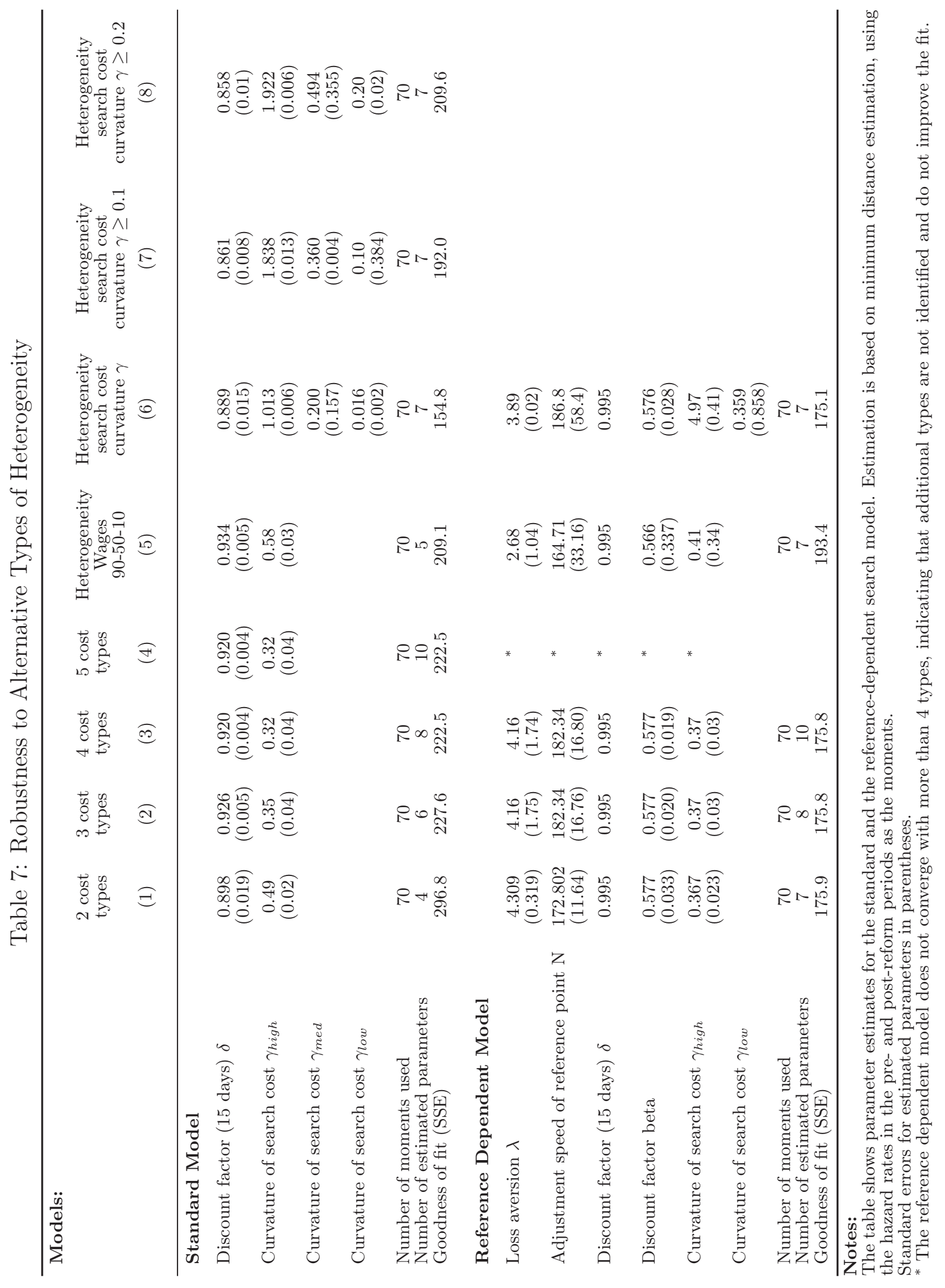


Figure 1: Model Simulations of the Standard and the Reference-Dependent model

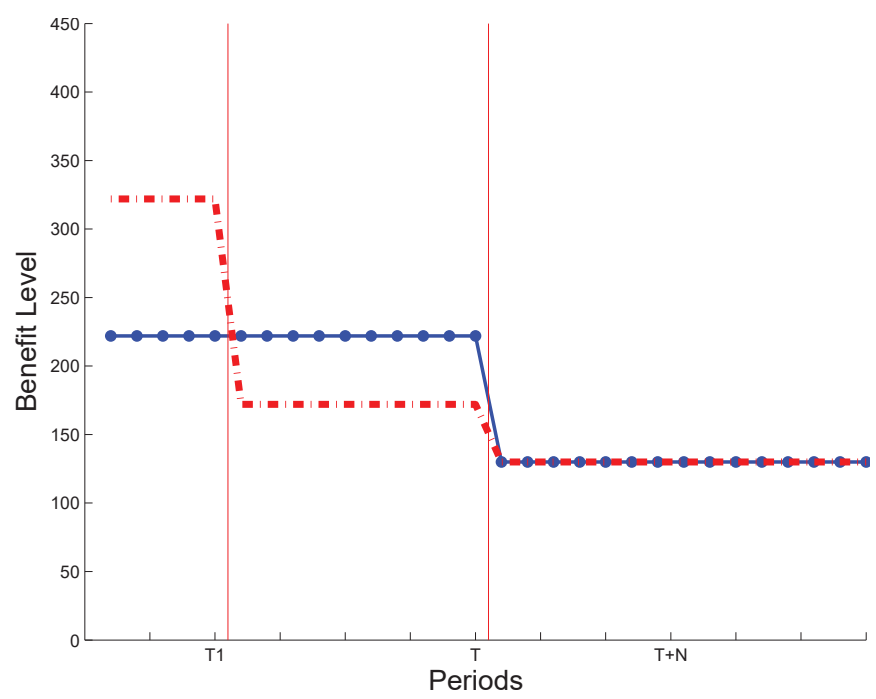

(a) Benefits

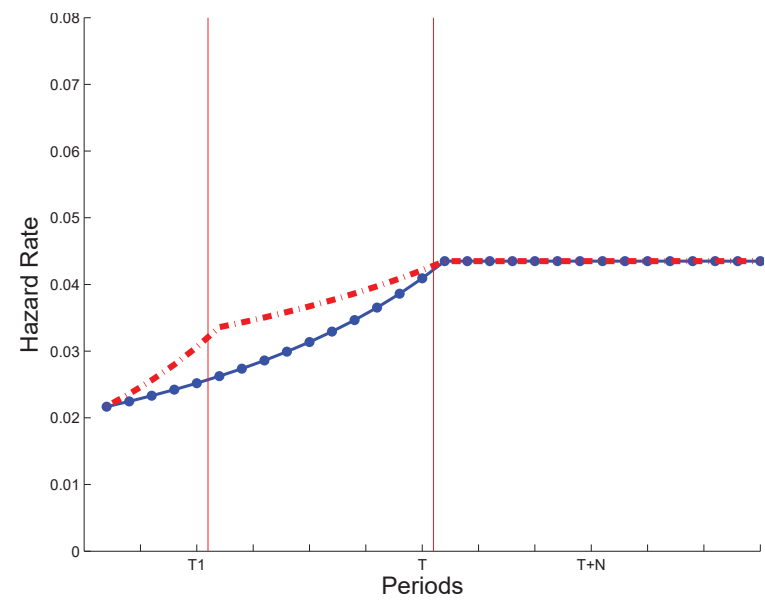

(b) Standard Model

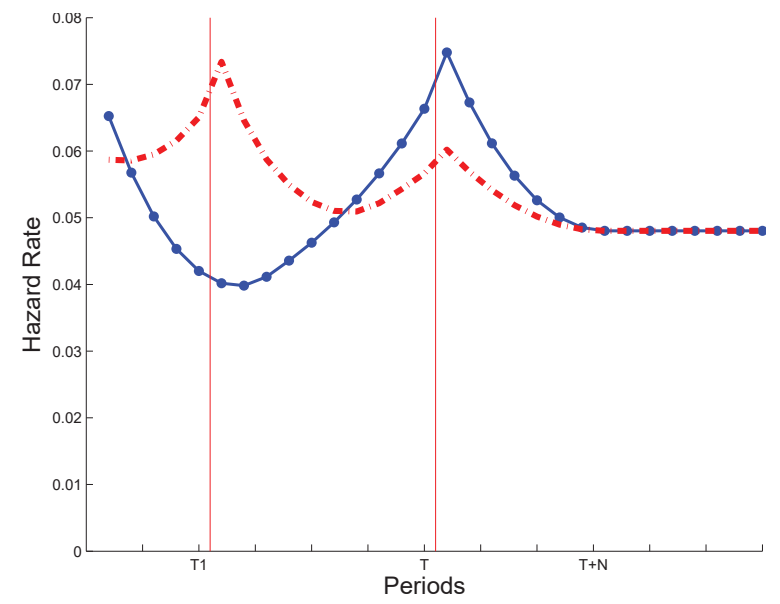

(c) Reference-Dependent Model

Notes: Panel (a) shows two benefit regimes, both of them having a step-down benefit system. After the first step benefits are higher in the regime represented by the circled blue line than in the regime represented by the red dashed line. After the second step benefits drop to the same level. Panel (b) shows the hazard rates predicted by the standard model (with $k=130, \gamma=0.6, w=555, \delta=0.99$ ) while Panel (c) the prediction of the reference-dependent model (with $k=160, \gamma=0.6, w=555$, $\delta=0.99, \lambda=2, N=10)$. 
Figure 2: Benefit Path Change, Main Sample

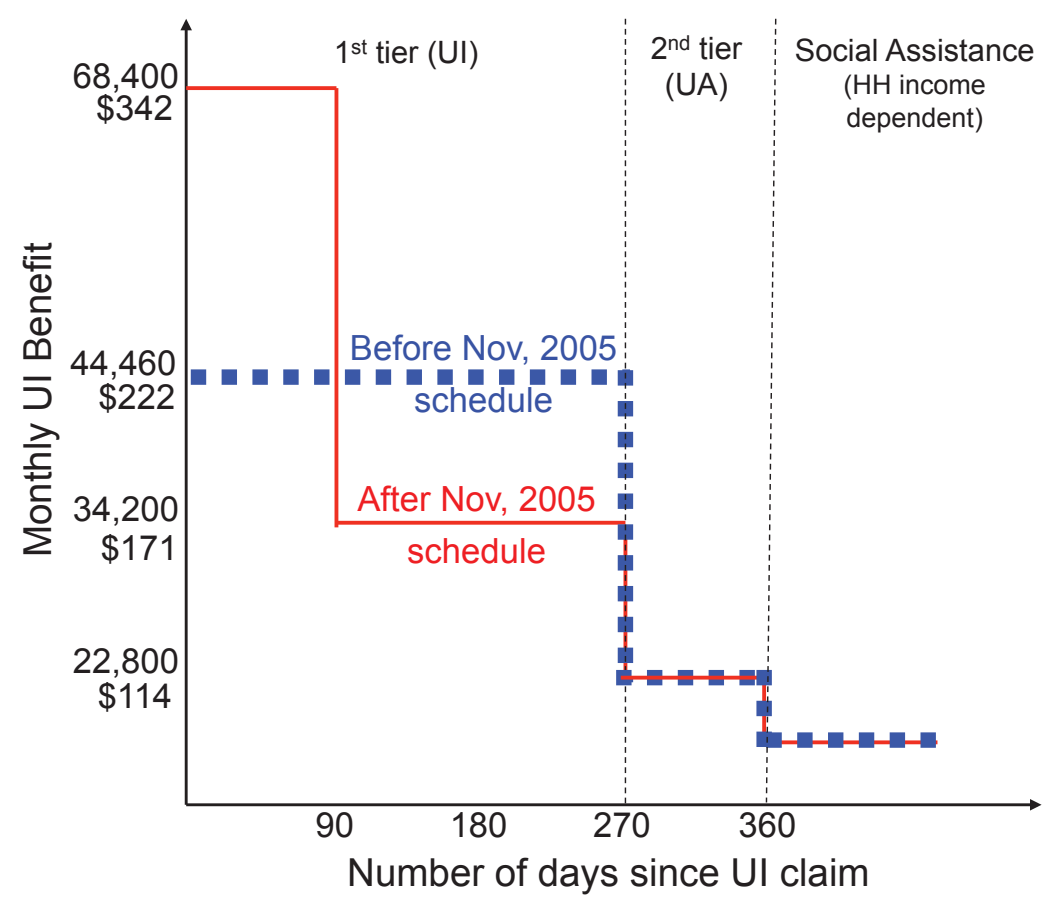

Notes: The figure shows the benefit schedule if UI is claimed on October 31, 2005 (old benefit schedule, dashed blue line) and benefit schedule if UI is claimed on November 1st, 2005 (new benefit schedule, solid red line) for individuals who had 270 potential duration in the first-tier, were less than 50 years old and earned more than 114,000 HUF (\$570) prior to entering UI. A hypothetical benefit level is shown under social assistance. Benefits levels in social assistance depended on family income, household size and wealth, which we do not observe these variables in our data. 
Figure 3: Before-After Comparison Groups for Quasi-experiment

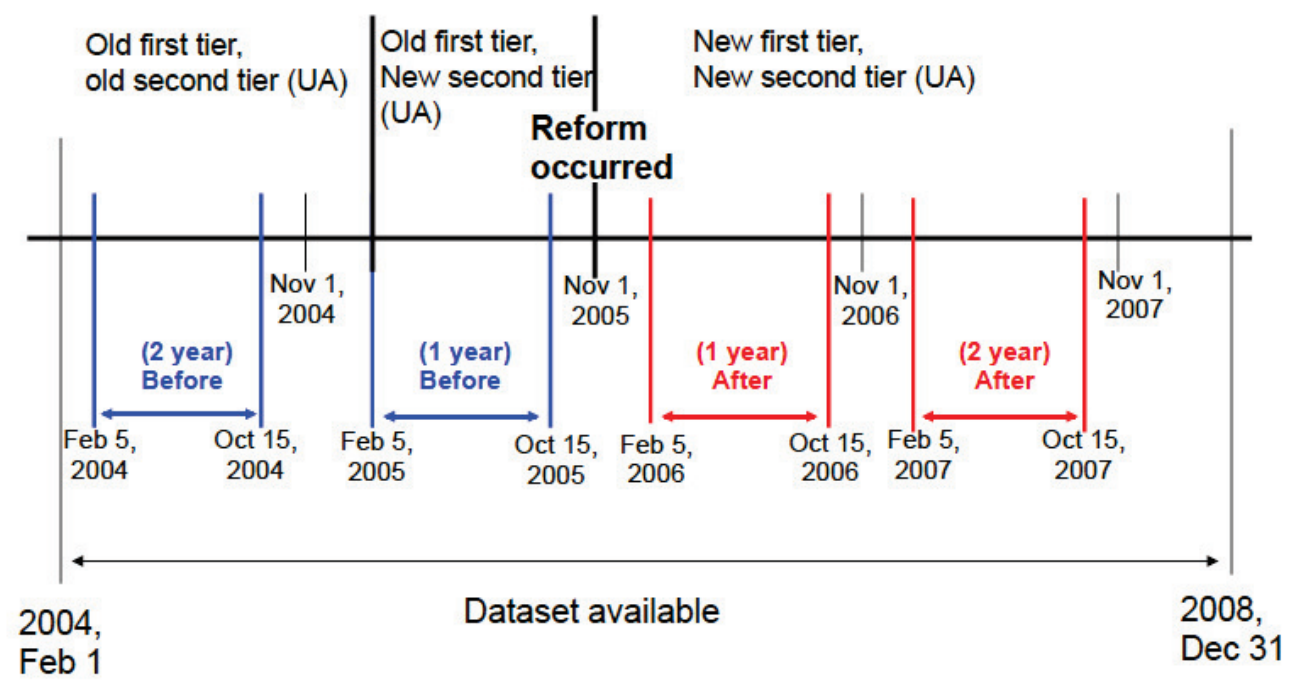

Notes: The figure shows the time frame for which we have access to administrative data on unemployment insurance records, the time of the reform and how we define the before and after periods that we use for our before-after comparison. The timing of the reform was the following: those who claimed UI benefit before February 5th, 2005 faced the old first tier schedule and old second tier schedule; those who claimed benefit between February 5th, 2005 and October 31th, 2005 faced the old benefit schedule in the first tier and the new benefit schedule in the second tier; those who claimed benefit after November 1st, 2005 faced the new benefit schedule in the first tier and the new benefit schedule in the second tier. To avoid complications caused by changes in the second tier, in our main specifications we focus on the (1 year) before sample, i.e. those who claimed UI between February 5th, 2005 and October 15th, 2005, and (1 year) after sample, i.e. those who claimed UI between February 5th, 2006 and October 15th, 2006. We use the (2 year) before sample and the (2 year) after sample to show that the changes in the hazard rates are in line with the timing of the reform. The first tier changes before and after October 31th, 2005 are presented in Figure 2. The changes in the second tier in February 5th, 2005 were the following: potential duration shortened to 180 days above age 50 and to 90 days below that. Before, it was 270 days above age 45 and 180 days below that. The benefit level was raised slightly from 21,000 HUF (\$101) to 22,800 HUF (\$114). 
Figure 4: Empirical Hazard and Survival Rates under the Old and the New Benefit Schedule

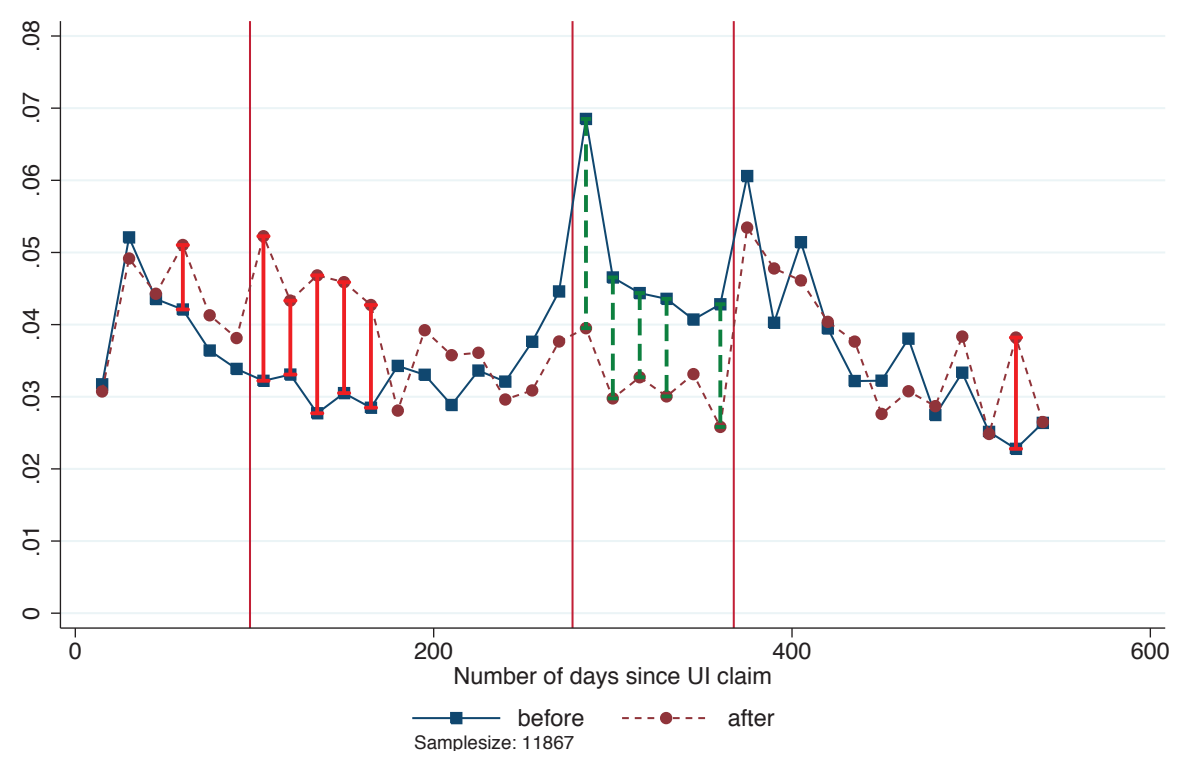

(a) Empirical hazard rates

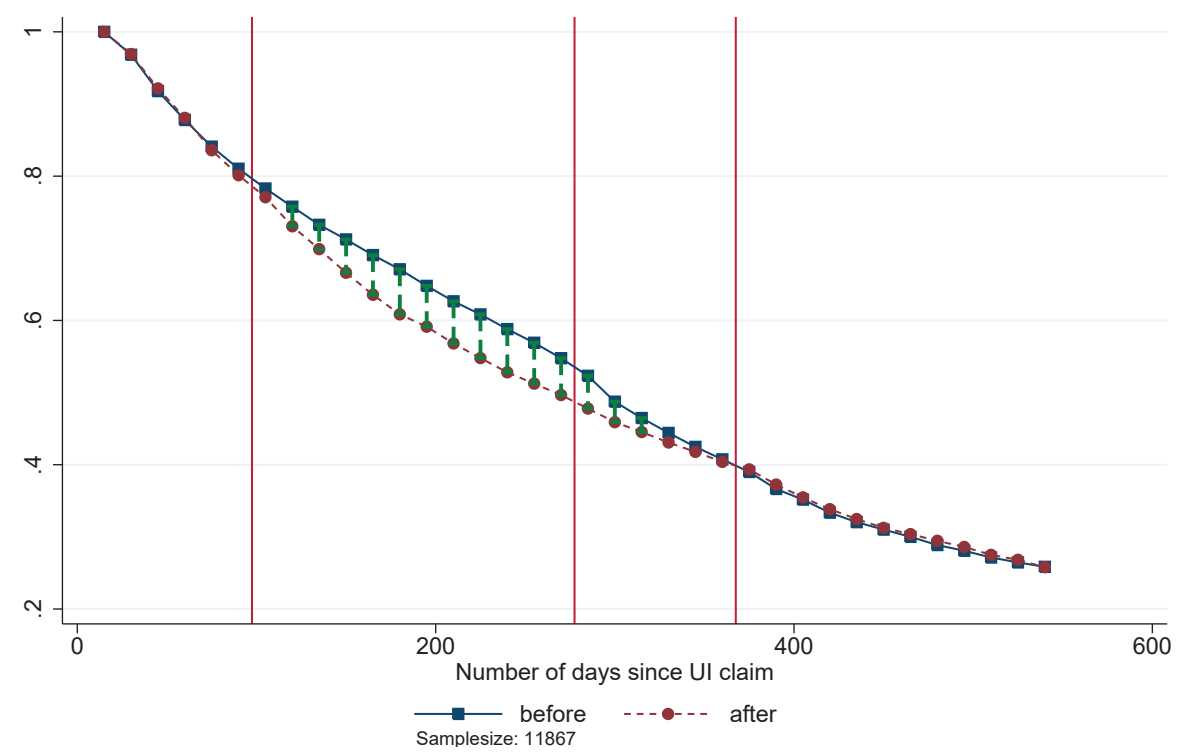

(b) Empirical survival rates

Notes: The figure shows point wise estimates for the empirical hazards, Panel (a), and for the empirical survival rates, Panel (b), before and after the reform. The differences between the two periods are estimated point-wise at each point of support and differences which are statistically significant $(p \leq 0.05)$ are indicated with a vertical bar (green dashed if pre-period hazard is above post period hazard, red solid otherwise). The three major (red) vertical lines indicate periods when benefits change in the new system. The sample consists of unemployed workers claiming UI between February 5th, 2005 and October 15th, 2005 (before sample) and February 5th, 2006 and October 15th, 2006 (after sample), who had 270 days of potential duration, were 25-49 years old, and were above the 70th percentile of the earnings base distribution of the UI claimants in the given year. 
Figure 5: Robustness Checks for change of Hazard rates before and after the reform

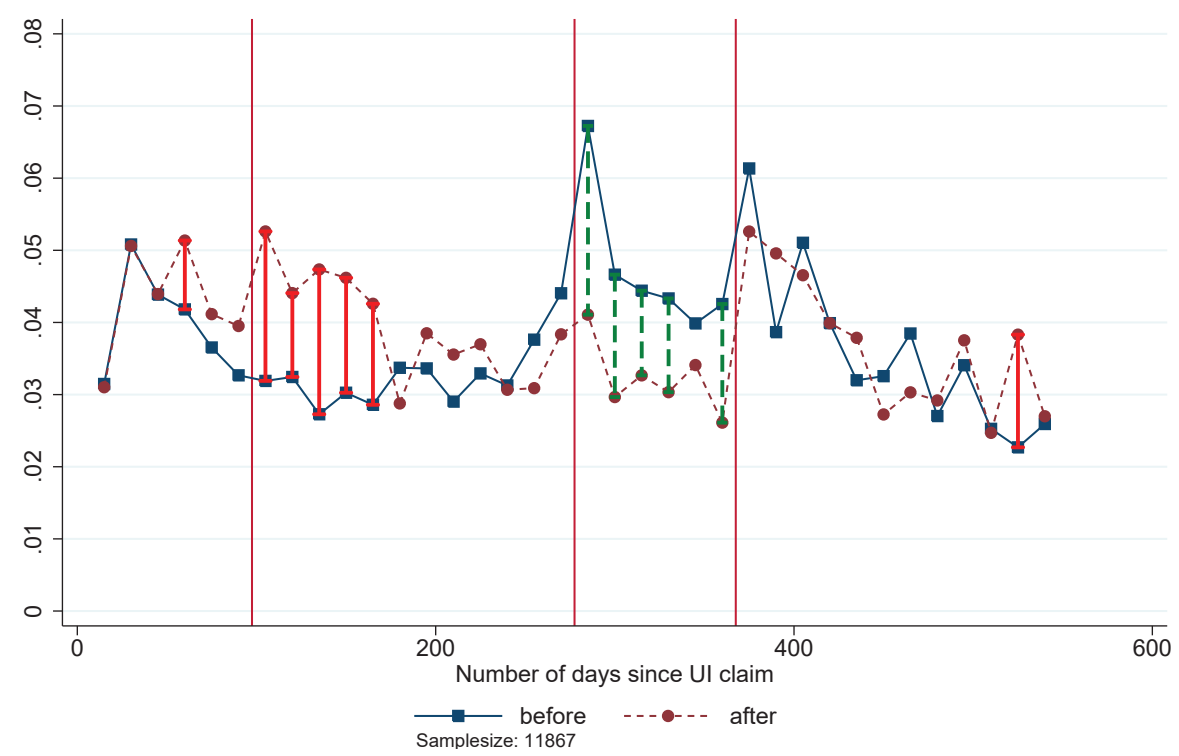

(a) Controlling for observable differences

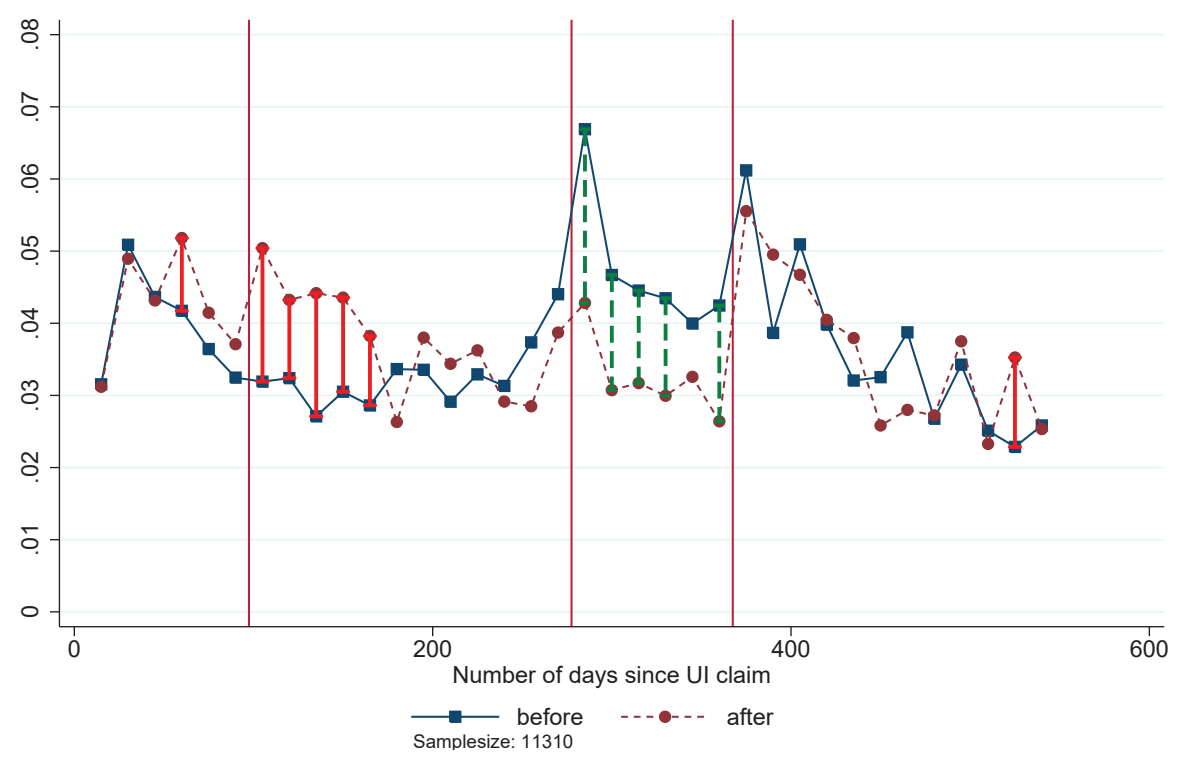

(b) Restricted sample

Notes: The figure shows point wise estimates for the empirical hazards before and after the reform. The differences between the two periods are estimated point-wise at each point of support and differences which are statistically significant are indicated with a vertical bar (green dashed if preperiod hazard is above post period hazard, red solid otherwise). The three major (red) vertical lines indicate periods when benefits change in the new system. In Panel (a) we controlled for sex, age, age square, waiting period (the number of days between job lost and UI claimed), the county of residence, day of the month UI claimed, education, occupation (1 digit) of the last job, and log earnings in 2002 and 2003. In Panel (b) in addition to controlling for these control variables we dropped reemployment bonus claimants and those participating in training programs (after the reform), see text for the details. The sample is otherwise the same as in Figure 4. 
Figure 6: Interrupted Time Series Analysis of Exit Hazards

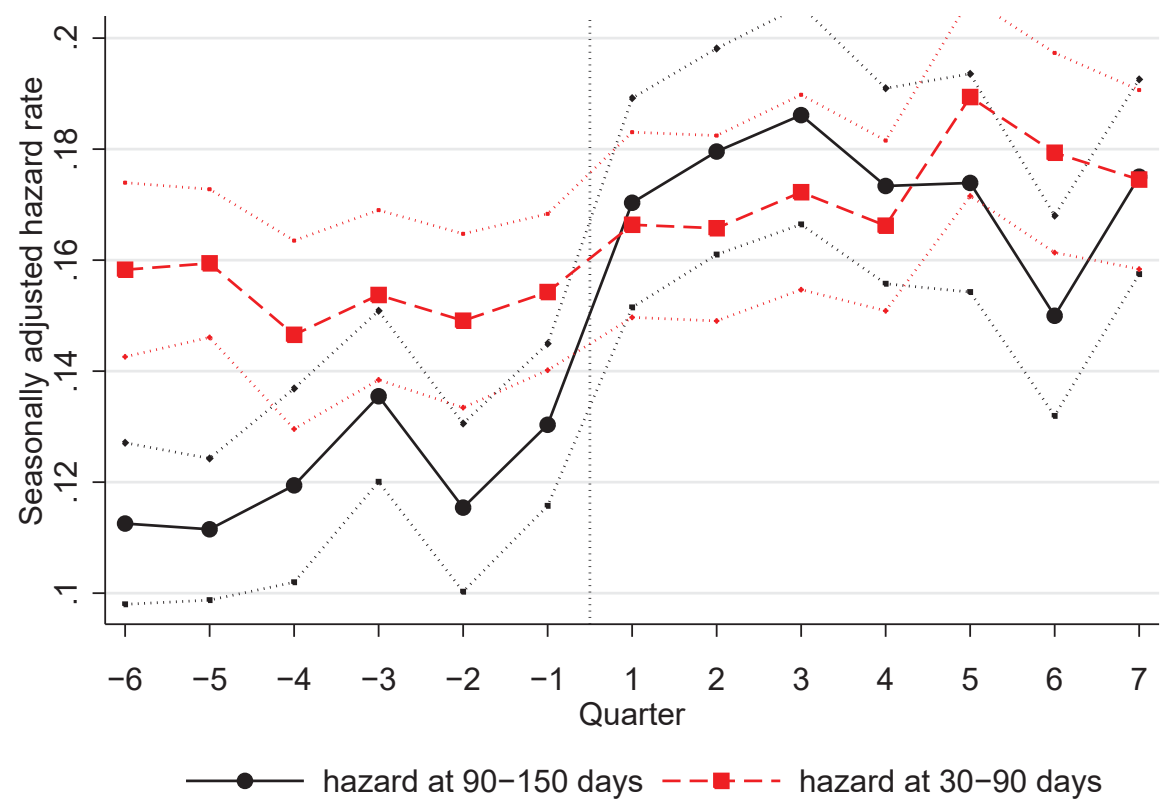

(a) The evolution of the hazard rates between 30 and 150 days

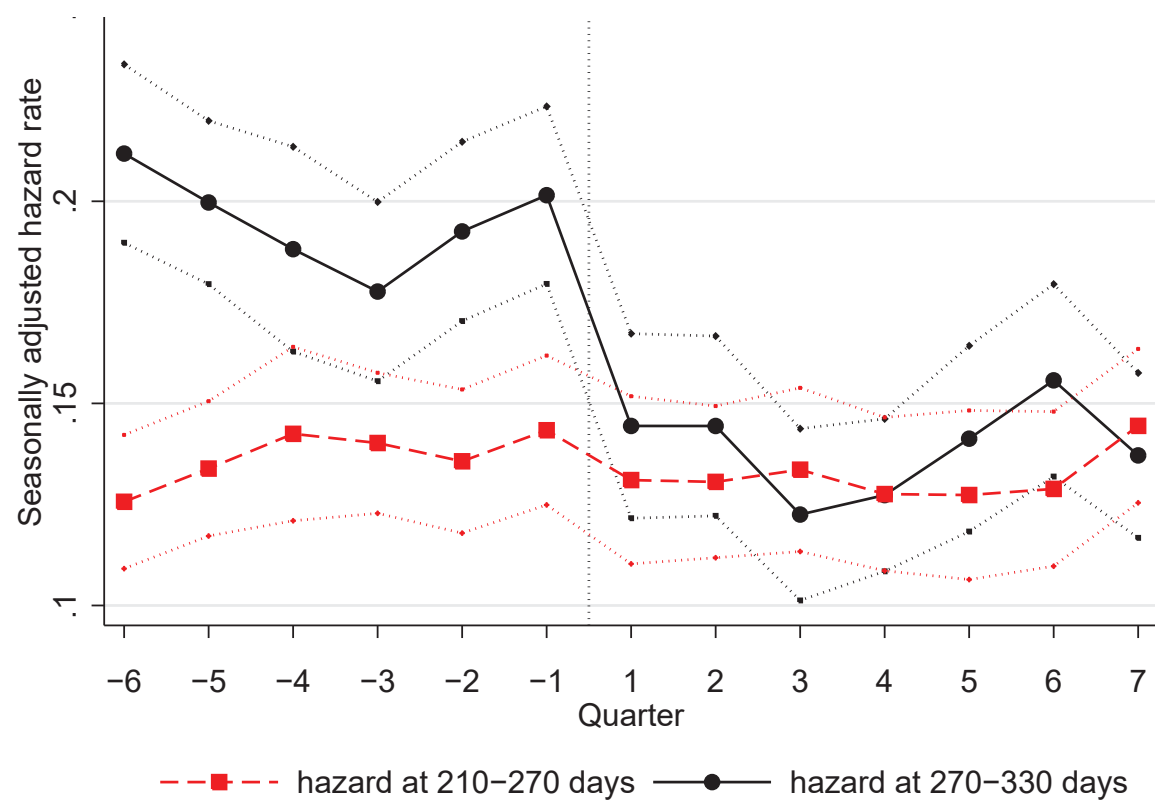

(b) The evolution of the hazard rates between 210 and 330 days

Notes: The figure shows the level of the most important hazard rates 6 quarters before and 7 quarters after the reform. Panel (a) shows the seasonally adjusted hazard rates between 30 and 150 days, while Panel (b) shows the seasonally adjusted hazard rates between 210 and 330 days. The monthly seasonal adjustment of hazard rates takes into consideration the level shift present in the data in November, 2005. The figures highlight that the shift in the hazard plots documented earlier corresponds to the precise timing of the reform. Other sample restrictions are the same as in Figure 4. 
Figure 7: Estimates of the Standard and Reference-dependent Model with Hand-toMouth Consumers

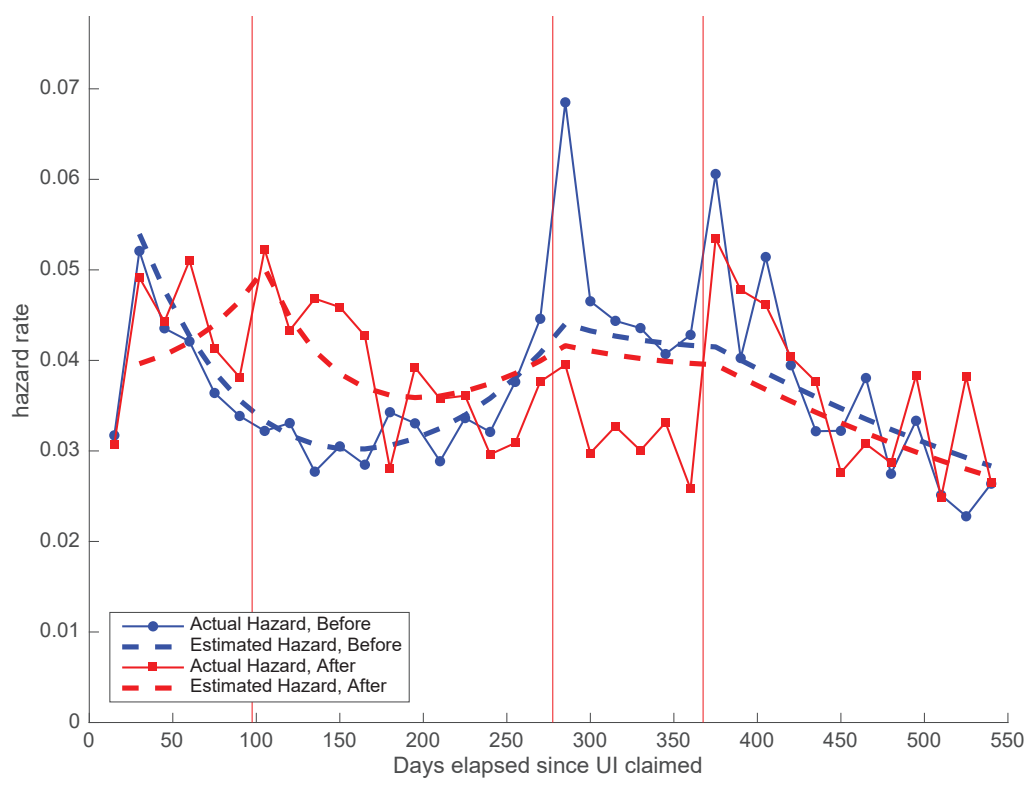

(a) Standard Model

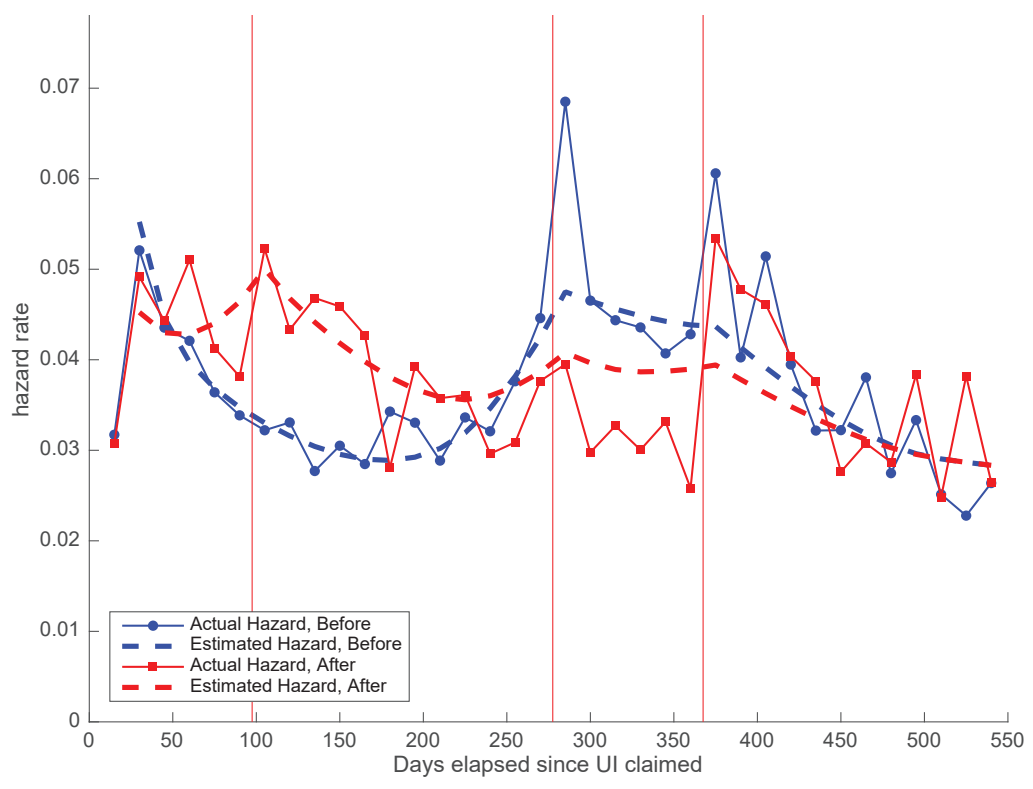

(b) Reference-dependent Model

Notes: The figure shows the empirical hazards and the predicted hazards of the standard and the reference-dependent model with hand-to-mouth consumers. Panel (a) corresponds to the standard model with 3 cost types, shown in Table 2 column (1), while Panel (b) corresponds to the referencedependent model with 2 cost types shown in Table 2 column (2). The three major (red) vertical lines indicate periods when benefits change in the new system. 
Figure 8: Benchmark Estimates of the Standard and Reference-Dependent Model (with Endogenous Savings)

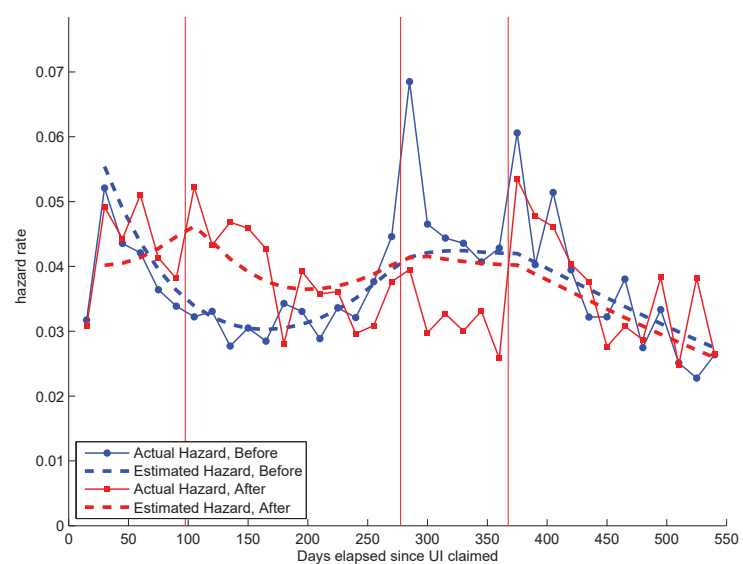

(a) Standard Model with estimated $\delta$

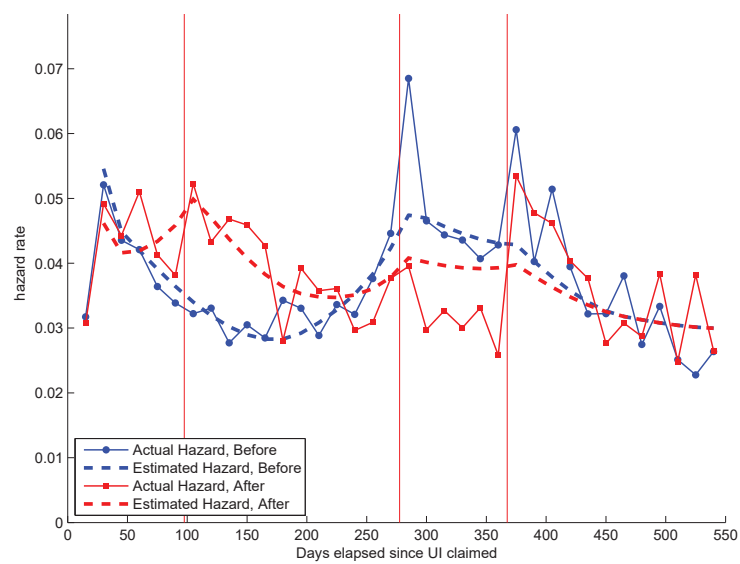

(c) Ref. Dep. Model, 2 cost types, estimated $\beta$

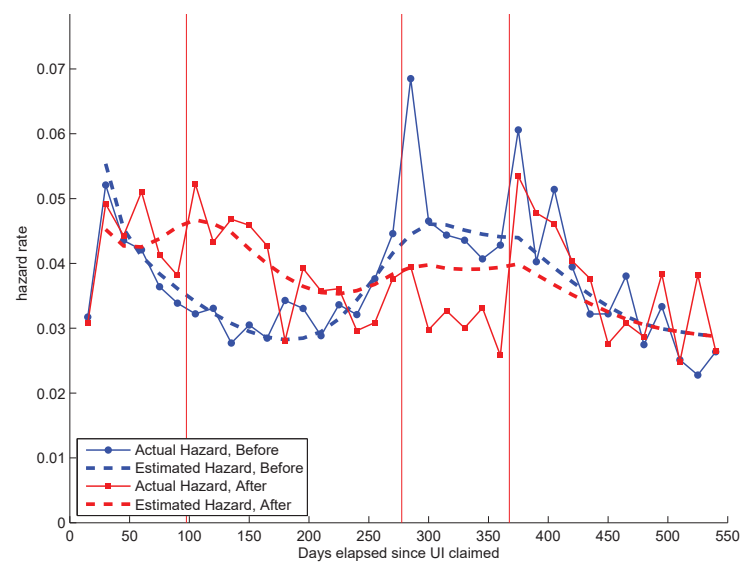

(b) Ref. Dep. Model, 2 cost types, estimated $\delta$

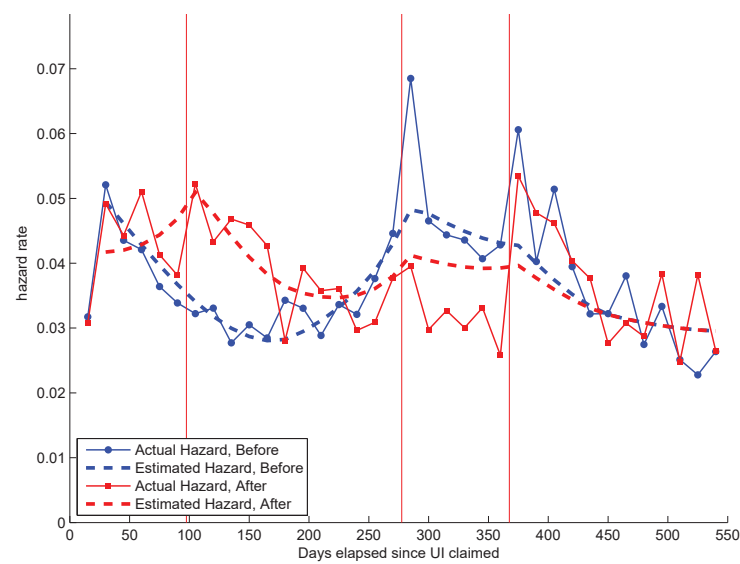

(d) Ref. Dep. Model, no heterog., estimated $\beta$

Notes: The figure shows the empirical hazards and the predicted hazards of the standard and the reference-dependent model with endogenous savings. Panel (a) corresponds to the standard model with 3 cost types and estimated $\delta$, shown in Table 3 Column (1). Panel (b) corresponds to the reference-dependent model with 2 cost types shown in Table 3 Column (2). Panel (c) shows the reference-dependent model with 2 types but present-bias ( $\beta \delta$-discounting) and estimated $\beta$ (Table 3 Column 4). Panel (d) shows the reference-dependent model with only 1 type and estimated $\beta$ (Table 3 Column 6). The three major (red) vertical lines indicate periods when benefits change in the new system. 
Figure 9: Alternative Estimates of the Reference-dependent Model

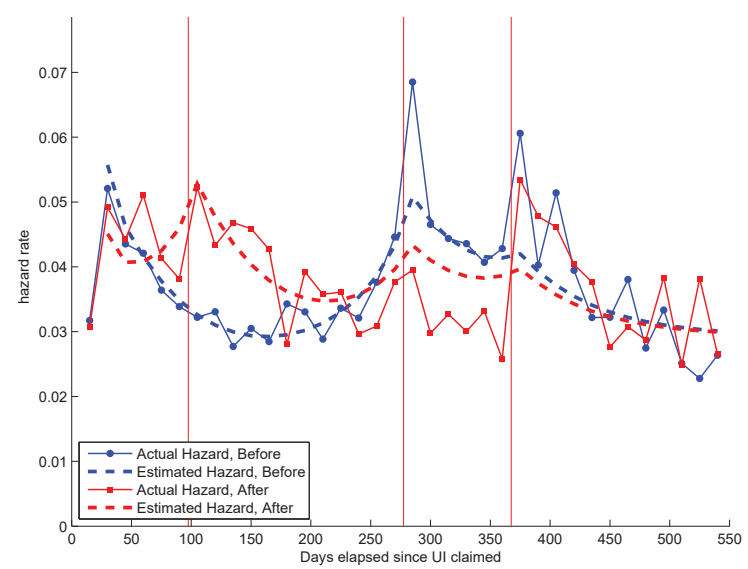

(a) Reference-Dependent Model, AR(1) update

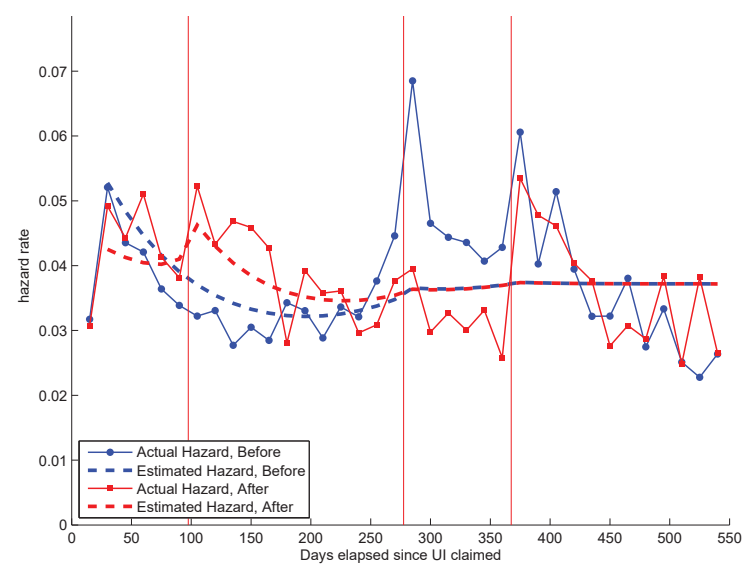

(c) Reference-Dependent Model, no loss utility

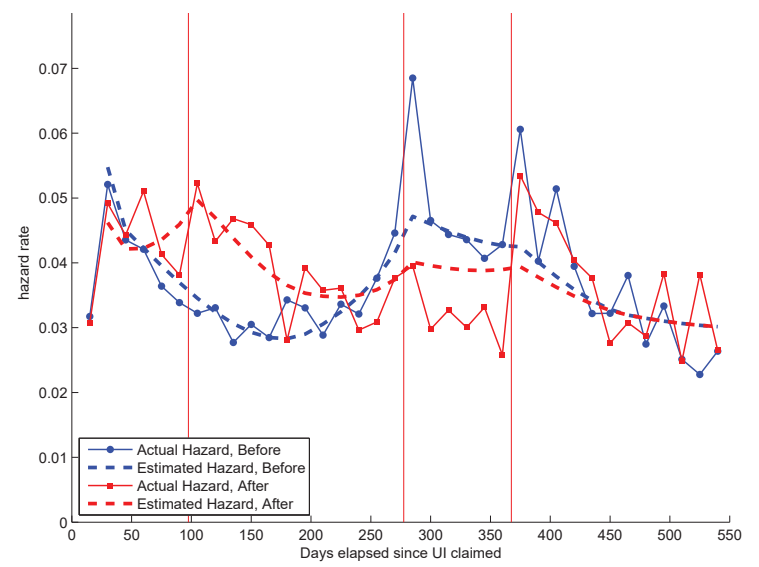

(b) Reference-Dependent Model, no gain

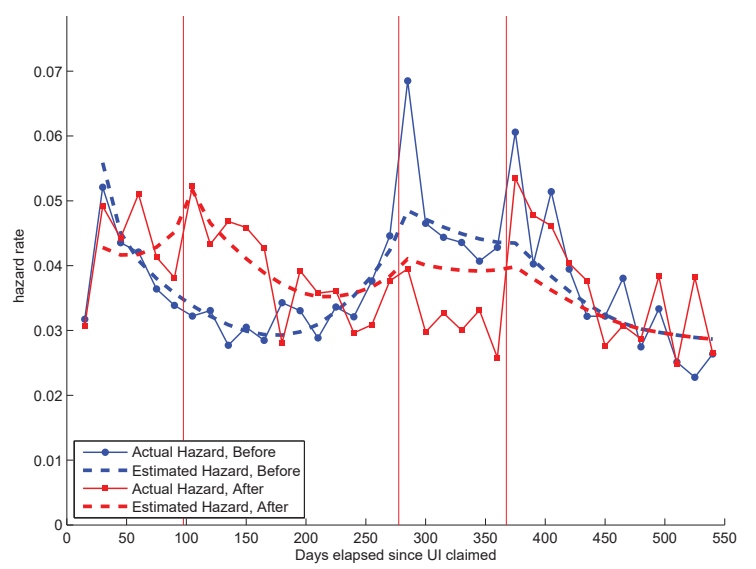

(d) Reference-Dependent Model, estimated $\eta$ and $\lambda$

Notes: The figure shows the empirical hazards and the predicted hazards of estimates of alternative versions of the reference-dependent model. Panel (a) shows the reference-dependent model where the reference point is updated using a AR(1) process (Table 4 column 2). Panel (b) shows the reference-dependent model without gain (only loss) utility (Table 4 column 3). Panel (c) without loss (only gain) utility (Table 4 column 4) and Panel (d) shows the reference-dependent model where both the gain $\eta$ and the loss part $\lambda \eta$ are estimated (Table 4 column 7 ). 
Figure 10: Habit Formation Model
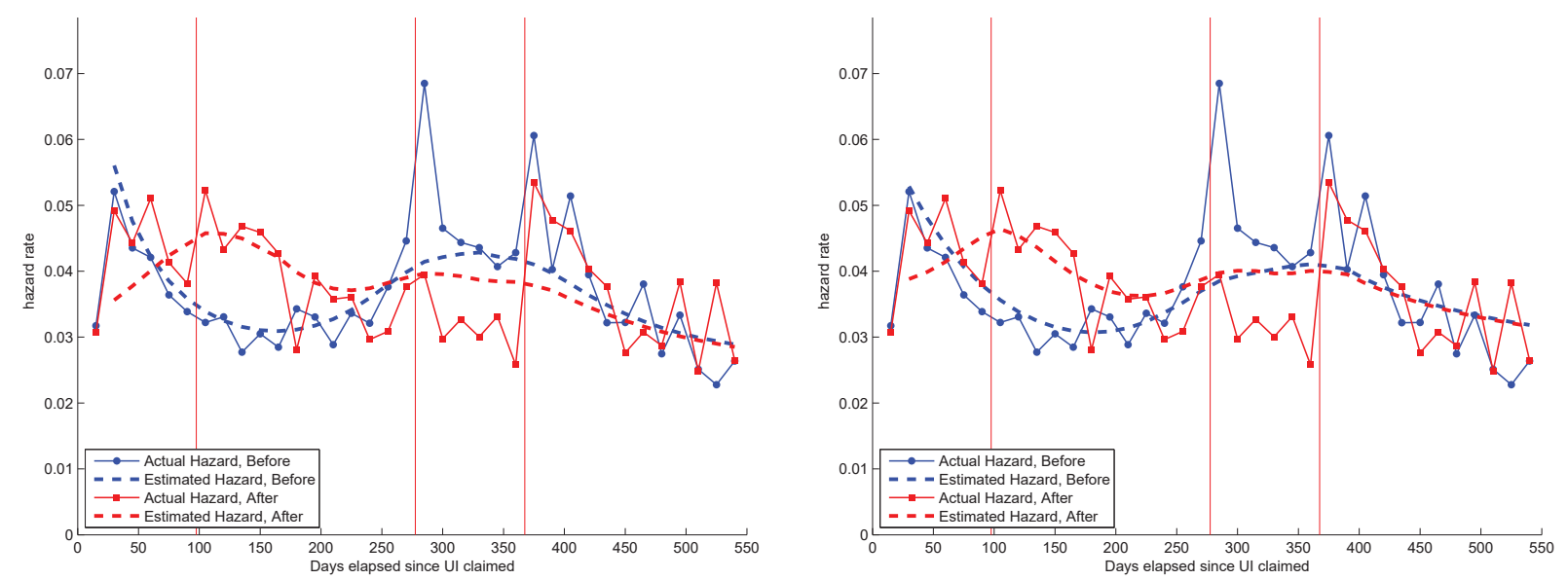

(a) Habit Model with 2 types (Constantinides 1990)

(b) Habit Model with 2 types and AR(1) updated ref. point

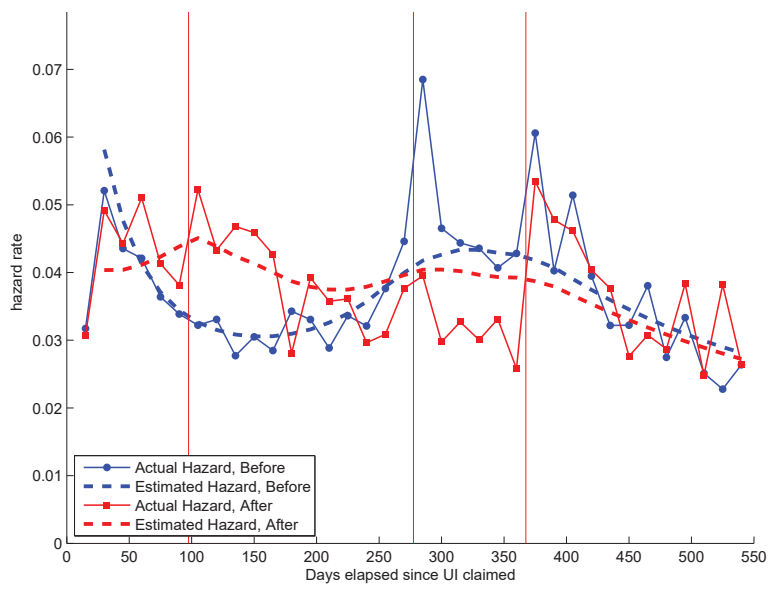

(c) Habit Model with 3 types

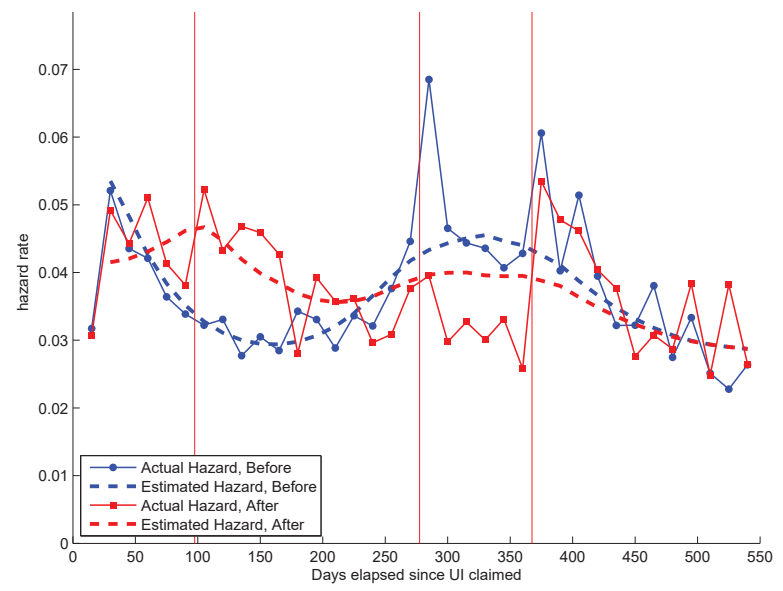

(d) Multiplicative Habit Formation (Abel 1990)

Notes: The figure shows the empirical hazards and the predicted hazards from estimating habit formation models (See Table 5). Panels (a) through (c) show the habit formation model of Constantinides (1990). The first panel uses the same reference point as our main specifications for the reference-dependent model, the second panel uses a reference point that is updated via an $\operatorname{AR}(1)$ process, the third panel allows for 3 types of heterogeneity and the last column uses the multiplicative functional form of the habit model from Abel (1990). 
Figure 11: Estimates of the Standard Model with Alternative Forms of Heterogeneity

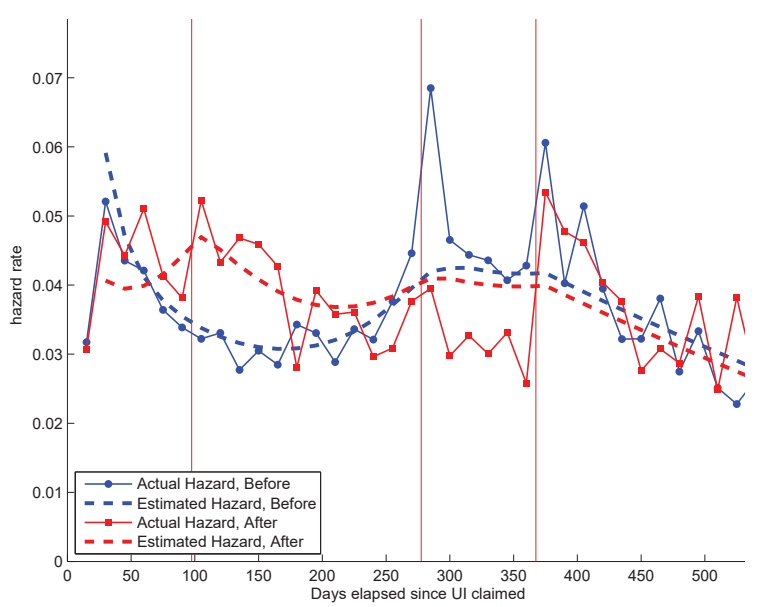

(a) 4 cost types

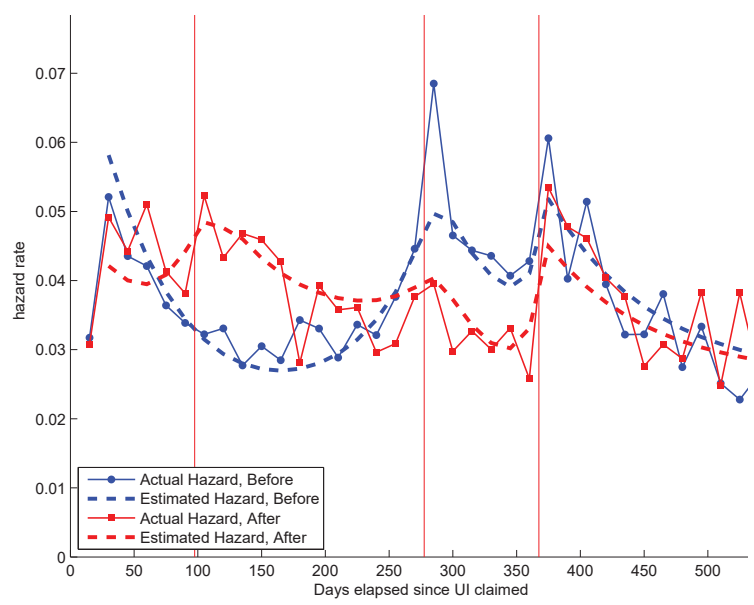

(c) Heterogeneity in Search Cost Curvature

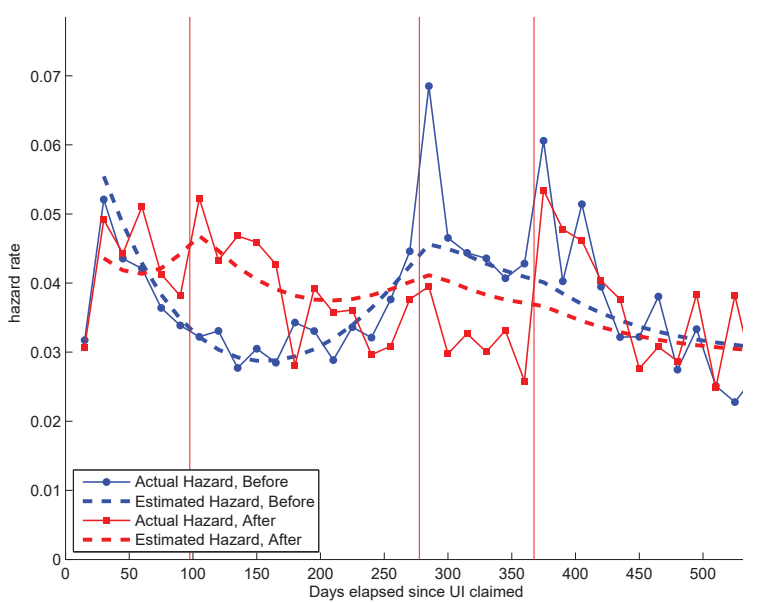

(b) Heterogeneity in Wages

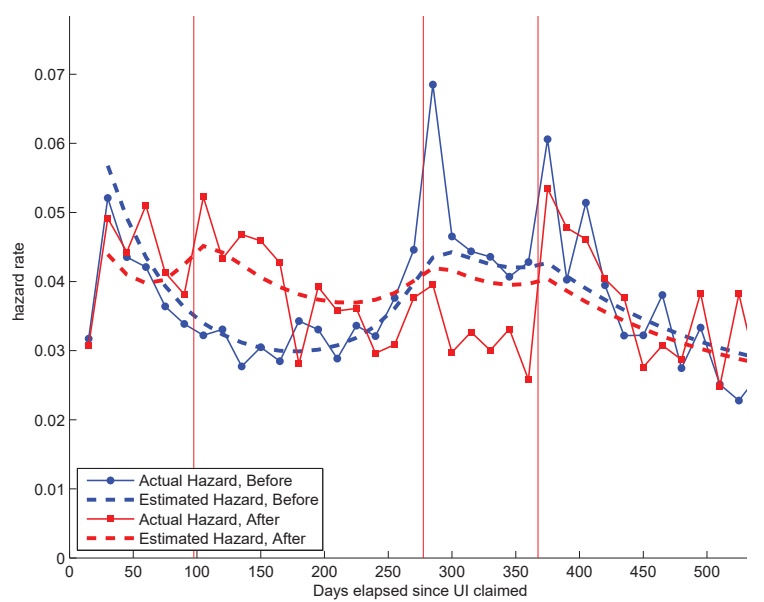

(d) Heterogeneity in Search Cost Curvature $(\gamma$ restricted to $\geq 0.2$ )

Notes: The figure shows the empirical hazards and the predicted hazards for estimations of the standard model under different specifications of heterogeneity (See Table 7). Panel (a) allows for 4 cost types. Panel (b) allows for three different types with different reemployment wages (calibrated to match the empirical distribution of reemployment wages). Panel (c) allows for three different types in the elasticity of the cost of job search $\gamma$ and Panel (d) is the same as Panel (c) but restricting the $\gamma$ to be larger or equal than 0.2 , which would imply an elasticity of search effort with respect to the returns to job search of less than 5 . 
Figure 12: Sensitivity to small changes in benefit path and out-of-sample performance of models
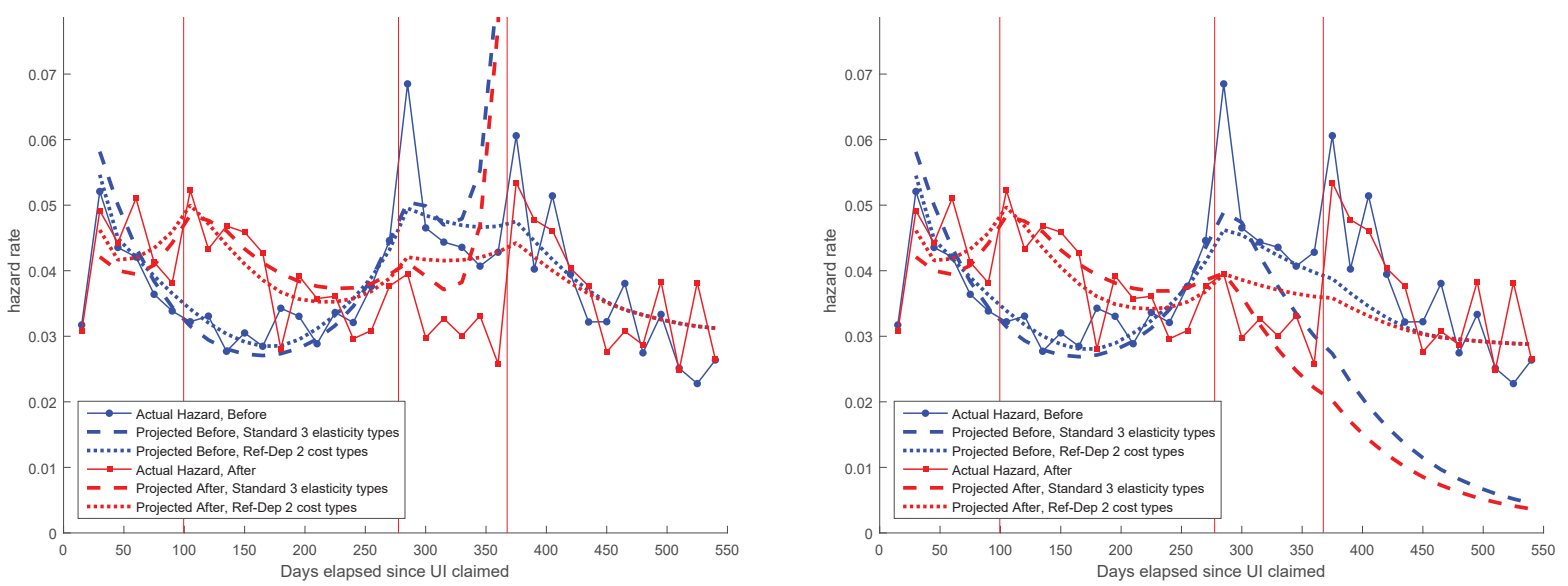

(a) Simulated hazard path for reducing welfare level (b) Simulated hazard path for increasing welfare level to $90 \%$ to $110 \%$

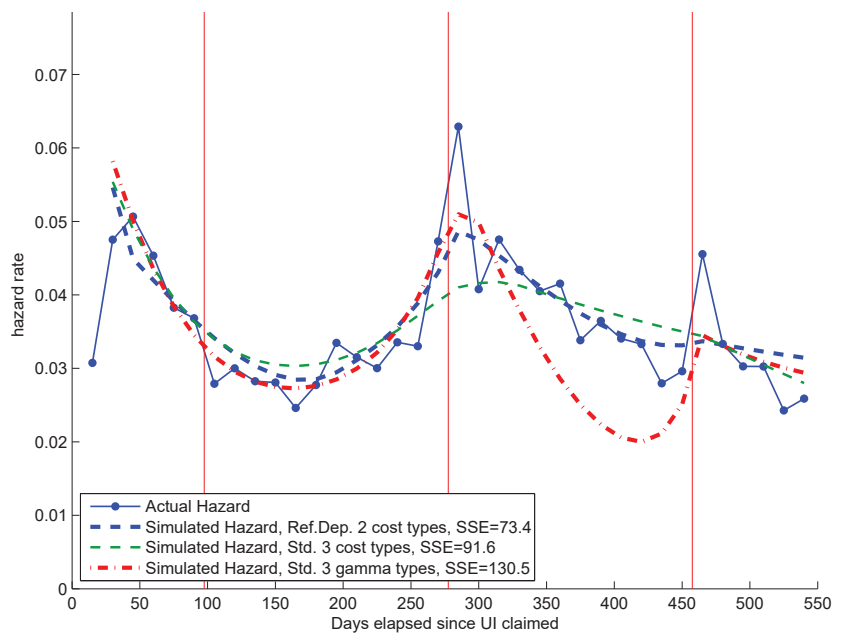

(c) Out-of-sample predictions of models for 2 year prior to reform and empirical hazard

Notes: The figures show the sensitivity of the estimated standard model with 3 search elasticity types (Table 7 column 6 top panel) and the reference-dependent model with 2 cost types (Table 3 column 2) to changes in the benefit path. Panel a) shows the estimated hazard rates in the preand post-reform periods. In addition it shows the simulated hazard rates from the two models if the level of welfare benefits (which start after 360 days) is reduced to 90 percent of the actual level. Panel b) shows the same but for the counterfactual of increasing the benefit level to 110 percent. Panel c) show the empirical and simulated hazard rates and for the period 2 to 1 years before the reform when unemployment assistance could be claimed until 460 days. 
Figure 13: Changes in Heterogeneity throughout the Unemployment Spell: Empirical Heterogeneity vs. Model Predictions

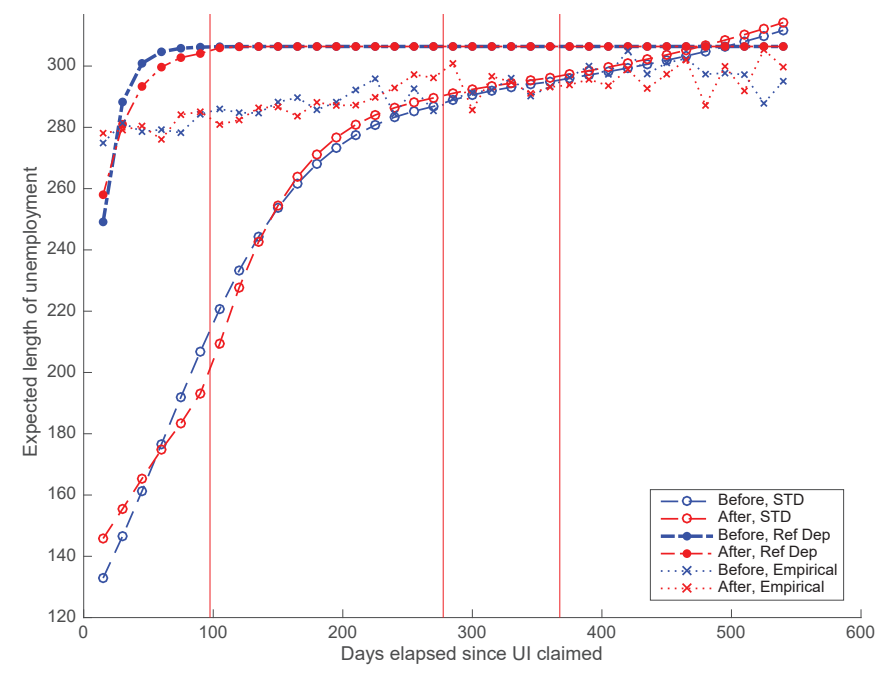

(a) Predicted total unemployment duration of individuals exiting at time t: Heterogeneity in cost levels $k$

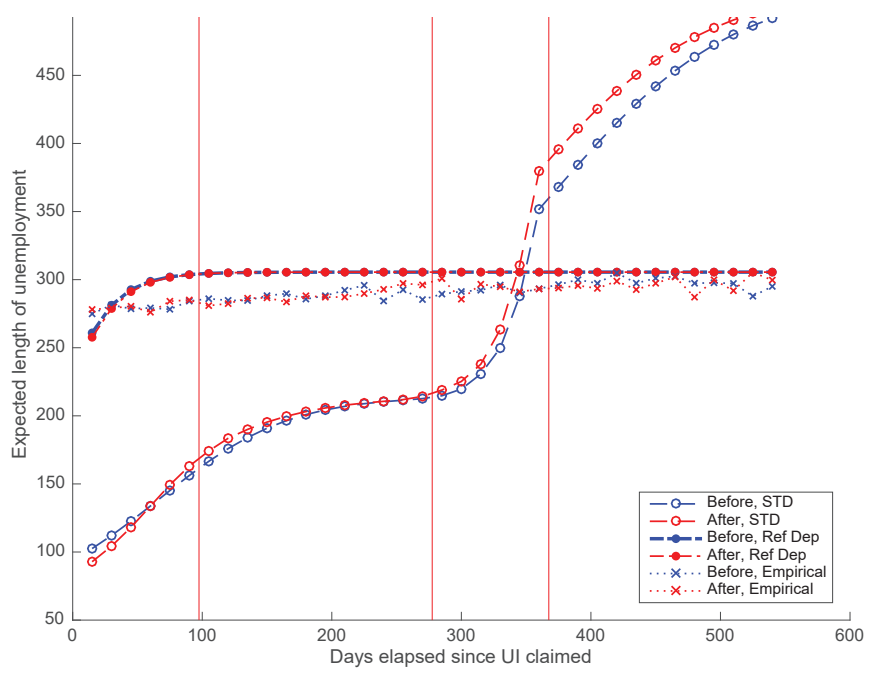

(b) Predicted total unemployment duration of individuals exiting at time t: Heterogeneity in search cost curvature $\gamma$

Notes: The figure shows estimates of the expected nonemployment duration of individuals who left unemployment in each time period, contrasting the empirically observed selection with the predicted selection from the estimated standard and reference-dependent models. The empirical expected nonemployment duration (lines with x's) for each individual is calculated as the predicted values from a regression of nonemployment duration on observable characteristics at the time of entering unemployment (see Web Appendix Table WA-1). The expected nonemployment durations predicted by the estimated standard ( 3 type) and reference dependent ( 2 type) model are displayed as the dashed and solid lines (from Table 3 in Panel a) and from Table 7 column 6 in Panel b)). 


\section{Appendix}

Table A-1: Robustness to Alternative Specifications for Utility Function and Estimation Methods

$\begin{array}{cccccc}\text { Identity } & \text { Moments } & \text { Probability } & \text { Probability } & 7 \text { day } & 30 \text { day } \\ \text { Weighting } & \text { with } & \text { Moments } & \text { Moments } & \text { time } & \text { time } \\ \text { Matrix } & \text { controls } & \text { Full Cov } & \text { Not full Cov } & \text { periods } & \text { periods }\end{array}$

(3)

(4)

(5)

(6)

\begin{tabular}{|c|c|c|c|c|c|c|}
\hline \multicolumn{7}{|l|}{ Standard Model } \\
\hline Discount factor ( 15 days) $\delta$ & $\begin{array}{c}0.872 \\
(0.008)\end{array}$ & $\begin{array}{c}0.918 \\
(0.044)\end{array}$ & $\begin{array}{c}0.928 \\
(0.011)\end{array}$ & $\begin{array}{c}0.928 \\
(0.011)\end{array}$ & $\begin{array}{l}0.968 \\
(0.00)\end{array}$ & $\begin{array}{c}0.876 \\
(0.018)\end{array}$ \\
\hline $\begin{array}{l}\text { Number of moments used } \\
\text { Number of estimated parameters } \\
\text { Goodness of fit (SSE) }\end{array}$ & $\begin{array}{c}70 \\
7 \\
0.0033\end{array}$ & $\begin{array}{c}70 \\
7 \\
187.5\end{array}$ & $\begin{array}{c}70 \\
7 \\
226.1\end{array}$ & $\begin{array}{c}70 \\
7 \\
226.1\end{array}$ & $\begin{array}{c}156 \\
7 \\
414.6\end{array}$ & $\begin{array}{c}36 \\
7 \\
148.19\end{array}$ \\
\hline \multicolumn{7}{|l|}{ Reference Dependent Model } \\
\hline Loss aversion $\lambda$ & $\begin{array}{c}4.41 \\
(1.81)\end{array}$ & $\begin{array}{c}5.68 \\
(1.75)\end{array}$ & $\begin{array}{c}5.69 \\
(0.40)\end{array}$ & $\begin{array}{c}5.69 \\
(0.41)\end{array}$ & $\begin{array}{c}4.55 \\
(2.55)\end{array}$ & $\begin{array}{c}3.41 \\
(1.31)\end{array}$ \\
\hline Adjustment speed of reference point $\mathrm{N}$ & $\begin{array}{l}168.7 \\
(16.7)\end{array}$ & $\begin{array}{l}154.9 \\
(16.2)\end{array}$ & $\begin{array}{l}164.5 \\
(11.3)\end{array}$ & $\begin{array}{l}164.5 \\
(11.2)\end{array}$ & $\begin{array}{l}194.7 \\
(18.5)\end{array}$ & $\begin{array}{l}152.1 \\
(13.8)\end{array}$ \\
\hline Discount factor $\delta$ & 0.995 & 0.995 & 0.995 & 0.995 & 0.995 & 0.995 \\
\hline Discount factor $\beta$ & $\begin{array}{c}0.53 \\
(0.32)\end{array}$ & $\begin{array}{c}0.55 \\
(0.11)\end{array}$ & $\begin{array}{c}0.55 \\
(0.01)\end{array}$ & $\begin{array}{c}0.55 \\
(0.01)\end{array}$ & $\begin{array}{c}0.52 \\
(0.32)\end{array}$ & $\begin{array}{c}0.61 \\
(0.344)\end{array}$ \\
\hline $\begin{array}{l}\text { Number of moments used } \\
\text { Number of estimated parameters } \\
\text { Goodness of fit (SSE) }\end{array}$ & $\begin{array}{c}70 \\
7 \\
0.0027\end{array}$ & $\begin{array}{c}70 \\
7 \\
143.7\end{array}$ & $\begin{array}{c}70 \\
7 \\
178.1\end{array}$ & $\begin{array}{c}70 \\
7 \\
178.1\end{array}$ & $\begin{array}{c}156 \\
7 \\
367.9\end{array}$ & $\begin{array}{c}36 \\
7 \\
106.5\end{array}$ \\
\hline
\end{tabular}

Notes:

The table shows parameter estimates for the standard and the reference-dependent search model. Estimation is based on minimum distance estimation, using the hazard rates in the pre- and post-reform periods as the moments. Standard errors for estimated parameters in parentheses. 
Figure A-1: The UI Benefit Schedule Before and After the 2005 Reform in Hungary

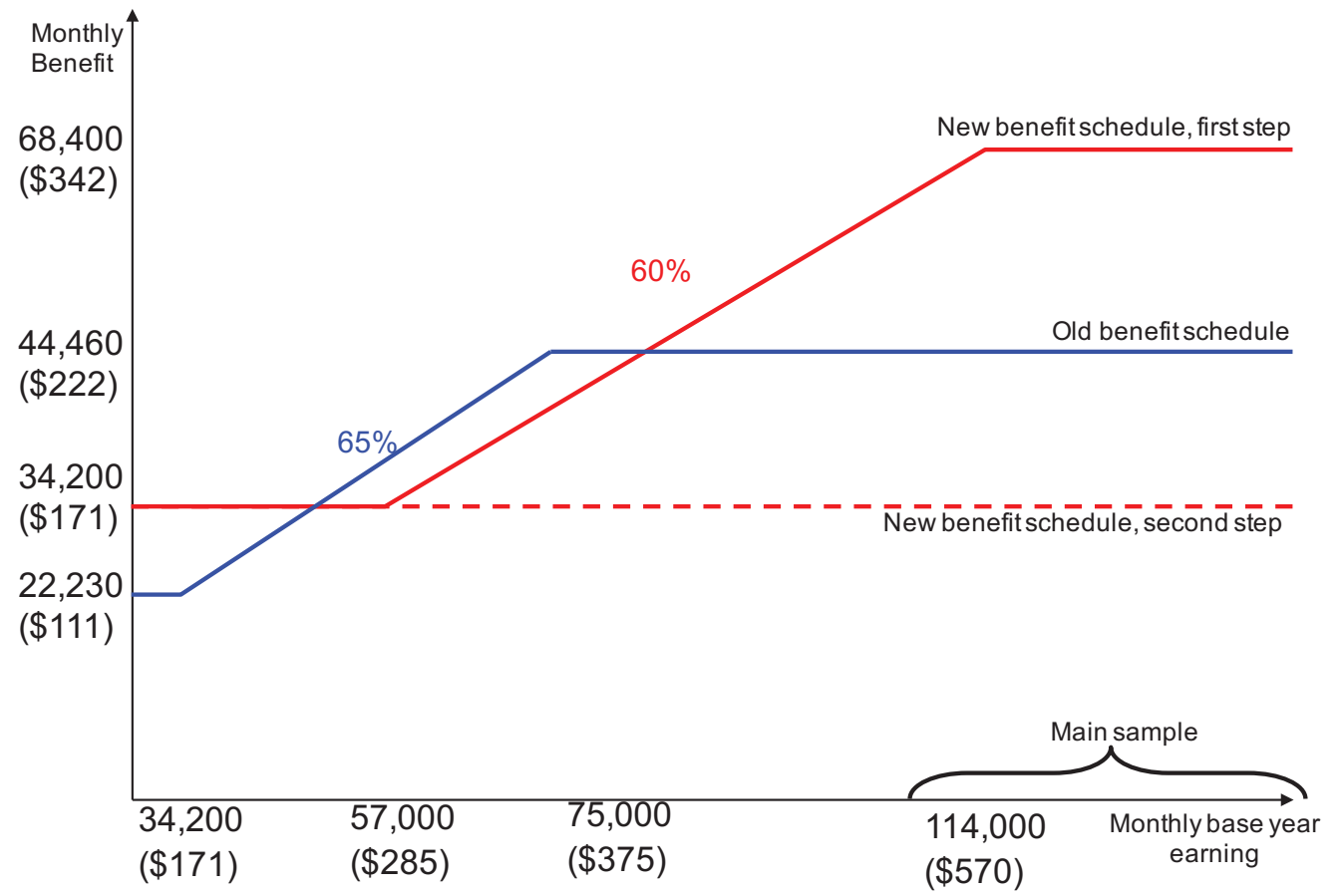

Notes: The figure shows monthly UI benefits in the first tier under the old rule (blue solid line) in the first 90 days under the new rules (red solid line) and between 91-270 days under the new rules (red dashed line) as a function of the monthly base salary. The main sample, defined by being above the 70th percentile of the earnings base distribution of the UI claimants in the given year, is indicated by the curly brackets. 
Figure A-2: GDP growth and unemployment rate in Hungary

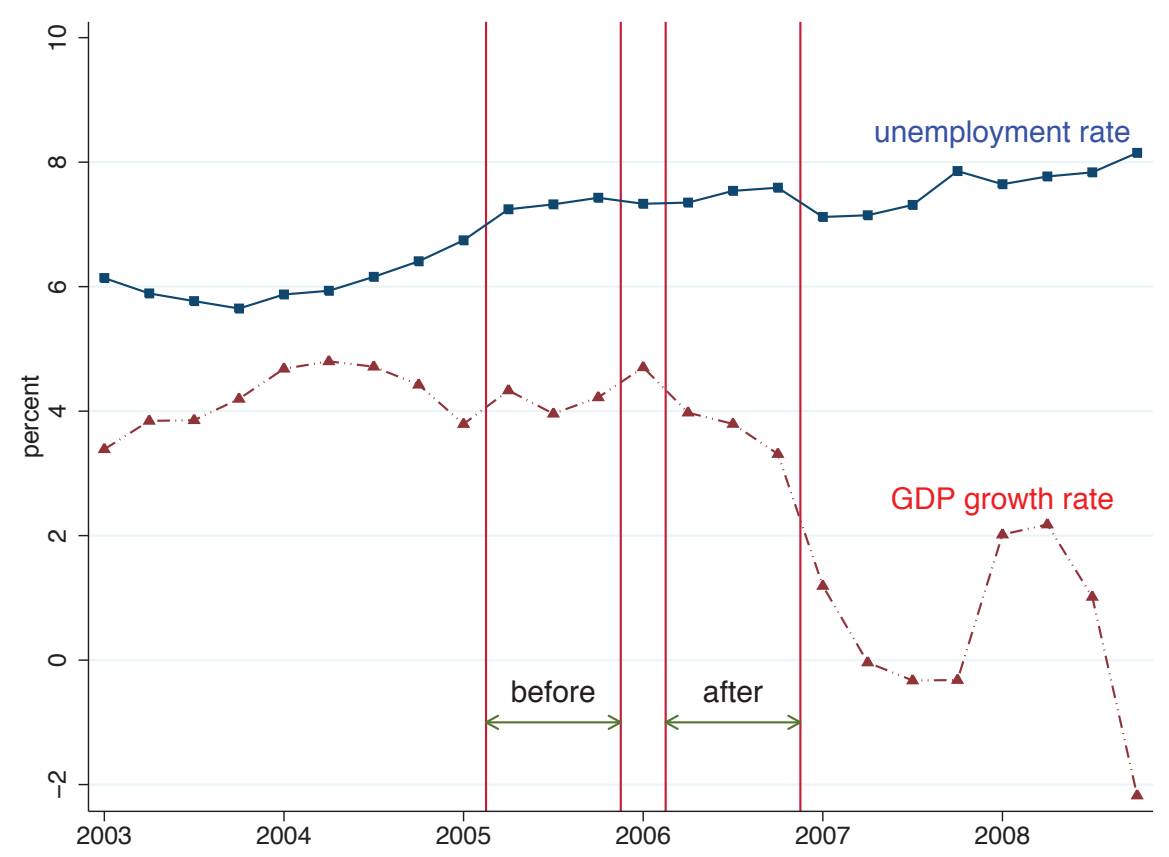

Notes: The figure shows the seasonally adjusted GDP growth rate (dashed red line) and the seasonally adjusted unemployment rate (solid blue) between 2003 and 2008 in Hungary. The major (red) vertical lines indicate the period we use for the before-after comparison. The data was obtained from the Hungarian Central Statistical Office. 
Figure A-3: Comparison of Hazards over Longer Time Frame

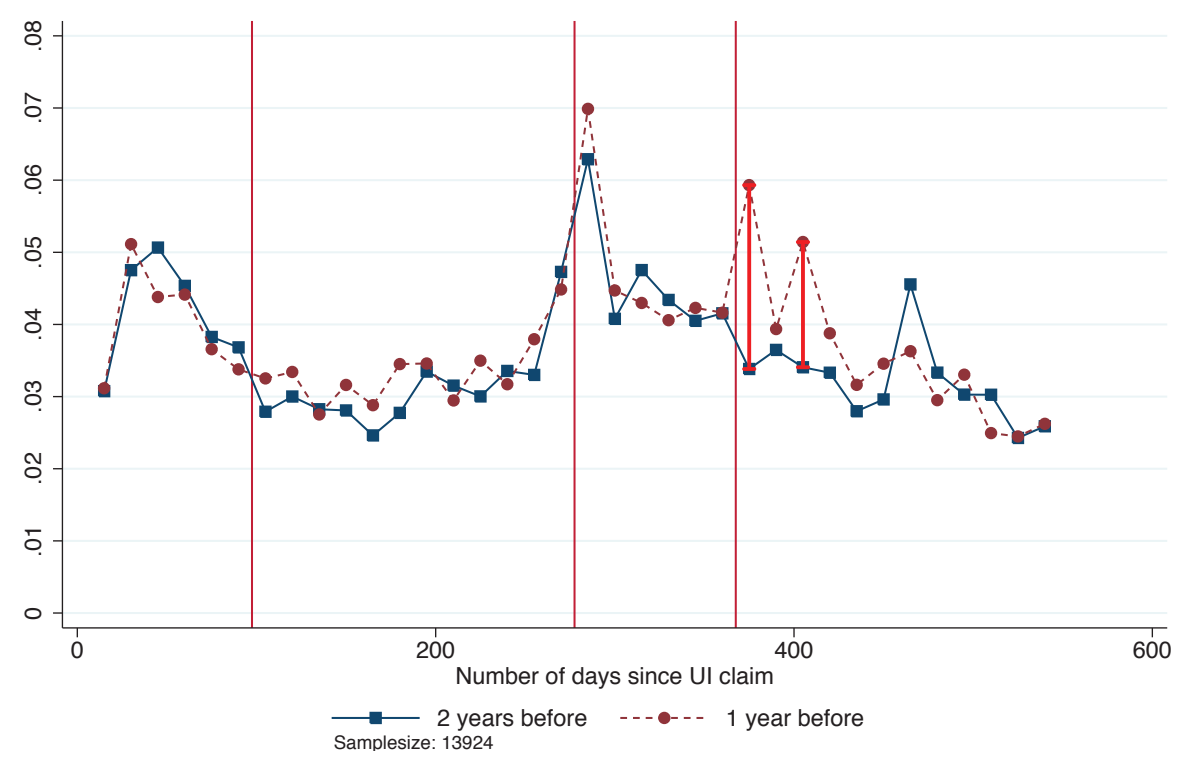

(a) Comparing the hazards 2 year before and 1 year before

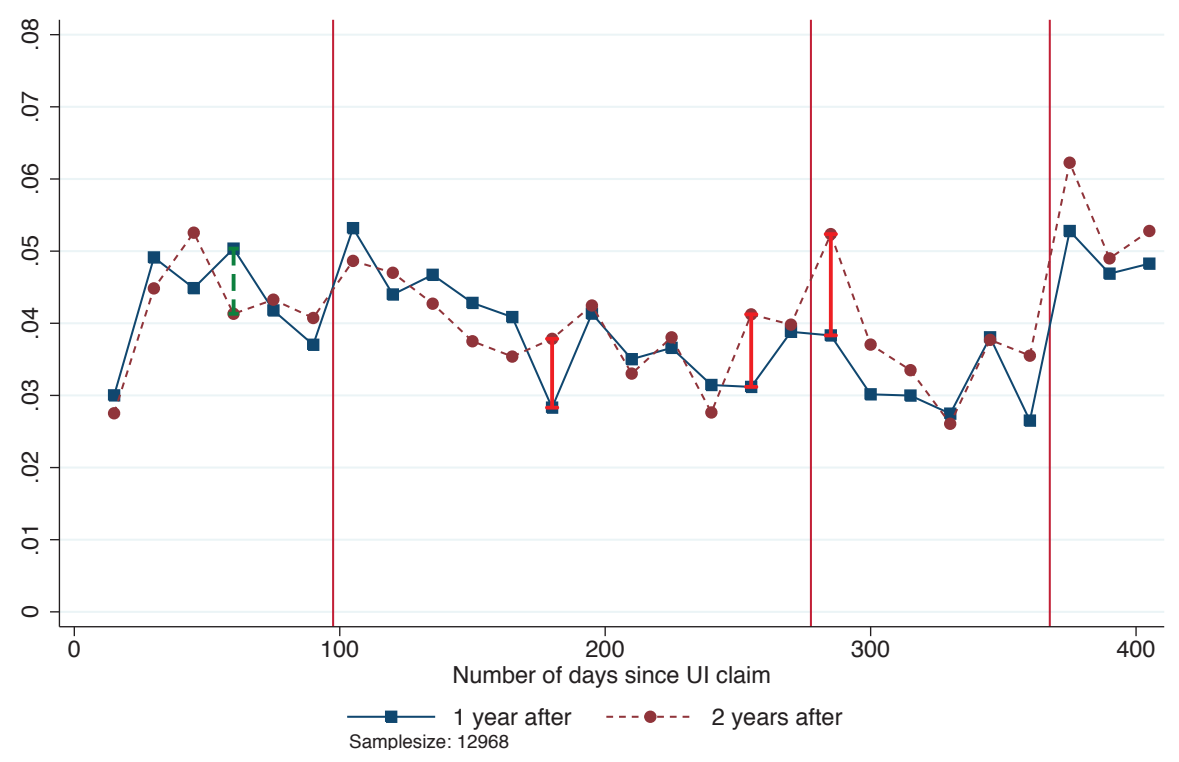

(b) Comparing the hazards 2 year after and 1 year after

Notes: Panel (a) shows point wise estimates for the empirical hazards for two year before (claimed benefit between February 5st, 2004 and October 15th, 2004) and one year before (claimed benefit between February 5th, 2005 and October 15th, 2005) the actual reform. Panel (b) shows point wise estimates for the empirical hazards for one year after (claimed benefit between February 5th, 2006 and October 15th, 2006) and two years after (claimed benefit between February 5th, 2007 and October 15th, 2007) the actual reform. This graph is censored at 400 days because of data limitations. The differences between the two periods are estimated point wise at each point of support and differences which are statistically significant are indicated with a vertical bar. The three major vertical lines indicate periods when benefits change in the new system. Other sample restrictions are the same as in Figure 4 in the main text. 


\section{Figure A-4: Model Fit as Function of Different Discount Rates}

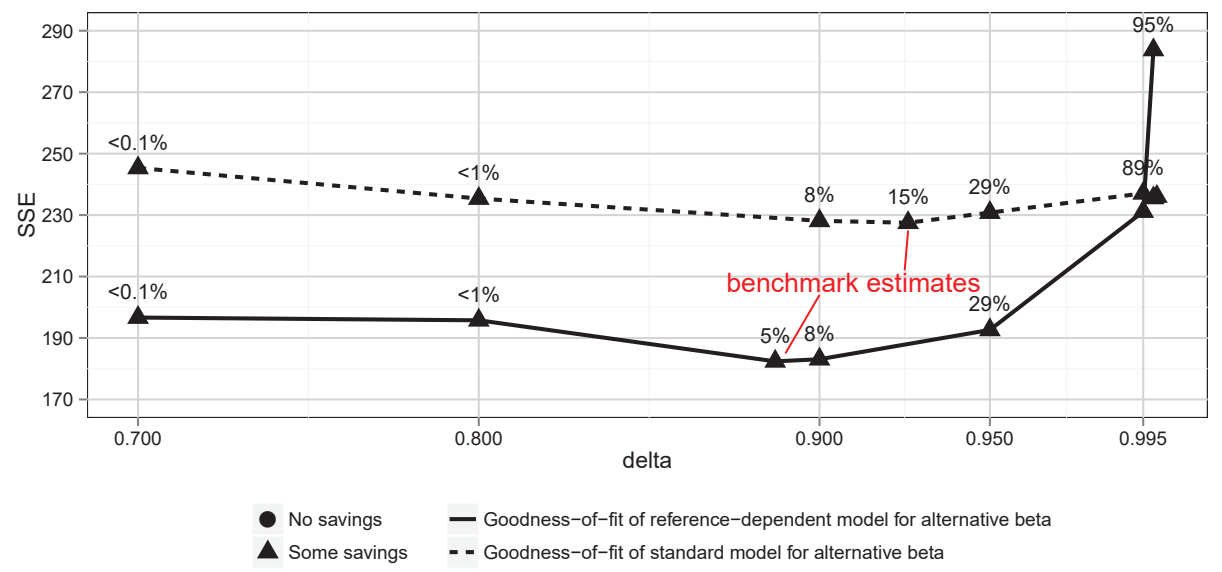

(a) Goodness of Fit of Standard and Reference-Dependent model for different $\delta$

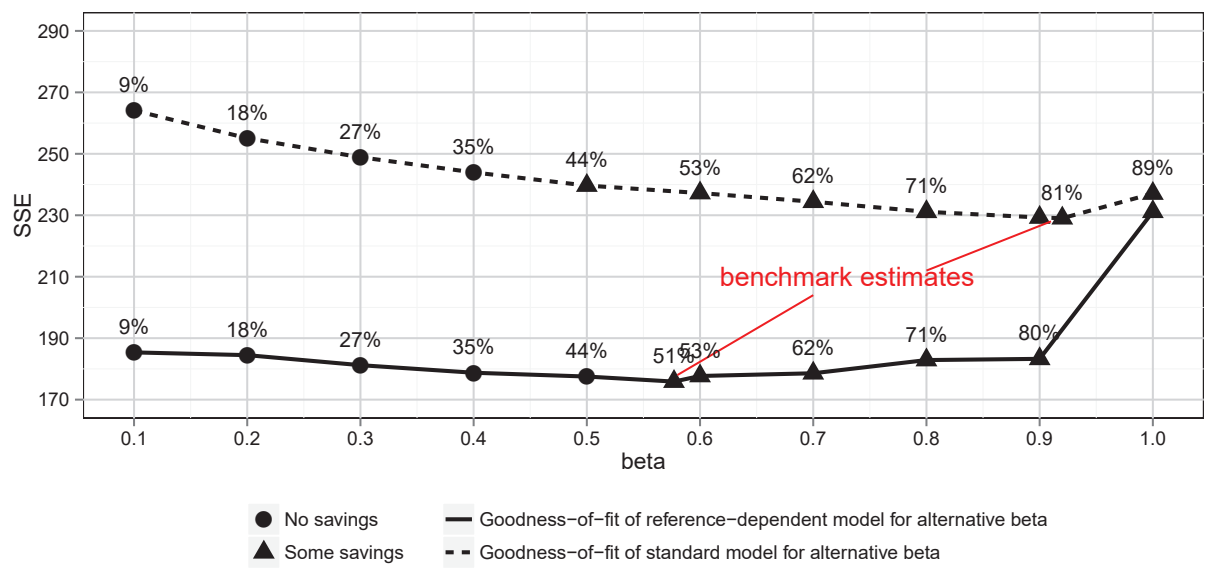

(b) Goodness of Fit of Standard and Reference-Dependent model for different $\beta$

Notes: The figures shows the goodness of fit statistics for the standard and reference-dependent model for different parameter values for $\delta$ (Panel a) and $\beta$ (Panel b). The standard model is estimated with 3 types of heterogeneity (in search costs) and the reference dependent model with 2 types of heterogeneity. Each symbol represents one estimation run. For each set of estimates we also indicate whether the estimated model features any savings on the side of individuals. The numbers next to the markers indicate the implied annual discount factor. 
Figure A-5: Model Components for Benchmark Estimates of Standard and ReferenceDependent Model for the High Cost Type, Part I

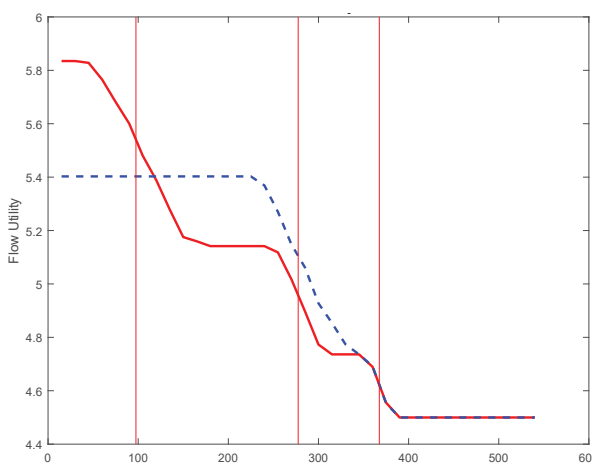

(a) Flow Utility, Standard Model

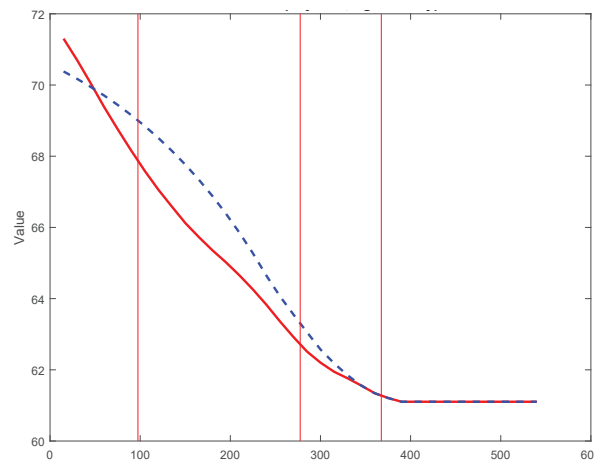

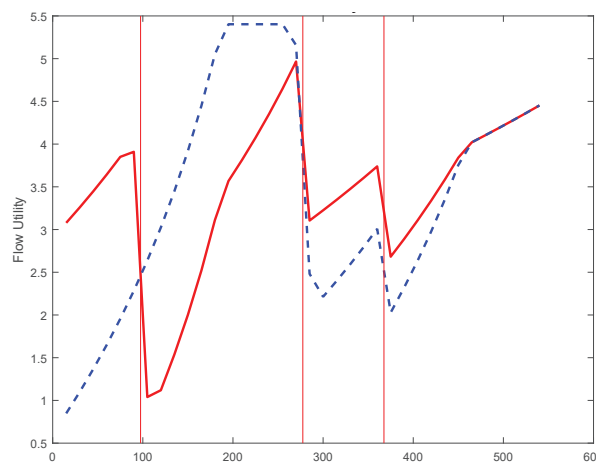

(b) Flow Utility, Reference-Dependent model

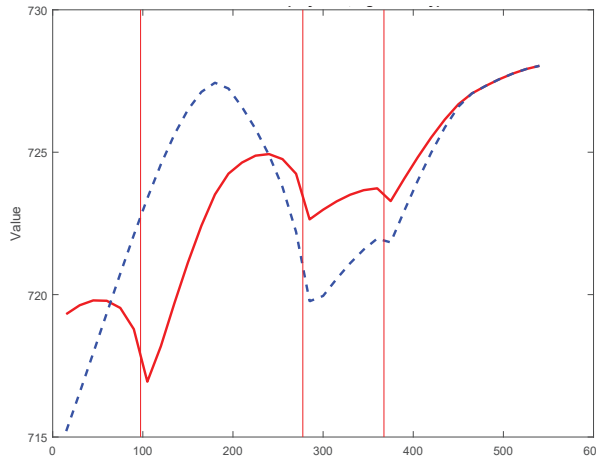

(c) Value of Unemployment, Standard (d) Value of Unemployment, ReferenceModel

Dependent model

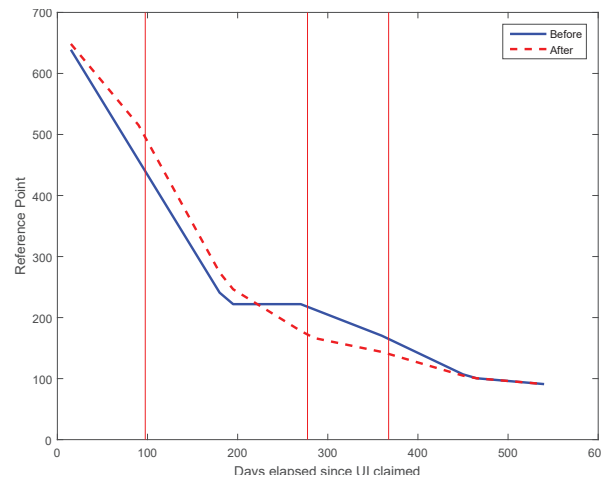

(e) Reference Point, ReferenceDependent Model

Notes: The figure shows the model components for the standard model (estimates shown in column (1) in Table 3) and for the reference-dependent model (estimates shown in column (2) in Table 3). Panel (a) and Panel (b) shows the flow utility for the standard model and for the reference-dependent model, respectively. Panel (c) and Panel (d) shows the value of unemployment for the high cost type for the standard model and for the reference-dependent model, respectively. Panel (e) shows the evolution of the reference point in the reference dependent model. The three major (red) vertical lines indicate periods when benefits change in the new system. 
Figure A-6: Model Components for Benchmark Estimates of Standard and ReferenceDependent Model for the High Cost Type, Part II
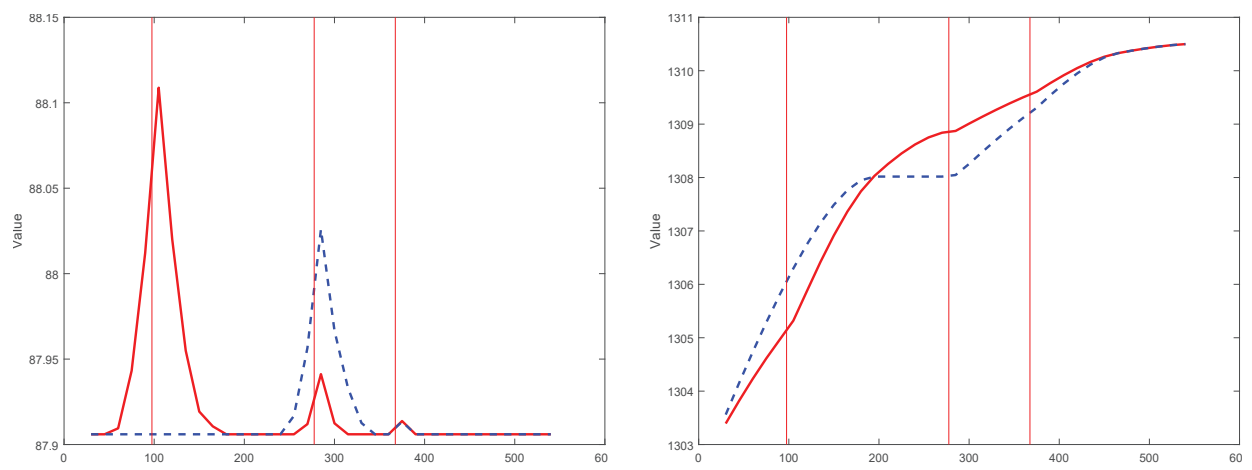

(a) Value of Employment, Standard (b) Value of Employment, ReferenceModel

Dependent model
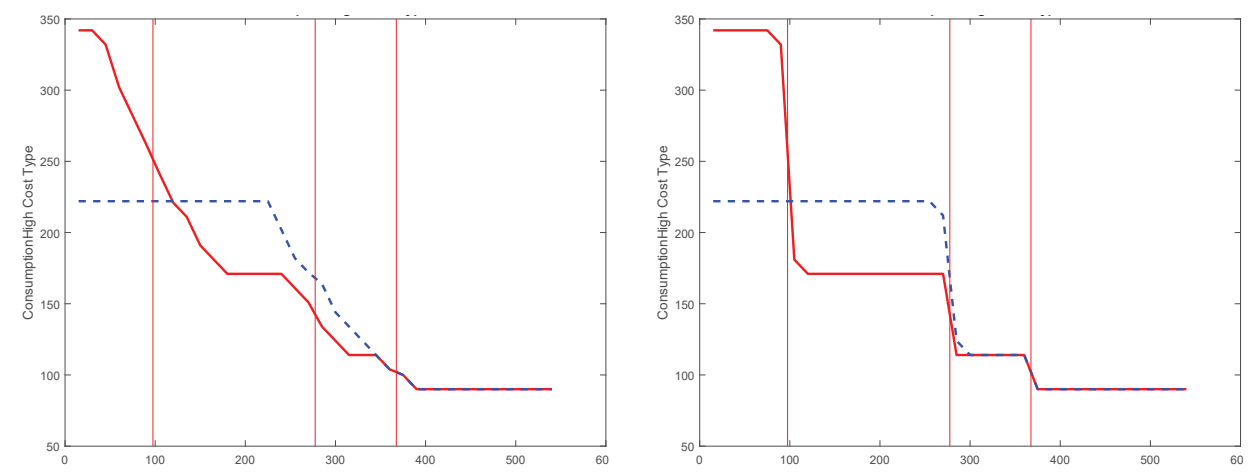

(c) Consumption, Standard Model

(d) Consumption, Reference-Dependent model
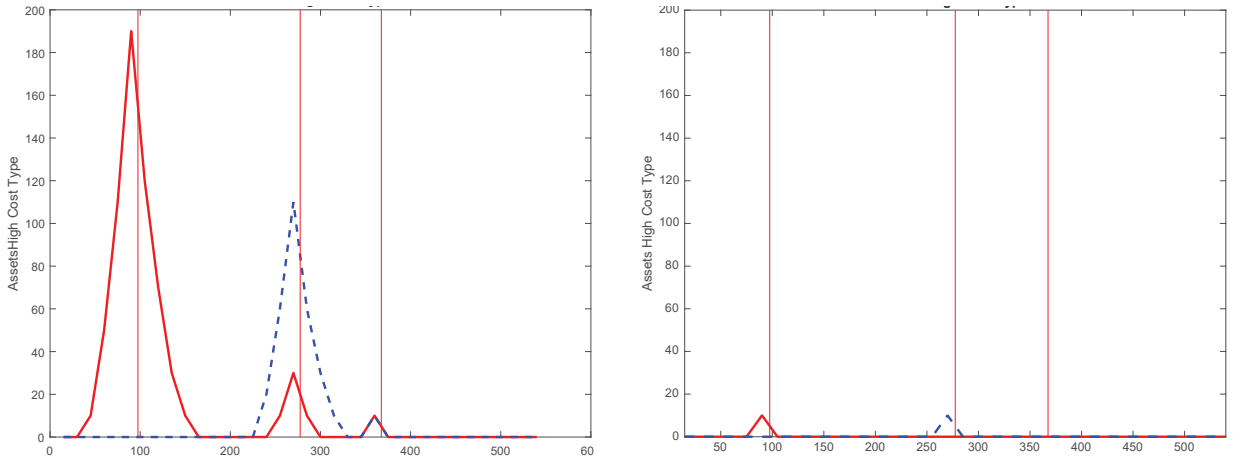

(e) Assets, Standard Model

(f) Assets, Reference-Dependent model

Notes: The figure shows the model components for the standard model (estimates shown in column (1) in Table 3) and for the reference-dependent model (estimates shown in column (2) in Table 3). Panel (a) and Panel (b) shows the value of employment for the standard model and for the reference-dependent model, respectively. Panel (c) to (f) show consumption and asset path for the two models. The three major (red) vertical lines indicate periods when benefits change in the new system. 
Figure A-7: Robustness Checks I

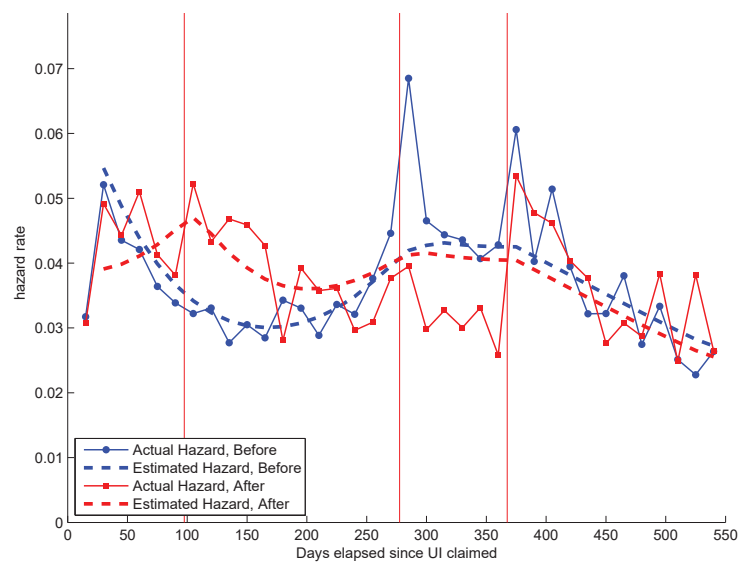

(a) Std. Model: Time-varying Search Cost

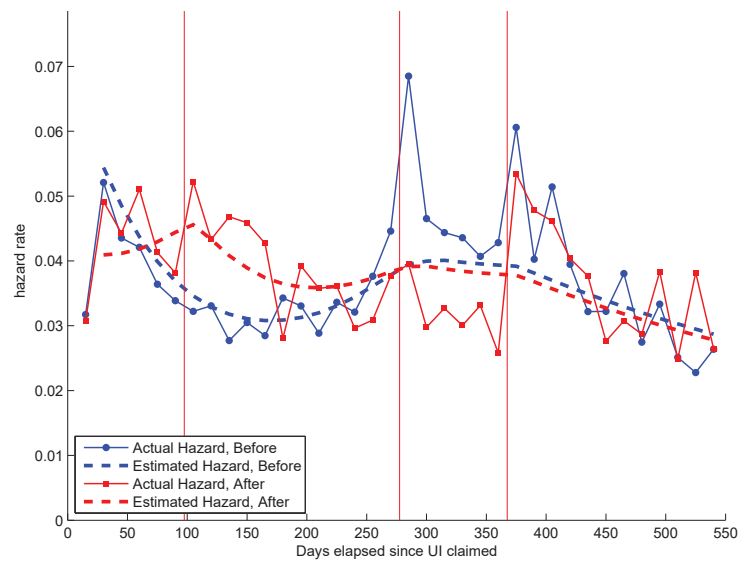

(c) Std. Model: Estimation without Spikes

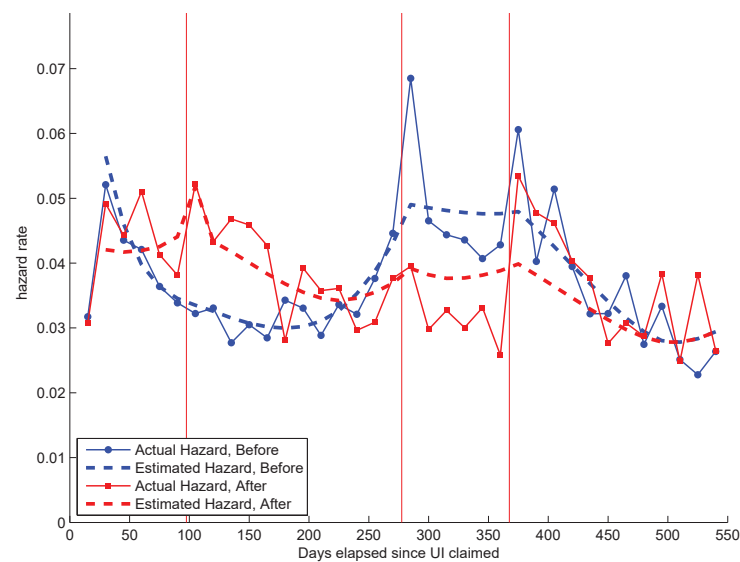

(b) Ref. Dep. Model: Time-varying Search Cost

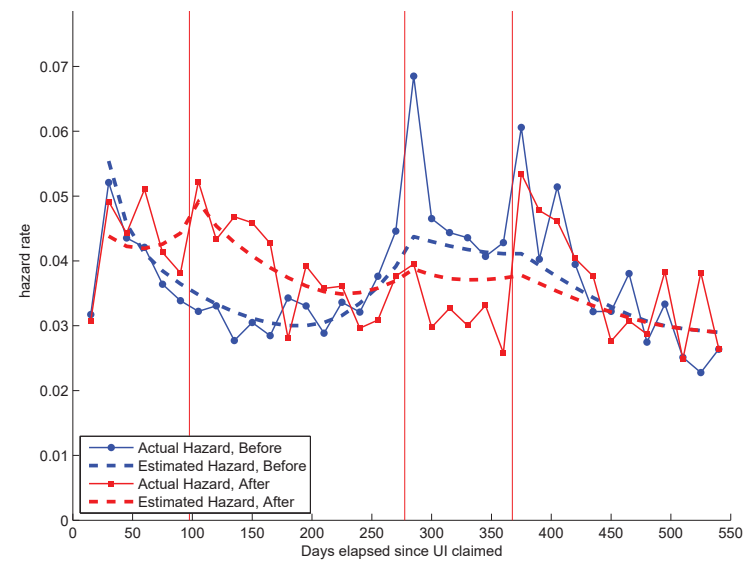

(d) Ref. Dep. Model: Estimation without Spikes

Notes: The figures shows estimates of the standard and reference-dependent model with search costs being a linear function of time (Panel $\mathrm{a}$ and $\mathrm{b}$ ) or when we estimate the model not using the sharp spikes in the exit hazard as moments (Panel c and d). See Table 6 for estimates. 
Figure A-8: Robustness Checks II

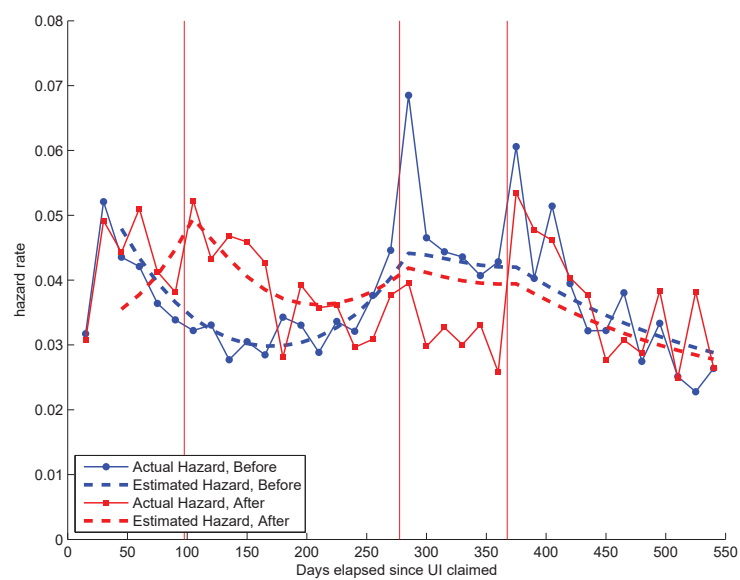

(a) Std. Model: Delayed Job Starting Date

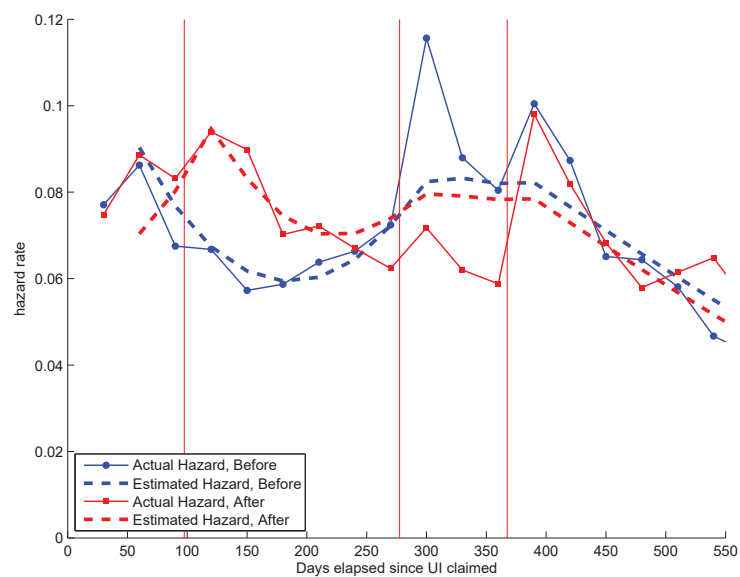

(c) Std. Model: 30-Day Hazards

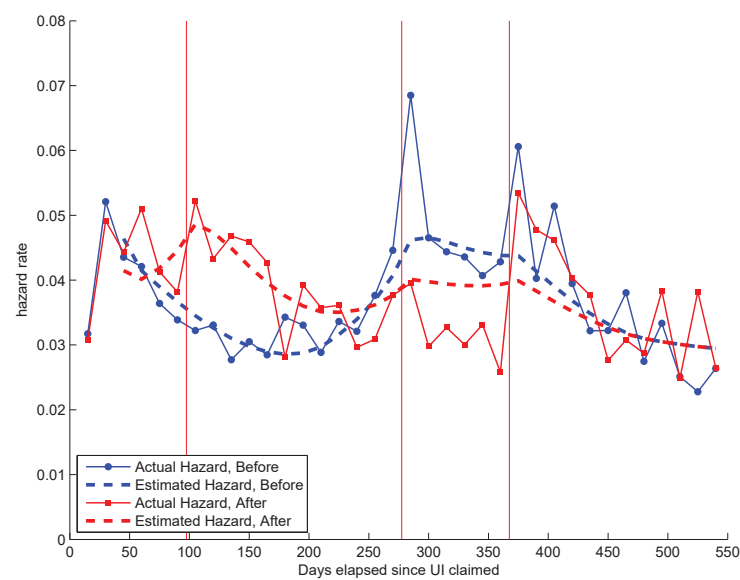

(b) Ref. Dep. Model: Delayed Job Starting Date

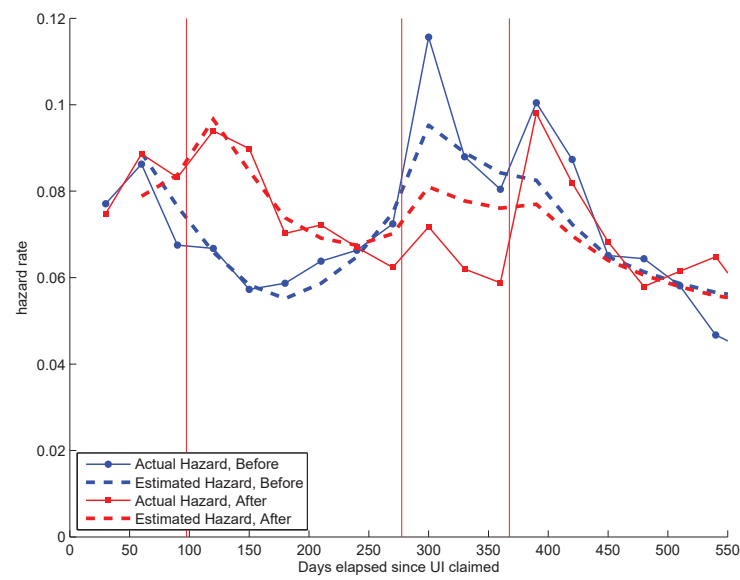

(d) Ref. Dep. Model: 30-Day Hazards

Notes: The figures shows estimates of the standard and reference-dependent model when we assume that jobs start with a 2 week delay (Panel a and b), see Table 6 , or when we estimate the model using 30-day time periods (Panel c and d), see Appendix Table A-1. 